\title{
VARIÁVEIS DE INFLUÊNCIA NO ENSINO APRENDIZAGEM DE MATEMÁTICA NO ENSINO MÉDIO
}

\section{Jefferson de Souza Pinto}

Maria Gabriela Leme Munhoz

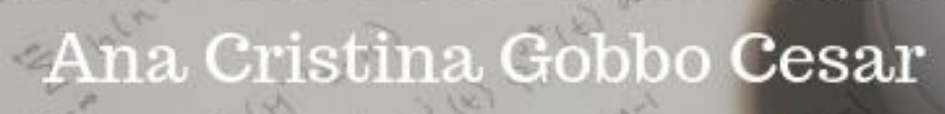


Jefferson De Souza Pinto

Maria Gabriela Leme Munhoz

Ana Cristina Gobbo Cesar

\title{
Variáveis de influência no ensino e aprendizagem de matemática no ensino médio
}

\author{
1․ Edição
}

Belo Horizonte

Poisson

2018 
Editor Chefe: Dr. Darly Fernando Andrade

\section{Conselho Editorial}

Dr. Antônio Artur de Souza - Universidade Federal de Minas Gerais

Dra. Cacilda Nacur Lorentz - Universidade do Estado de Minas Gerais

Dr. José Eduardo Ferreira Lopes - Universidade Federal de Uberlândia

Dr. Otaviano Francisco Neves - Pontifícia Universidade Católica de Minas Gerais

Dr. Luiz Cláudio de Lima - Universidade FUMEC

Dr. Nelson Ferreira Filho - Faculdades Kennedy

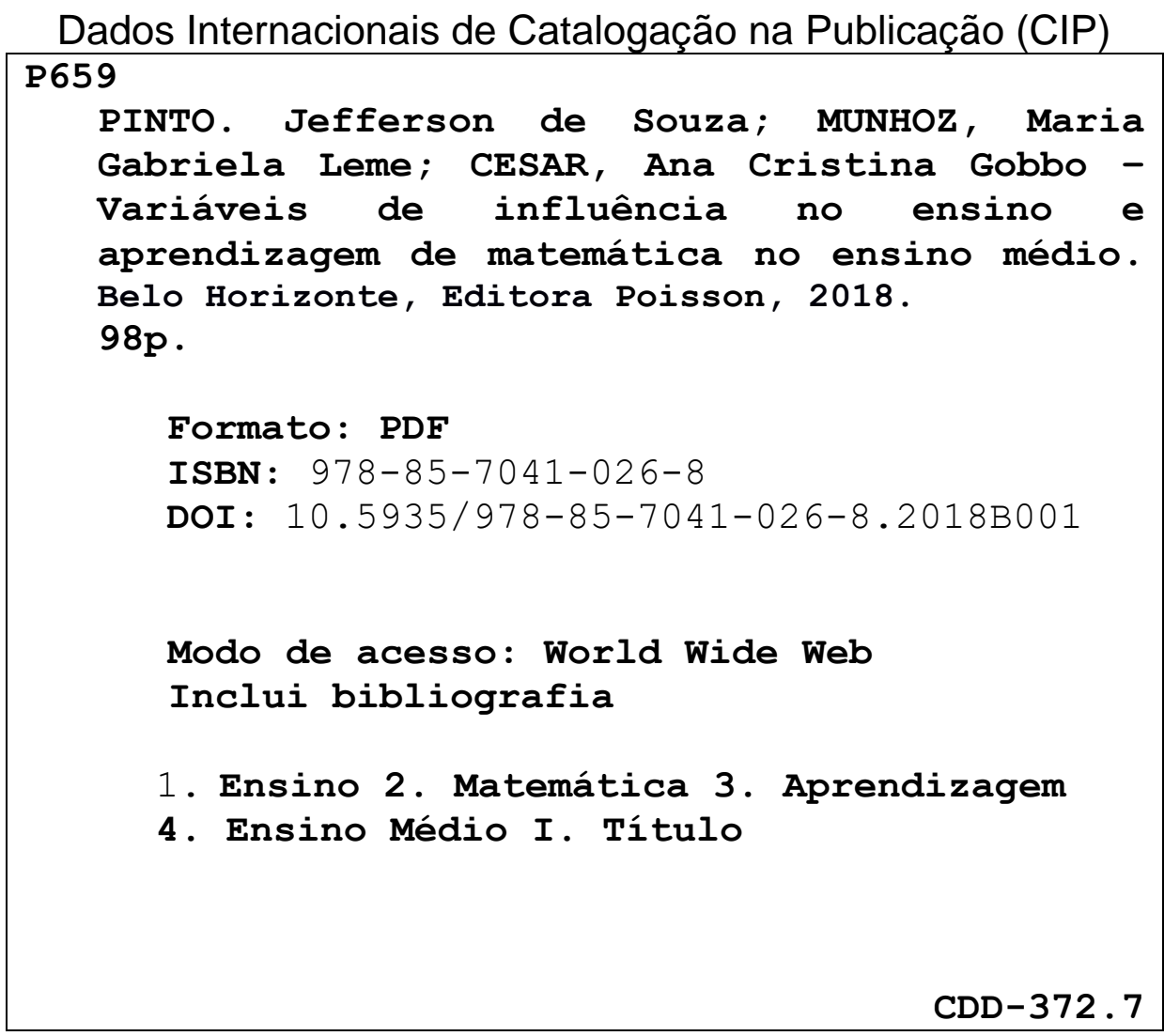

O conteúdo dessa obra e seus dados em sua forma, correção e confiabilidade são de responsabilidade exclusiva dos seus respectivos autores.

www.poisson.com.br

contato@poisson.com.br 


\section{APRESENTAÇÃO}

A matemática é considerada uma área do conhecimento fundamental para o desenvolvimento da humanidade, tanto no que tange às esferas tecnológicas e científicas quanto na realização de ações simples da vida diária. Também merece destaque a utilização da matemática para realizar diversas profissões como engenharia, arquitetura, agronomia, etc. Nas escolas não é diferente. A matemática é vista como uma disciplina de extrema importância, pois é durante a vida escolar que as principais habilidades matemáticas como raciocínio lógico e dedutivo, aritmética e geometria plana e espacial são desenvolvidas.

Para os docentes da área em questão, os desafios no ensino e aprendizagem são inúmeros. Desde a formação do professor até a utilização de meios tecnológicos para auxiliar no ensino. Outros tópicos como indisciplina na sala de aula, metodologia de ensino e liberdade para sanar dúvidas com o professor não ficam de fora dessa vasta lista de obstáculos.

Nesta obra, Jefferson de Souza Pinto, Maria Gabriela Leme Munhoz e Ana Cristina Gobbo Cesar apresentam, de forma detalhada, a influência desses tipos de variáveis, no Ensino e Aprendizagem de Matemática no Ensino Médio em uma Escola Técnica Federal. Através de uma pesquisa exploratória e de natureza qualitativa levam o leitor a refletir sobre a influência do ambiente escolar e temas como disciplina, motivações externas e não aprendizagem de conteúdos anteriores. Fazem isso aplicando um questionário com os alunos da escola pesquisada e comparando as variáveis levantadas utilizando técnicas estatísticas de Análise Multivariadas, como o Escalonamento Multidimensional e a Análise de Conglomerados. Os resultados são apresentados de forma clara e objetiva, destacando as variáveis que mais influenciam no ensino e na aprendizagem no caso pesquisado. Isso permite que os docentes, a partir dessas informações busquem ferramentas e maneiras para aprimorar o processo de ensino, proporcionando ao estudante uma aprendizagem mais eficiente e eficaz.

Por fim, esta é uma leitura indispensável para professores que desejam conhecer as principais dificuldades da relação professor-aluno com o intuito de explorar diferentes estratégias de ensino que possam contribuir com uma aprendizagem mais significativa.

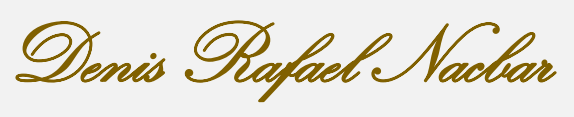

Professor da área de matemática do Instituto Federal de Educação, Ciência e Tecnologia de São Paulo, campus Bragança Paulista. Doutor e mestre em Ciência e Tecnologia de Materiais pela Universidade Estadual Paulista Júlio de Mesquita Filho. Graduação em Licenciatura em Matemática pela Universidade Estadual Paulista Júlio de Mesquita Filho. 


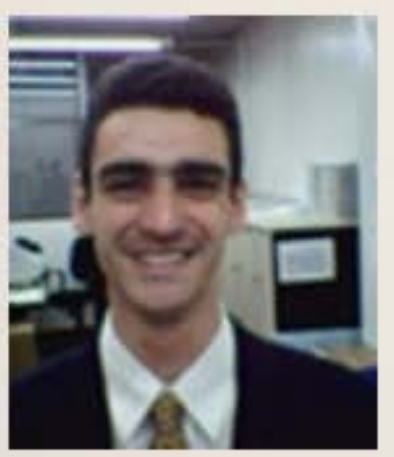

\section{Jefferson de Souza Pinto}

Pós-doutor em Engenharia Mecânica pela Universidade Estadual de Campinas (2014, 2016 e 2018). Doutor (2012) com pesquisa na área de Gestão de Projetos e Mestre (2004) em Engenharia Mecânica pela Universidade Estadual de Campinas. Especialista em Gestão de Processos Industriais pela Universidade Estadual de Campinas (2002). Administrador de Empresas com habilitação em Comércio Exterior pela Universidade São Francisco (1999).

Pesquisador colaborador e professor colaborador da Faculdade de Engenharia Mecânica da Universidade Estadual de Campinas.

Atualmente é professor concursado do Instituto Federal de Educação, Ciência e Tecnologia de São Paulo (IFSP). Campus Bragança Paulista. Possui experiência e pesquisas nas áreas de Empreendedorismo. Gestão da Produção e Operações. Gestão da Qualidade, Gestão da Cadeia de Suprimentos e Gestão de Projetos. Detém mais 27 artigos científicos publicados em periódicos nacionais e internacionais correlacionados nas áreas mencionadas.

\section{Maria Gabriela Leme Munhoz}

Graduada em Licenciatura em Matemática pelo Instituto Federal de Educação, Ciência e Tecnologia de São Paulo, Campus Bragança Paulista, e Licenciada em Pedagogia pela Universidade Paulista. Cursou especialização em Metodologia de Ensino de Matemática na Faculdades XV de Agosto. Atualmente cursa Mestrado Profissional em Ensino de Ciências e Matemática. Desenvolveu pesquisa na área de mutagênese, na qual empregava análises estatísticas e também pesquisas na área de Ensino e Aprendizagem de Matemática e formação de professores. Além disso, pesquisa sobre a avaliação interna, especificamente sobre a avaliação em fases em um curso de Licenciatura em Matemática. Trabalhou como professora na Prefeitura Municipal de Pedra Bela e atualmente é professora de Matemática no Estado de São Paulo.

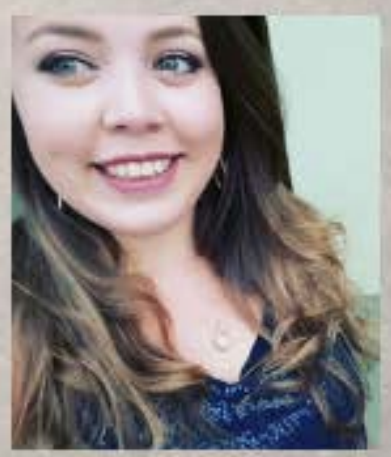




\section{Ana Cristina Gobbo Cesar}

Graduada em Licenciatura e Bacharelado em Ciências Biológicas pela Universidade Federal de São Carlos, Mestre em Genética e Evolução pela Universidade Federal de São Carlos. Doutora em Genética pela Universidade Estadual Paulista Júlio de Mesquita Filho e Pós-doutora pela Faculdade de Engenharia de Guaratinguetá - FEG - UNESP. Já atuou como pesquisadora colaboradora do Instituto Nacional de Análise Integrada do Risco Ambiental (INAIRA) e professora na Universidade de Taubaté (UNITAU) na graduação e pós-graduação, no EAD e no PIBID Diversidade (Capes). Atualmente, atua como professora no Instituto Federal de Educação. Ciência e Tecnologia de São Paulo. Campus Bragança Paulista. Desenvolve pesquisa sobre biomonitoramento de ambientes aquáticos e sobre o impacto dos poluentes atmosféricos na saúde humana.

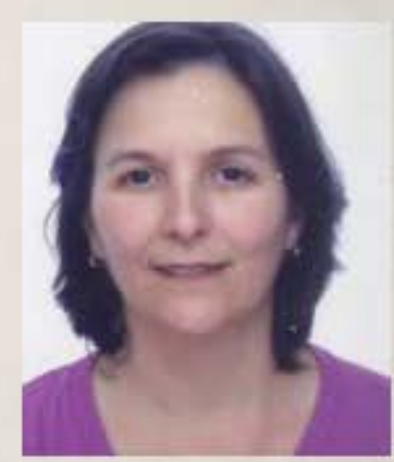




\section{SUMÁRIO}

\begin{tabular}{|l|l|c|}
\hline 1 & INTRODUÇÃO & 7 \\
\hline 2 & FUNDAMENTAÇÃO TEÓRICA & 13 \\
\hline 3 & MÉTODO & 27 \\
\hline 4 & APRESENTAÇÃO E ANÁLISE DE DADOS & 39 \\
\hline 5 & CONCLUSÕES & 71 \\
\hline 6 & REFERÊNCIAS & 74 \\
\hline 7 & APÊNDICES E ANEXOS & 81 \\
\hline
\end{tabular}




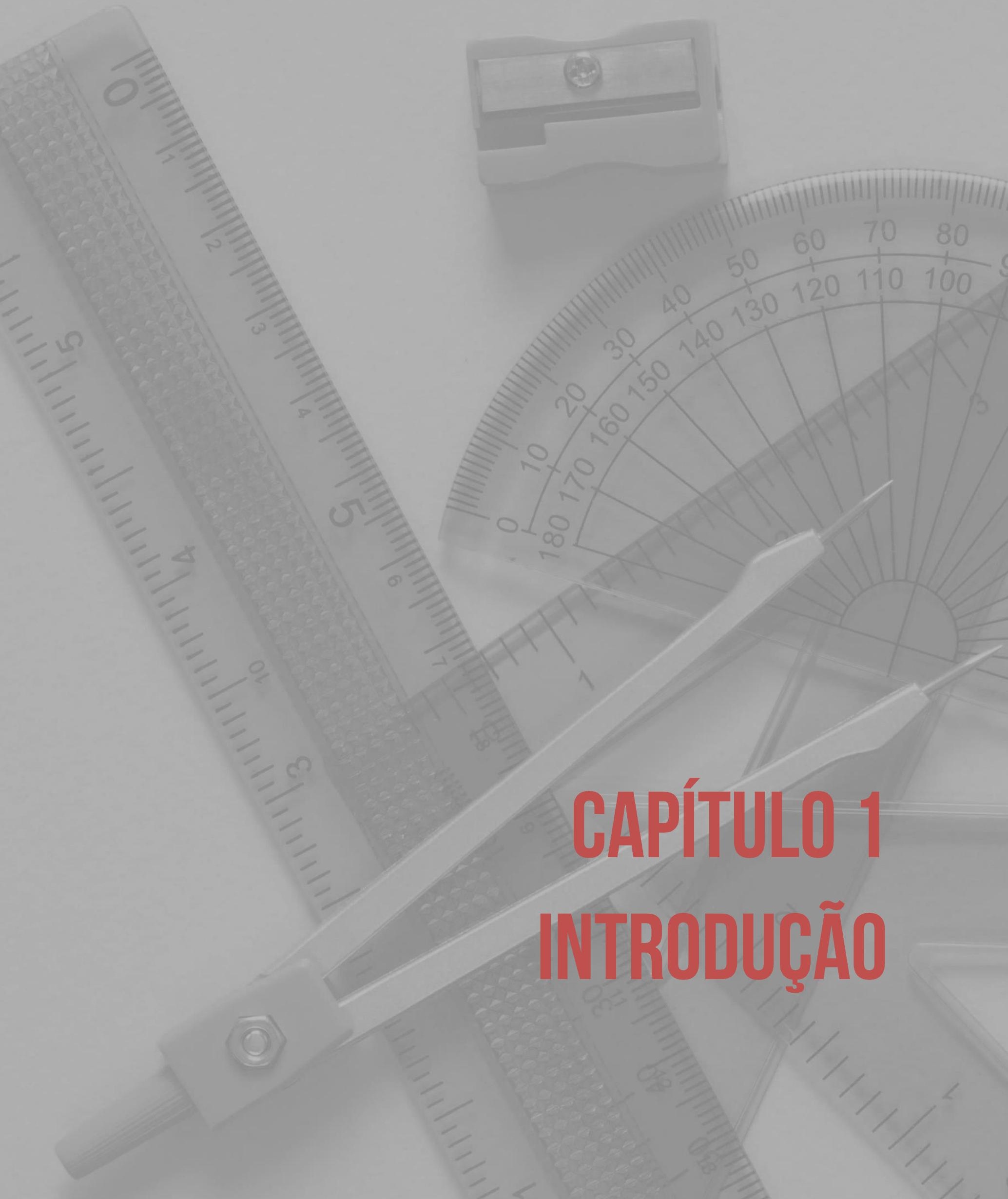


A ciência e a tecnologia se fazem presentes em todos os setores da vida contemporânea e estão causando profundas transformações econômicas, sociais e culturais.

Ao analisar esse momento histórico, Behrens (2003, p.17) ressalta que "um dos grandes méritos deste século é o fato de os homens terem despertado para a consciência da importância da educação como necessidade preeminente para viver em plenitude como pessoa e como cidadão na sociedade".

A matemática, parte fundamental em todas as ciências, está presente diariamente na vida do ser humano, e conforme estabelecem os Parâmetros Curriculares Nacionais (2000) auxilia a estruturar o pensamento e o raciocínio dedutivo, além de ser uma ferramenta para tarefas específicas em quase todas as atividades humanas.

A educação é, segundo a Constituição da República Federativa do Brasil (BRASIL, 1988), Capitulo III, secção I, Art. 205, "direito de todos é dever do Estado e da Família, será promovida e incentivada com a colaboração da sociedade, visando ao pleno desenvolvimento da pessoa, seu preparo para o exercício da cidadania e sua qualificação para o trabalho" (BRASIL, 1988, p. 97).

De acordo com a Lei de Diretrizes e Bases da Educação Nacional no Art.2º da lei 9.394/96 "a educação básica tem por finalidade desenvolver o educando, assegurar-lhe a formação comum indispensável para o exercício da cidadania e fornecer-lhe meios para progredir no trabalho e em estudos posteriores". Observa-se que embora exista uma legislação própria que garanta o desenvolvimento educacional, a qualidade do ensino da matemática vem ocasionando uma preocupação entre os estudiosos da educação. No Brasil, em 2001, somente 5,99\% dos alunos do país possuíam o nível desejado de conhecimento na disciplina matemática (BRASIL, 2001).

Ensinar matemática é um desafio ao professor, e aprende-la é um desafio para o aluno. Além disso, em sala de aula o professor é mais que alguém que ensina, ele é um educador. A esse respeito Werneck (1996, p.61) elucida que:

Educar é difícil, trabalhoso, exige dedicação, sobretudo aos que mais necessitam. Transferir problemas é fugir da verdadeira educação, é uma espécie de médico que transfere o doente de hospital, lava as suas mãos e não se sente comprometido com o caso quando da morte do paciente, porque aconteceu em outro hospital e em outras mãos.

Nos últimos anos muito se tem refletido, discutido e pesquisado sobre a questão das dificuldades do aprendizado em matemática nas séries iniciais do nível médio. Segundo Oliveira (2009) pode-se afirmar, baseando-se na comunicação informal que ocorria entre professores de nossas melhores escolas secundárias, que a atenção para essa questão foi provocada pelo decrescente índice de aproveitamento dos conceitos matemáticos, em especial aos $9^{\circ}$ anos e $3^{a}$ séries do Ensino Médio. Além disso, nos rankings internacionais o Brasil está mal posicionado.

A relevância deste estudo está em estudar, analisar e apontar as variáveis que influenciam o ensino e a aprendizagem de matemática no Ensino Médio em uma Escola Técnica Federal na Região Bragantina.

\subsection{CONTEXTO E JUSTIFICATIVA}

A matemática está presente na vida e no dia a dia do ser humano desde o seu nascimento como uma aritmética do dia a dia, entretanto, de maneira geral não aprendemos a utilizá-la formalmente e a potencializar seu uso até nossa vida escolar. Além disso, a matemática se faz fundamental no aspecto de desenvolvimento e evolução do raciocínio lógico, sendo que muitas vezes isto acontece apenas na escola.

O Ensino Médio é a etapa final da educação básica no Brasil e seu principal objetivo, segundo os documentos oficiais (BRASIL, 1998), é a autonomia do estudante frente às determinações do mercado de trabalho. Visa-se a um processo educativo centrado nos sujeitos da aprendizagem, jovens ou adultos, respeitando-se suas características biopsicológicas, socioculturais e econômicas. O ensino médio é a preparação essencial para o jovem alcançar seu espaço na sociedade. Para que isso ocorra é necessário que ele conclua essa etapa com bons conhecimentos em diversas 
áreas, desenvolva a capacidade de aprendizagem, resolução de problemas e tomada de decisões. Segundo os Parâmetros Curriculares Nacionais (PCNs) do Ensino Médio (BRASIL, 2000, p. 40),

A Matemática no Ensino Médio tem um valor formativo, que ajuda a estruturar 0 pensamento e o raciocínio dedutivo, porém também desempenha um papel instrumental, pois é uma ferramenta que serve para a vida cotidiana e para muitas tarefas específicas em quase todas as atividades humanas.

Assim sendo, a aprendizagem da matemática é fundamental para a vida do aluno e por isso esta etapa deve ser pesquisada constantemente com o intuito de melhorar o ensino e a aprendizagem.

De acordo com Resende e Mesquita (2013), a história da Educação no Brasil tem indicado caminhos, papéis, deveres e estigmas que se modificam por meio do tempo, a medida que a sociedade, a família e a escola também mudam. A função do professor muda e torna-se um desafio diante das transformações por que passa a Educação. Além disso, devem-se considerar a complexidade do processo de ensino e aprendizagem e as muitas tendências que este sofre. Segundo Nacarato (2005, p.5):

Não há como desconsiderar a complexidade da sala de aula, bem como a impossibilidade da adoção de uma única tendência para o ensino de Matemática. Assim, muitas vezes, o professor precisa utilizar uma diversidade de materiais, podendo transitar por diferentes tendências.

Além disso, o ensino de matemática encontra muitas dificuldades com "o distanciamento entre o conteúdo abordado, e a realidade do aluno" (LEIVAS e CURY, 2009, p. 4), o que dificulta o ensino e a aprendizagem de matemática em qualquer etapa da vida escolar do aluno. Assim sendo, torna-se necessária uma contextualização da matéria estudada e a vida dos educandos. Segundo os PCNs (2000), a contextualização tem como característica fundamental, o fato de que todo conhecimento envolve uma relação entre sujeito e objeto, ou seja, quando se trabalha o conhecimento de modo contextualizado a escola está retirando o aluno da sua condição de expectador passivo. Deste modo, não é possível que a Matemática seja trabalhada de forma descontextualizada, fragmentada e repetitiva, sem considerar a realidade em que a escola está inserida, sendo assim, é necessária uma constante reflexão a respeito do que está sendo ensinado, por que e para que está sendo ensinado. Desta forma, a escola precisa trabalhar como afirmado por Rodrigues (1997, p.64):

A escola tem por função preparar e elevar o indivíduo ao domínio de instrumentos culturais, intelectuais, profissionais e políticos. Isso torna sua responsabilidade pesada e importante. Assim dimensionada a tarefa da escola, evidencia-se a expectativa que sobre ela recai no contexto da sociedade.

A escola precisa ser pensada como "preparação" para a vida, sendo assim, a escola é muito importante na formação do cidadão, e atrelado a isso, está a Educação Matemática quepara Fiorentini e Lorenzato (2009, p.10), busca "a melhoria da qualidade de ensino e da aprendizagem matemática". A Matemática integrante comum da base de formação educacional do indivíduo caracteriza-se como um campo de saber essencial, ainda mais nos dias atuais, em que o aparato tecnológico, construído em grande parte a partir deste conhecimento, torna-se necessário em quase todas as atividades do cotidiano. Assim,

A Matemática, por sua universalidade de quantificação e expressão, como linguagem, ocupa uma posição singular. No Ensino Médio, quando nas ciências torna-se essencial uma construção abstrata mais elaborada, os instrumentos matemáticos são especialmente importantes. Mas não é só nesse sentido que a Matemática é fundamental. Possivelmente, não existe nenhuma atividade da vida contemporânea, da música à informática, do comércio à meteorologia, da medicina à cartografia, das engenharias às comunicações, em que a Matemática não compareça de maneira insubstituível para codificar, ordenar, quantificar e interpretar compassos, taxas, dosagens, coordenadas, tensões, freqüências e quantas outras variáveis houver (BRASIL, 2000, p.9).

Deste modo, a partir dos PCNs, a matemática é uma ciência indispensável, sendo, portanto, obrigação e prazer do professor ensina-la segundo o que está previsto neste documento e nas demais diretrizes fornecidas aos profissionais. 
As políticas públicas para o Ensino Médio foram muito poucas nas últimas décadas, um dos fatores refere-se à universalização tardia do Ensino Fundamental no Brasil, que se configura como a principal razão para que o nível médio só apareça na agenda pública, com força nunca antes vista, no início deste século atual (NEUBAUER et al., 2011).

Entretanto, de acordo com os dados do Índice de Desenvolvimento da Educação Básica (IDEB) (INEP, 2018) apresentados nas Tabelas 1.1 e 1.2, verifica-se que a rede pública de ensino não atingiu as metas, mesmo estas estando abaixo de cinco (5), de um total de dez (10) pontos.

Tabela 1.1 IDEB 2005, 2007, 2009, 2011, 2013, 2015 e 2017 e Projeções para o Brasil - Anos Finais do Ensino Fundamental.

\begin{tabular}{|c|c|c|c|c|c|c|c|c|c|c|c|c|c|c|c|}
\hline & \multicolumn{7}{|c|}{ IDEB Observado } & \multicolumn{8}{|c|}{ Metas } \\
\hline & 2005 & 2007 & 2009 & 2011 & 2013 & 2015 & 2017 & 2007 & 2009 & 2011 & 2013 & 2015 & 2017 & 2019 & 2021 \\
\hline Total & 3.5 & 3.8 & 4.0 & 4.1 & 4.2 & 4.5 & 4.7 & 3.5 & 3.7 & 3.9 & 4.4 & 4.7 & 5.0 & 5.2 & 5.5 \\
\hline \multicolumn{16}{|c|}{ Dependência Administrativa } \\
\hline Pública & 3.3 & 3.6 & 3.8 & 3.9 & 4.0 & 4.2 & 4.5 & 3.3 & 3.5 & 3.8 & 4.2 & 4.5 & 4.8 & 5.1 & 5.3 \\
\hline Estadual & 3.1 & 3.4 & 3.6 & 3.8 & 3.8 & 4.1 & 4.3 & 3.1 & 3.3 & 3.5 & 3.9 & 4.3 & 4.6 & 4.9 & 5.1 \\
\hline Municipal & 5.8 & 5.8 & 5.9 & 6.0 & 5.9 & 6.1 & 6.4 & 5.8 & 6.0 & 6.2 & 6.5 & 6.8 & 7.0 & 7.1 & 7.3 \\
\hline Privada & 3.2 & 3.5 & 3.7 & 3.9 & 4.0 & 4.2 & 4.4 & 3.3 & 3.4 & 3.7 & 4.1 & 4.5 & 4.7 & 5.0 & 5.2 \\
\hline
\end{tabular}

Os resultados marcados em verde referem-se ao IDEB que atingiu a meta. Fonte: Sistema de Avaliação da Educação Básica (SAEB)/Censo Escolar (2018).

Tabela 1.2 IDEB 2005, 2007, 2009, 2011, 2013, 2015 e 2017 e Projeções para o Brasil - Ensino Médio.

\begin{tabular}{|c|c|c|c|c|c|c|c|c|c|c|c|c|c|c|c|}
\hline & \multicolumn{7}{|c|}{ IDEB Observado } & \multicolumn{8}{|c|}{ Metas } \\
\hline & 2005 & 2007 & 2009 & 2011 & 2013 & 2015 & 2017 & 2007 & 2009 & 2011 & 2013 & 2015 & 2017 & 2019 & 2021 \\
\hline Total & 3.4 & 3.5 & 3.6 & 3.7 & 3.7 & 3.7 & 3.8 & 3.4 & 3.5 & 3.7 & 3.9 & 4.3 & 4.7 & 5.0 & 5.2 \\
\hline \multicolumn{16}{|c|}{ Dependência Administrativa } \\
\hline Estadual & 3.0 & 3.2 & 3.4 & 3.4 & 3.4 & 3.5 & 3.5 & 3.1 & 3.2 & 3.3 & 3.6 & 3.9 & 4.4 & 4.6 & 4.9 \\
\hline Privada & 5.6 & 5.6 & 5.6 & 5.7 & 5.4 & 5.3 & 5.8 & 5.6 & 5.7 & 5.8 & 6.0 & 6.3 & 6.7 & 6.8 & 7.0 \\
\hline Pública & 3.1 & 3.2 & 3.4 & 3.4 & 3.4 & 3.5 & 3.5 & 3.1 & 3.2 & 3.4 & 3.6 & 4.0 & 4.4 & 4.7 & 4.9 \\
\hline
\end{tabular}

Os resultados marcados em verde referem-se ao IDEB que atingiu a meta.

Fonte: Sistema de Avaliação da Educação Básica (SAEB)/Censo Escolar (2018).

É possível perceber que que nos anos finais do Ensino Fundamental em 2017 a meta não foi atingida de maneira geral, e nem por nenhuma escola, sendo que a Escola Pública atingiu 4.5, em uma meta de 4.8. No Ensino Médio em 2017, as metas também não foram atingidas por nenhuma escola. Também é possível notar que de 2011 a 2017, nas escolas públicas não houve um progresso nos dois últimos anos no IDEB das escolas públicas; enquanto que, nas escolas privadas houve uma queda e posteriormente uma melhoria no índice.

Os dados das Tabelas 1.1 e 1.2 retratam um déficit em relação as metas nas escolas públicas de maneira geral, sendo necessário compreender porque isso acontece e o que pode ser feito para melhorar o ensino e a aprendizagem. Todavia o Ensino Médio integrado ao técnico nas escolas da Rede federal de Ensino vive uma realidade diferenciada das demais escolas públicas, e "é atualmente uma das mais importantes políticas públicas e está articulada à ideia de se considerar a diversidade dos sujeitos que precisam se inserir na vida econômico-produtiva" (LOPES, 2011, p.4).

A partir do que foi dito, este trabalho se justifica pela necessidade de avaliar a o Ensino Médio em uma Escola Técnica Federal na região de Bragança Paulista. 


\subsection{PROBLEMA DE PESQUISA}

A partir de pesquisa bibliográfica, análises feitas pelo autor desta proposta dentro da escola e das informações apresentadas, tornou-se possível definir o seguinte problema de pesquisa: "Quais variáveis influenciam o ensino e a aprendizagem de matemática no Ensino Médio em uma Escola Técnica Federal?"

\subsection{HIPÓTESES}

A hipótese que se faz inicialmente é de que as variáveis que influenciam o ensino e a aprendizagem de matemática no Ensino Médio em uma Escola Técnica Federal são:

a) Disciplina;

b) Motivações externas; e,

c) Não aprendizagem de conteúdos anteriores;

Mas isso só será comprovado ou não de acordo com as análises e observações realizadas com os alunos escolhidos como objeto de estudo.

\subsection{OBJETIVO GERAL E ESPECÍFICO}

Tendo em vista a atual situação da educação no Brasil e a necessidade de estudá-la para poder aprimorá-la, este trabalho objetiva identificar e analisar as variáveis que contribuem e influenciam o ensino e a aprendizagem de matemática no Ensino Médio em uma Escola Técnica Federal.

A partir do estabelecimento da proposta, ao realizar uma análise em relação ao ensino e aprendizagem de matemática, este trabalho tem como objetivos específicos:

a) Levantar na literatura os aspectos teóricos relativos ao ensino e aprendizagem de matemática em geral e no ensino médio, além de especificamente em uma Escola Técnica Federal;

b) Levantar na literatura e apontar os possíveis aspectos que influenciam o ensino e a aprendizagem de matemática por meio dos instrumentos de pesquisa;

c) Analisar e fundamentar os dados obtidos a partir da aplicação de questionários com os alunos no âmbito da escola pesquisada e,

d) Analisar e comparar as variáveis levantadas que influenciam o ensino e a aprendizagem de matemática por meio das Técnicas de Análise Multivariadas.

\subsection{APRESENTAÇÃO DA ESTRUTURA DO TRABALHO}

O presente trabalho visa levantar e analisar as variáveis que influenciam o ensino e a aprendizagem de matemática no Ensino Médio em uma Escola Técnica Federal. Para melhor compreensão e organização das análises, o trabalho está estruturado da seguinte forma:

Além dessa introdução, no Capítulo 2, intitulado "Revisão da Literatura", são apresentados fundamentos da pesquisa apoiados nas considerações de diversos autores.

No Capítulo 3, sob título "Método", apresentam-se os procedimentos metodológicos e são caracterizados os sujeitos de pesquisa e descritos os procedimentos da investigação para a coleta de dados.

No Capítulo 4, sob título "Apresentação e Análise de Dados" são apresentados os dados recolhidos a partir de um questionário e a análise destes dados.

No Capítulo 5, "Conclusões", são apresentadas as principais conclusões, oriundas das análises dos instrumentos utilizados na pesquisa, as considerações finais, as análises da pesquisa e as delimitações da mesma, além de propostas para trabalhos futuros. 


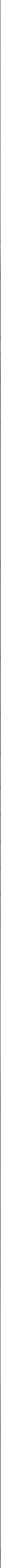


Neste capítulo é tratado o Ensino e Aprendizagem de Matemática e sobre a Matemática no Ensino Médio. Também será tratado sobre as Escolas Técnicas Federais e os fatores positivos e problemas que influenciam o Ensino e Aprendizagem de Matemática.

\subsection{ENSINO E APRENDIZAGEM DE MATEMÁTICA}

A educação faz toda a diferença na vida do homem e "percebe-se que a educação é o caminho fundamental para transformar a sociedade" (MORAN, 2000, p.137). Além disso,

Educar é colaborar para que professores e alunos - nas escolas e organizações transformem suas vidas em processos permanentes de aprendizagem. É ajudar os alunos na construção da sua identidade, do seu caminho pessoal e profissional - do seu projeto de vida, no desenvolvimento das habilidades de compreensão, emoção e comunicação que thes permitam encontrar seus espaços pessoais, sociais e profissionais e tornar-se cidadãos realizados e produtivos (MORAN, 2008, p.137).

Moura et al. (2010) apresentam a pergunta fundamental para aqueles que tem como atividade principal o ensino, "Quais as possibilidades de a teoria, a partir das pesquisas que as sustentam, orientar as ações pedagógicas?" (MOURA et al., 2010, p.207). A partir disto pode-se refletir sobre a dualidade entre a teoria e a prática no processo de ensino e aprendizagem, e com isso, deve-se considerar que,

Diante da complexidade dos fenômenos multifacetados que constituem a educação escolar, é necessário combater uma visão muitas vezes naturalizada, segundo a qual essa multiplicidade de fenômenos termina por levar o professor ou os responsáveis pela educação escolar a se aterem apenas aos fenômenos mais aparentes da educação escolar, tais como o pouco desempenho dos estudantes, a formação incipiente dos professores, a falta de motivação para o estudo, a indisciplina e a violência nas escolas (MOURA et al., 2010, p.207).

É possível perceber que nem sempre o ensino promovido no ambiente escolar permite que o aluno se aproprie dos conhecimentos científicos de forma a compreende-los, questioná-los e utilizá-los como forma de pensamento além da sala de aula e da escola. Segundo Mortimer (1996), grande parte do saber científico transmitido na escola é rapidamente esquecida, prevalecendo ideias alternativas ou de senso comuns bastante estáveis e resistentes, identificadas, até mesmo, entre estudantes universitários.

A aprendizagem, conforme defende Vigotski (2002, p. 115), "[...] pressupõe uma natureza social específica e um processo através do qual as crianças penetram na vida intelectual daqueles que a cercam". É na relação do sujeito com o meio físico e social, mediada por instrumentos e signos (entre eles a linguagem), que se processa o seu desenvolvimento cognitivo. Assim, de acordo com o conceito de trabalho de Marx e Engels (1977), ao transformar a natureza o homem também se transforma.

Ao tratar da aprendizagem, Rubtsov (1996) o faz na perspectiva da atividade ressaltando o papel do coletivo na sua realização, de acordo com o autor:

[...] as pesquisas dos psicólogos mostraram que a aptidão para a aprendizagem é, na verdade, resultado de uma determinada interiorização, de maneira que a atividade de aprendizagem se apresenta, essencialmente, sob a forma de uma atividade realizada em comum (RUBTSOV, 1996, p. 134).

Entender a escola como o lugar social privilegiado para a apropriação de conhecimentos produzidos historicamente passa necessariamente por assumir que a ação do professor deve estar organizada intencionalmente para esse fim (MOURA et al., 2010, p.212).

Embora o sujeito possa se apropriar dos mais diferentes elementos da cultura humana de modo não intencional, não abrangente e não sistemático, de acordo com suas próprias necessidades e interesses, é no processo de educação escolar que se dá a apropriação de conhecimentos aliada à questão da intencionalidade social, o que justifica a importância da organização do ensino, como aponta Moura (2002). 
Assim, no processo de ensino e de aprendizagem "estão presentes o conteúdo de aprendizagem, o sujeito que aprende, o professor que ensina e, o mais importante, a constituição de um modo geral de apropriação da cultura e do desenvolvimento do humano genérico" (MOURA et al., 2010, p.216).

Segundo Fetzer (2011), um dos temas mais discutidos nas últimas décadas é a relação entre a educação matemática e a inteligência, principalmente porque se percebe que as habilidades humanas não são essencialmente adquiridas em sua formação biológica, mas a partir de diversos instrumentos que ampliam nossa capacidade de percepção, ação e resolução de problemas.

Estes instrumentos são desenvolvidos e com eles o conhecimento é aprimorado. Eles são adquiridos principalmente com a formalização do saber, na escola, sendo essa uma importante intervenção do professor na construção do conhecimento do aluno. Infelizmente, às vezes, este trabalho se restringe ao "ensino de técnicas ou instrumentos que poderão ser utilizados pelos alunos na vida prática para solucionar problemas" (NUNES, 2005, p. 35).

Os instrumentos e técnicas são importantes, mas apenas seu uso, sem a compreensão contextual do conteúdo, pode tornar "à aprendizagem receptiva e mecânica" (FETZER, 2011, p.2), sem contemplar o que a aprendizagem deve significar para o aluno. Desta maneira, o conteúdo deve ser apresentado "de forma a valorizar as múltiplas competências" (PAIS, 2006, p.56) e ser sempre desenvolvido de forma a atrair o interesse do aluno de forma a facilitar a aprendizagem.

Segundo Miguel (2005), as crianças que chegam à escola normalmente gostam de Matemática. Entretanto, não será difícil constatar também que esse gosto pela Matemática decresce proporcionalmente ao avanço dos alunos pelos diversos ciclos do sistema de ensino, processo que culmina com o desenvolvimento de um sentimento de aversão, apatia e incapacidade diante da Matemática.

Com isso, temos diversas explicações para este acontecimento, que são dadas e transitam entre "ideias de formação inadequada do professor, condições inadequadas de trabalho no magistério, dificuldades de aprendizagem dos alunos, desvalorização da escola, currículos e programas de ensino obsoletos, entre outras" (MIGUEL, 2005, p.375), sendo que cada um destes aspectos merece consideração e cumpre um papel no desempenho dos alunos nesta área do conhecimento.

\subsection{A MATEMÁTICA NO ENSINO MÉDIO}

A Lei de Diretrizes e Bases da Educação Nacional, LDBEN 9.394/96, modificada pela Lei 11.274 (BRASIL, 2006), posiciona o Ensino Médio como a etapa final da Educação Básica, complementando o aprendizado iniciado no Ensino Fundamental. A nova proposta curricular para o Ensino Médio tem como objetivo respeitar o princípio de flexibilidade, orientador da Lei de Diretrizes e Bases (LBD), e se mostrar exequível em todos os Estados da Federação, considerando as desigualdades regionais.

Segundo os Parâmetros Curriculares Nacionais para o Ensino Médio (PCNEM) (BRASIL, 2000), o currículo a ser elaborado deve corresponder a uma boa seleção e deve contemplar aspectos dos conteúdos e de práticas que precisam ser enfatizadas. Outros aspectos merecem menor ênfase e devem mesmo ser abandonados por parte dos organizadores de currículos e professores.

Skovsmose (2001) discute a respeito do papel que a Matemática tem na sociedade. Para ele, ela interfere na realidade, e apesar de ser uma construção social, tem o poder de "formatar nossa sociedade", ou seja, nós vivemos envoltos em Modelos Matemáticos elaborados para atender aos mais diversos interesses como os governamentais por exemplo, ao calcular impostos, o PIB (Produto Interno Bruto) ou dos bancos, ao cobrar juros, entre outros. Assim, esse autor defende que a escola deve ter, como objetivo, capacitar os alunos para analisar as informações de cunho matemático com os quais se depara. Para isso, propõe o ensino de uma matemática crítica que adota uma postura reflexiva diante das informações matemáticas, já que a mesma intervém na realidade e pode ser manipulada.

Assim, "o desenvolvimento das habilidades linguísticas deveria se realizar de maneira integrada e conjunta com as atividades matemáticas, desde muito cedo, o que traz sérias consequências para o planejamento das ações didáticas e para a organização curricular nas escolas" (MIGUEL, 2005, p.378). Na atividade de ensino estão presentes o conteúdo de aprendizagem, o sujeito que 
aprende, o professor que ensina e, o mais importante, a constituição de um modo geral de apropriação da cultura e do desenvolvimento do humano genérico (MOURA et al., 2010, p.216).

A partir disto, escola deve se organizar de forma a dar condições aos estudantes de desenvolverem habilidades e competências necessárias para compreensão da sociedade e da importância que a matemática representa na construção do conhecimento científico ao longo da história da humanidade, e da necessidade da apropriação deste conhecimento para atuar numa sociedade altamente tecnológica. D'Ambrosio (2001) salienta que a forma como a Matemática tem sido ensinada não está capacitando os estudantes para os desafios com os quais estes se deparam hoje,

[...] a matemática e a educação matemática não podem ser insensíveis aos problemas maiores que afeta o mundo moderno, principalmente a exclusão de indivíduos, comunidades, e até nações, dos benefícios da modernidade. A matemática é o maior fator de exclusão nos sistemas escolares. O número de reprovações e evasões é intolerável (D’AMBROSIO, 2001, p. 16).

Em busca de promover a melhora do desempenho na aprendizagem da Matemática na escolaridade básica, são apresentadas, de tempos em tempos, algumas mudanças curriculares e sugestões de novas metodologias e ferramentas que podem contribuir para isso. Desta maneira "o Ensino Médio, particularmente, tem o desafio de promover a ampliação da visão de mundo dos estudantes, e desenvolver suas competências gerais, a fim de articularem os conhecimentos e os usarem na vida cotidiana" (LOPES, 2011, p.9).

Assim, "é preciso que o ensino da Matemática seja interessante e integrada às problemáticas da atualidade e, para alcançarmos esse desafio, é preciso investigar os processos de aquisição do conhecimento matemático" (LOPES, 2011, p.11), especialmente no Ensino Médio, auxiliando o repensar do currículo de Matemática para esse curso e, mais ainda, na construção da identidade desse nível de ensino.

Levando em consideração estas afirmações, o ensino de Matemática deve ir além do simples reconhecimento de símbolos, manejo de fórmulas, utilização de regras e técnicas para resolver problemas modelos. Fato que corrobora com a concepção de Lopes (2011, p.10) a respeito do ensino de matemática, a qual afirma que:

É, sobretudo, promover situações de aprendizagem que possibilitem aos estudantes a construção de competências para saberem lidar com os conceitos, utilizando-os na resolução de problemas, avaliação de resultados encontrados, questionamento de informações, desenvolvimento de atitudes criativas que contribuam para o exercício de uma profissão, e que os levem a exercer sua cidadania de forma crítica e participativa.

Pois é fundamental que ao se formar no Ensino Médio, o aluno possa ser um cidadão crítico e participativo, sendo que,

O desenvolvimento de uma consciência crítica que permite ao homem transformar a realidade se faz cada vez mais urgente. Na medida em que os homens, dentro de sua sociedade, vão respondendo aos desafios do mundo, vão temporalizando os espaços geográficos e vão fazendo história pela sua própria atividade criadora (FREIRE, 2003, p.33).

Assim, o papel do professor é fundamental, pois este deve criar e mediar situações de aprendizagem que estimulem seu aluno. Deste modo, "educar seria proporcionar ao aluno um encontro pedagógico com os conceitos; a formação de uma visão de transformação e de movimento contínuo da realidade humana" (SOUSA, 2009, p. 88), e desta forma, "cabe à Matemática do Ensino Médio apresentar ao aluno o conhecimento de novas informações e instrumentos necessários para que seja possível a ele continuar aprendendo" (GODOY, 2010, p. 81). Mas, os alunos precisam compartilhar responsabilidades sobre o processo de ensino $e$ aprendizagem, valorizando o raciocínio matemático, formulando questões, perguntando-se sobre a existência de solução, levantando hipóteses, apresentando conclusões, considerando exemplos e contraexemplos, generalizando situações, percebendo e abstraindo regularidades, criando modelos, argumentando com fundamentação lógico-dedutiva. 
Desta forma, surge a discussão, de quais são conceitos matemáticos essenciais para o Ensino Médio, que de acordo com Lopes (2011, p.11) são:

a) O estudo dos Números e Operações deve proporcionar aos alunos uma diversidade de situações, de forma a capacitá-los para resolver problemas do quotidiano, em como científicos, que envolvam números naturais, racionais, irracionais e complexos. Destaca-se a importância da estimativa e do cálculo mental frente ao uso da tecnologia;

b) Da abordagem de Funções, deve-se iniciar pela exploração qualitativa de relações entre duas grandezas, em diferentes situações. Vale um destaque ao estudo das funções trigonométricas que devem ser entendidas como extensões das razões trigonométricas, priorizando-se o estudo das funções seno, cosseno e tangente;

c) A Matemática Financeira deve ocupar um lugar especial no currículo como um assunto a ser tratado quando do estudo da função exponencial e não se recomenda um estudo exaustivo dos logaritmos;

d) O estudo da Geometria deve possibilitar o desenvolvimento da capacidade para a resolução de problemas práticos do quotidiano, permitindo orientação espacial, leitura de mapas, estimativa e comparação de distâncias percorridas, reconhecimento de propriedades de formas geométricas básicas, uso de diferentes unidades de medida;

e) O trabalho com a Geometria Analítica deve permite a articulação entre Geometria e Álgebra, assim como, o estudo de sistemas de equações deve colocar a Álgebra sob o olhar da Geometria; e,

f) O bloco Análise de Dados e Probabilidade justifica-se pela necessidade de os alunos ampliarem e formalizarem seus conhecimentos sobre o raciocínio combinatório, probabilístico e estatístico.

Estas perspectivas curriculares apontadas por Lopes (2011) requerem que professores trabalhem em conjunto com a equipe gestora da escola a fim de proporcionar aos alunos a chance de aprender significativamente a matemática no Ensino Médio.

\subsection{AS ESCOLAS TÉCNICAS FEDERAIS}

No documento do Ministério da Educação, intitulado Proposta em Discussão: políticas públicas para a educação e tecnológica (BRASIL, 2004), encontramos a defesa por uma educação profissional, tanto em termos nacionais quanto mundiais,

[...] como elemento estratégico para a construção da cidadania e para uma melhor inserção de jovens e trabalhadores na sociedade contemporânea, plena de grandes transformações e marcadamente tecnológica. Suas dimensões, quer em termos conceituais, quer em suas práticas, são amplas e complexas, não se restringindo, portanto, a uma compreensão linear, que apenas treina o cidadão para a empregabilidade, nem a uma visão reducionista, que objetiva simplesmente preparar o trabalhador para executar tarefas instrumentais. No entanto, a questão fundamental da educação profissional e tecnológica envolve necessariamente o estreito vínculo com o contexto maior da educação, circunscrita aos caminhos históricos percorridos por nossa sociedade.

Assim, este documento defende que a educação profissional e tecnológica deve ser concebida como um processo de construção social que ao mesmo tempo qualifique o cidadão em bases científicas, assim como ético-políticas, para compreender a tecnologia como produção do ser social, que estabelece relações sócio históricas e culturais de poder. Desta forma, a educação "despontaria como processo mediador que relaciona a base cognitiva com a estrutura material da sociedade, evitando o erro histórico de se transformar em mercadoria e de considerar a educação profissional e tecnológica como adestramento ou treinamento" (ESCOTT e MORAES, 2012, p.9).

Em decorrência do que é evidenciado por Escott e Moraes (2012), é necessária uma organização especial nos Institutos Federais, e conforme Pacheco (2010) a nova organização acadêmica, singular aos Institutos Federais - IFs, aponta para a ruptura da reprodução de modelos externos e 
toma a inovação a partir da relação entre o ensino técnico e o científico, articulando trabalho, ciência e cultura na perspectiva da emancipação humana. Ainda para o autor,

Na proposta dos Institutos Federais, agregar à formação acadêmica a preparação para o trabalho (compreendendo-o em seu sentido histórico, mas sem deixar de firmar o seu sentido ontológico) e discutir os princípios das tecnologias a ele concernentes dão luz a elementos essenciais para a definição de um propósito específico para a estrutura curricular da educação profissional e tecnológica. O que se propõem é uma formação contextualizada, banhada de conhecimentos, princípios e valores que potencializam a ação humana na busca de caminhos de vida mais dignos.

Assim, derrubar as barreiras entre o ensino técnico e o científico, articulando trabalho, ciência e cultura na perspectiva da emancipação humana, é um dos objetivos basilares dos Institutos. Sua orientação pedagógica deve recusar o conhecimento exclusivamente enciclopédico, assentando-se no pensamento analítico, buscando uma formação profissional mais abrangente e flexível, com menos ênfase na formação para ofícios e mais na compreensão do mundo do trabalho e em uma participação qualitativamente superior neste. Um profissionalizarse mais amplo, que abra infinitas possibilidades de reinventar-se no mundo e para o mundo, princípios estes válidos, inclusive, para as engenharias e licenciaturas (PACHECO, 2010, p. 10).

Nesse aspecto, aparentemente a política que orienta os Institutos Federais, reafirma que a formação humana, cidadã, precede a qualificação para a trabalho, assumindo o compromisso de assegurar aos profissionais formados a possibilidade de continuar em desenvolvimento ao longo de sua vida.

Nesse contexto, o Instituto Federal aponta para um novo tipo de instituição, identificada e pactuada com o projeto de sociedade em curso no país. Representa, portanto, um salto qualitativo em uma caminhada singular, prestes a completar cem anos. Trata-se de um projeto progressista que entende a educação como compromisso de transformação e de enriquecimento de conhecimentos objetivos capazes de modificar a vida social e de atribuir-lhe maior sentido e alcance no conjunto da experiência humana, proposta incompatível com uma visão conservadora de sociedade. Trata-se, portanto, de uma estratégia de ação política e de transformação social (PACHECO, 2010, p. 12).

Os Institutos Federais, desta forma, apresentam em sua proposta político-pedagógica, como princípio,

a oferta da educação básica, principalmente em cursos de ensino médio integrado à educação profissional técnica de nível médio; ensino técnico em geral; graduações tecnológicas, licenciatura e bacharelado em áreas em que a ciência e a tecnologia são componentes determinantes, em particular as engenharias, bem como, programas de pós- graduação lato e stricto sensu, enfocando, também, a formação inicial e continuada de trabalhadores. (ESCOTT e MORAES, 2012, p.9).

Assim, nestas instituições a matemática é importante, sendo que,

a matemática e sua relação com o desenvolvimento técnico-científico e a formação para o trabalho se constitui numa temática fundamental para a organização curricular das Escolas Técnicas Federais e dos Centros Federais de Educação Tecnológica. Atualmente denominadas de Institutos Federais de Educação, Ciência e Tecnologia, formam a Rede Federal de Educação Tecnológica (PINTO e SANTOS, 2011, p. 2). 
Assim, percebe-se, de acordo com Pinto e Santos (2011), Escott e Moraes (2012), Pacheco (2010), BRASIL (2004) que os Institutos Federais são importantes e oferecem uma educação diferenciada, além de fazerem parte das Escolas Públicas.

\subsection{FATORES POSITIVOS, NEGATIVOS E PROBLEMAS QUE INFLUENCIAM O ENSINO E APRENDIZAGEM DE MATEMÁTICA}

A matemática é uma disciplina presente em toda a vida escolar do aluno, e "as dificuldades encontradas por alunos e professores no processo ensino-aprendizagem da matemática são muitas e conhecidas" (FIORENTINI e MIORIM, 1990, p.5). E essas dificuldades influenciam o desempenho escolar do aluno, sendo assim muito importante estuda-las. Segundo Vergani (2007, p.23), "o desastre prolonga-se no tempo e a sociedade continua a consentir no escandaloso fracasso do ensino escolar da matemática", revelado pelo reconhecimento do nível insatisfatório do aprendizado matemático dos alunos, e pelas ações incipientes para mudar o rumo desse processo educativo.

Desta forma, "o aluno não consegue entender a matemática que a escola lhe ensina, muitas vezes é reprovado nesta disciplina, ou então, mesmo que aprovado, sente dificuldades em utilizar o conhecimento 'adquirido'" (FIORENTINI e MIORIM, 1990, p.5). Por outro lado, o professor "consciente de que não consegue alcançar resultados satisfatórios junto a seus alunos e tendo dificuldades de, por si só, repensar satisfatoriamente seu fazer pedagógico procura novos elementos que, acredita, possam melhorar este quadro" (FIORENTINI e MIORIM, 1990, p.5).

Assim, é fundamental estudar os fatores que permeiam o ensino e a aprendizagem de matemática, sejam estes positivos ou negativos. Para Abreu e Masetto (1996), a aprendizagem é dividida em três categorias: a da cognição, a de valores e atitudes e a de habilidades (correspondendo a aprender a fazer). O professor em seu cotidiano escolar trabalha com o estudante envolvendo estas categorias em sua totalidade. Desta forma, "muitos são os componentes que estão presentes no processo de ensino e aprendizagem. Podem-se citar, entre outras, as questões ligadas à formação docente, ao domínio afetivo, a relação interpessoal entre professor e aluno" (ROCHA e GUELLER, 2013a, p.3).

Além disso, é preciso considerar que "nada nem ninguém pode forçar um aluno a aprender se ele mesmo não se empenhar no processo de aprendizagem." (TARDIF, 2002, p. 132) e assim é fundamental entender o que influencia a aprendizagem do aluno para poder estimular o acontecimento da mesma.

Assim, este trabalho visa estudar as seguintes influencias no processo de ensino e aprendizagem de matemática no ensino médio, dentre as quais se pode citar: formação do professor; relação interpessoal entre professor e aluno; motivação do aluno e do professor; indisciplina; material didático; didática; currículo; relação sociocultural; dedicação do aluno a disciplina; e, a existência de um método para estudar matemática. Há outras possíveis variáveis, mas não serão tratadas no decorrer deste estudo.

\subsubsection{A QUESTÃO DA FORMAÇÃO DO PROFESSOR}

A formação de docentes para a área de matemática está regulamentada por resolução do Conselho Nacional de Educação (CNE) (BRASIL, 2002), que orientam e buscam estabelecer a estruturação dos cursos de licenciatura a partir de ações que possam ser geradoras de conhecimentos. Atualmente, a formação de professores tem sido bastante discutida entre os pesquisadores brasileiros e estrangeiros, tais como: Gimeno e Gomez (1998), García (1999a), Veiga (2010), entre outros. Lima (2012) ressalta a incessante busca de caminhos pedagógicos que contribuam na formação docente na atualidade, onde a relação dialética entre teoria e prática pode contribuir no princípio formativo.

A formação do professor é diferente da formação de outros profissionais, pois são formados profissionais que futuramente estarão no papel de formadores, sendo assim objeto de preocupação de muitos dos pesquisadores da área. Entretanto, "diversas investigações vêm mostrar que, com alguma frequência, os professores principiantes não se sentem satisfeitos com a sua formação inicial, apontando diversas lacunas" (OLIVEIRA, 2004, p. 123). Silva (1997), por exemplo, menciona 
que os professores no seu $1^{\circ}$ ano de carreira retêm imagens pouco positivas da sua formação, afirmando, por um lado, sentir muitas insuficiências quanto aos conteúdos a leccionar, que os obrigam continuamente a estudar e, por outro, a existência de uma certa artificialidade no estágio, visto serem-lhes atribuídas turmas "quase ideais" e não terem uma turma a seu cargo. Vários estudos evidenciam que os futuros professores, antes de iniciarem o período de prática pedagógica nas escolas, têm expectativas muito elevadas quanto ao seu desempenho na profissão (BULLOUGH, 1997). No entanto, este otimismo vai-se "esbatendo à medida que se vão confrontando com diversos constrangimentos, nomeadamente, com as exigências dos orientadores" (OLIVEIRA, 2004, p. 123), por isso, "não há nenhum modelo de formação que, por si só, dê conta da multidimensionalidade e multirreferencialidade do ensino e da formação" (ESTRELA, 2002, p. 26).

Tardif (2002) e Shön (2000) destacam que os saberes dos professores são construídos desde que eram alunos da escola básica, em sua trajetória pré-profissional e estes influenciaram sua atuação docente. Mas, a identidade profissional do professor não pode ser compreendida fora dos contextos sociais, culturais e políticos em que se insere a atividade do professor. Hargreaves (1996), por exemplo, argumenta que os contextos escolares exercem uma influência sobre a "forma como os professores veem os seus alunos, os seus colegas, o seu trabalho e a sua própria eficácia" (HARGREAVE, 1996, p. 16), e que as condições de trabalho afetam diretamente a sua satisfação profissional e o seu sentimento de integração na escola.

Apesar disso, uma das relações entre teoria e prática na formação do professor deve ocorrer na área de conhecimento especializado. Ora, se no futuro será necessário que o professor desenvolva em seus alunos a capacidade de relacionar a teoria à prática, é indispensável que, em sua formação, os conhecimentos especializados que o professor está constituindo sejam contextualizados para promover uma permanente construção de significados desses conhecimentos com referência a sua aplicação, sua pertinência em situações reais, sua relevância para a vida pessoal e social, sua validade para a análise e compreensão de fatos da vida real (MELLO, 2000,p. 103).

De acordo com Mello (2000), esse tipo de relação entre teoria e prática, decisiva para o professor, pois ele terá de refazê-la com seus alunos, é relevante para qualquer situação de formação profissional: o aluno da licenciatura em matemática, por exemplo, precisa compreender o significado e a função dos vários anos de cálculo integral a que é submetido, mesmo que este conteúdo não se destine ao magistério da matemática. Desta forma,

O professor de Matemática pode ser um agente criativo e inovador no processo de questionamento, característico das práticas reflexivas, mas o foco desse questionamento deve estar enraizado nos problemas que afetam o ensino e a aprendizagem (OLIVEIRA e SERRAZINA, 2002, p. 39).

Porém, "há outra relação entre teoria e prática que é específica da formação do professor: a aprendizagem da transposição didática do conteúdo, seja ele teórico ou prático" segundo a concepção de Mello (2000, p. 103). A prática do curso de formação docente é o ensino e portanto, de acordo com Mello (2000), cada conteúdo que é aprendido pelo futuro professor em seu curso de formação profissional precisa estar relacionado com o ensino desse mesmo conteúdo na educação básica e,

isso implica um tipo de organização curricular que, em todas as disciplinas do curso de formação, permita também: a transposição didática do conteúdo aprendido pelo futuro professor; e a contextualização do que está sendo aprendido na realidade da educação básica. Ainda com o exemplo anterior, é imprescindível que o aluno da licenciatura de matemática compreenda qual a relevância do cálculo integral para o ensino da matemática na educação básica (MELLO, 2000, p. 103).

Ceron (2004, p. 17) afirma que " o professor, consequentemente deverá superar as lacunas deixadas por seus cursos de formação". A importância da matemática faz-se perante a percepção da mesma, não só como uma disciplina da grade curricular, mas como área de conhecimento cientifico, em que "o domínio de conceitos básicos da matemática é necessidade intrínseca na atual sociedade, pois deve garantir vida social e cidadania, na medida em que serve de instrumento na busca incessante de aprimoramento e conhecimento" (ibid). Assim, como todos os profissionais, 
o professor precisa fazer ajustes permanentes em suas ações. Boa parte dos ajustes tem de ser feita em tempo real ou em intervalos relativamente curtos, minutos e horas, na maioria dos casos, dias ou semanas, na hipótese mais otimista, sob risco de passar a oportunidade de intervenção no processo de ensino e aprendizagem (MELLO, 2000, p. 104).

Sendo que, quando uma oportunidade se perde há o risco de se perder uma oportunidade única de aprendizagem para o aluno. Além disso, há fatores além do tempo que limitam o período dos ajustes necessários ao professor, sendo que os resultados das ações pedagógicas de ensino são previsíveis apenas em parte. Assim, "ensinar requer dispor e mobilizar conhecimentos para improvisar, intuir, atribuir valores e fazer julgamentos que fundamentem a ação mais pertinente e eficaz possível" (MELLO, 2000, p. 105).

Desta forma, a formação do professor é fundamental na maneira como este se relaciona com seus alunos e, consequentemente no processo de ensino e aprendizagem, sendo assim fundamental uma boa formação para que haja bons professores.

\subsubsection{RELAÇÃO INTERPESSOAL ENTRE PROFESSOR E ALUNO}

A relação professor-aluno "é fundamental para o desenvolvimento integral das crianças. A partir da relação com os docentes, ela adquire conhecimentos para todo o curso de vida e tem suas capacidades psicossociais promovidas" (BARBOSA, CAMPOS e VALENTIM, 2011, p. 453). Baker (2006) destaca que a relação professor-aluno é necessária para o engajamento das crianças na aprendizagem; é, também, a base para o desenvolvimento de crenças adaptativas sobre si mesmo e sobre o mundo social, e para a aquisição de comportamento se competências autorreguladoras e socioemocionais, essenciais no ambiente escolar. Baker (2006) ainda afirma que a qualidade desta relação é um forte indicador da adaptação escolar, especialmente para crianças que apresentam problemas comportamentais em sala de aula.

Além disso, a "relação professor-aluno é uma forma de interação que dá sentido ao processo educativo, uma vez que é no coletivo que os sujeitos elaboram conhecimentos" (SILVA e NAVARRO, 2012, p.95), por isso, o docente precisa refletir a todo o momento sobre sua prática, "fundamentando-se em uma base teórica e sólida" (SILVA e NAVARRO, 2012, p.95). Além disso, de acordo com Veiga (1993, p.147),

A relação professor-aluno passa pelo trato do conteúdo de ensino. A forma como o professor se relaciona com sua própria área de conhecimento é fundamental, assim como sua percepção de ciência e de produção do conhecimento. E isto interfere na relação professor-aluno, e parte desta relação.

E segundo Morales (1998, p.49):

A relação professor-aluno na sala de aula é complexa e abarca vários aspectos; não se pode reduzi-la a uma fria relação didática nem a uma relação humana calorosa. Mas é preciso ver a globalidade da relação professor-aluno mediante um modelo simples relacionado diretamente com a motivação, mas que necessariamente abarca tudo o que acontece na sala de aula e há necessidade de desenvolver atividades motivadoras.

Além disso, segundo Lopes (2001), a relação professor-aluno deve ser assimétrica, sendo que o professor é encarregado de transmitir ao aluno um conjunto de conhecimentos, hábitos e habilidades. "Essa interação compreende, normalmente, um componente de apoio/suporte, como a intimidade, e componentes estressores, como o conflito" (HAMRE, PIANTA, DOWNER, MASHBURN, 2008). Neste sentido, percebe-se a importância da relação professor-aluno no processo de ensino e aprendizagem, pois:

O grande desafio no ensino é, então, encontrar as estratégias mediadoras que permitam ao aluno operar reflexivamente na direção da apropriação do conhecimento. Se the for dado o apoio adequado para suas operações mentais ele avança (mesmo que minimamente), no seu processo de conhecimento e assim também no seu desenvolvimento (TACCA, 2000, p.326). 
Por outro lado, de acordo com Veiga (1994, p. 5), "ensinar é um exercício de imortalidade. De alguma forma continuamos a viver naqueles cujos olhos aprenderam a ver o mundo pela magia de nossa palavra. O professor, assim, não morre jamais." Desse modo, a reflexão sobre a importância e o papel do professor e do seu relacionamento com o educando, vai bem mais além, pois, " estamos diante de constantes mudanças, em que o novo sempre traz expectativas que muitas vezes são obscuras, preocupam e deixam profissionais perdidos" (SILVA e NAVARRO, 2012, p.98). Deste modo, percebe-se a importância do professor no processo de ensino e aprendizagem, e segundo os Parâmetros Curriculares Nacionais para Matemática (1997. p. 40):

Numa perspectiva de trabalho em se considere a criança como protagonista da construção de sua aprendizagem, o papel do professor ganha novas dimensões. Uma faceta desse papel é a de organizador da aprendizagem, para desempenhá-la, além de conhecer as condições socioculturais, expectativas e competência cognitiva dos alunos.

Assim, pode-se perceber a importância da relação entre professor e aluno e segundo Rebolo (1999), conquistar a simpatia e a amizade dos alunos é um aspecto importante e que faz com que os professores se sintam recompensados e aceitos como pessoas. Partilhar da amizade dos alunos gera um sentimento de segurança e de bem-estar suscetíveis de criar um clima agradável, indispensável para se obter a eficiência do ensino. A este respeito, Leite (1993, p. 236) lembra que "o professor vence ou é derrotado na profissão não apenas pelo seu saber maior ou menor, mas principalmente pela sua capacidade de lidar com alunos e ser aceitos por eles". Quando negativa, a relação professor-aluno pode ser associada à pobreza acadêmica e social na escola, à evasão escolar, a uma menor cooperação em sala de aula, a atitudes escolares negativas, a um comportamento menos autodirigido, ao isolamento social, a sentimentos de solidão e a um menor engajamento (BIRCH e LADD, 1997; BAKER, 2006).

Esse vínculo afetivo, porém, não pode ser o único existente, nem tão pouco, no caso da profissão docente, substituir o vínculo mediado pelo conhecimento, "pois se isso acontece o trabalho fica descaracterizado e as expectativas geradas a partir da escolha feita anteriormente pelo professor de "como" e "para que" trabalhar serão frustradas" (REBOLO, NOGUEIRA e SOARES, 2010, p. 114). E ainda,

O objetivo do trabalho do professor é a aprendizagem dos alunos. Para que a aprendizagem ocorra, muitos fatores são necessários. [...] Através de um contato tácito, onde o professor se propõe a ensinar e os alunos se dispõem a aprender, uma corrente de elos de afetividade vai se formando, propiciando uma troca entre os dois. [...] O professor precisa que os alunos confiem em si, acreditem que aquele conteúdo Ihes será útil; outra vez a sedução, outra vez a afetividade (CODO, 1999, p.50).

Desta forma, Abreu e Masetto (1996) afirmam que é o modo de agir do professor em sala de aula, mais do que suas características de personalidade, colabora para uma adequada aprendizagem dos alunos. Este modo de agir fundamenta-se numa determinada concepção do papel do professor, que por sua vez reflete valores e padrões da sociedade. Além disso,

o trabalho do professor só será direcionado rumo ao desenvolvimento dos alunos se forem estabelecidas genuínas relações entre eles. Isso é condição para que aconteça a sintonia de ideias, pensamento e motivação (TACCA, 2006, p.62).

Deste modo, "a relação de apoio entre professor e aluno pode, portanto, habilitar as crianças para se tornarem autodirigidas e participantes responsáveis na sala de aula" (BARBOSA, CAMPOS e VALENTIM, 2011, p. 453), sendo assim importante no processo de ensino e aprendizagem em todas as etapas da vida escolar, devendo assim, não deixar de ser estudada.

\subsubsection{MOTIVAÇÃO DO ALUNO E DO PROFESSOR}

Motivação é o processo pelo qual uma ação ou um conjunto de ações são iniciados tendo em vista o alcance de uma meta estabelecida. Pode-se dizer que "o processo motivacional dá início, dirige e integra o comportamento, sendo um dos principais determinantes do modo como uma pessoa se comporta" (BORUCHOVITCH et al., 2013, p. 426). A motivação é, segundo Lens, Matos e 
Vanteenkiste (2008), um processo psicológico no qual interatuam as características de personalidade (por exemplo, motivos, razões, habilidades, interesses, expectativas, perspectiva de futuro) e as características ambientais percebidas. Isso implica que a motivação dos alunos pode ser modificada por meio de mudanças nos mesmos e também por mudanças em seu ambiente de aprendizagem na cultura escolar.

A motivação também é, de acordo com Goya, Bzuneck e Guimarães (2008) um construto, ou seja, não é algo diretamente observável, mas uma entidade "construída" pelos psicólogos para explicar a ocorrência dos comportamentos humanos. Além disso, a motivação nos contextos de aprendizagem "é detectável por meio de comportamentos observáveis dos alunos, que incluem iniciar prontamente uma tarefa, empenhar-se nela com esforço razoável e persistir apesar das dificuldades" (GOYA, BZUNECK e GUIMARÃES, 2008, p. 54).

A importância da motivação nas atividades de ensino tem sido:

reforçada por pedagogos e psicólogos e o seu estudo pelo educador representa uma necessidade amplamente reconhecida, principalmente em escolas democráticas, nas quais os conteúdos e os métodos da educação devem, sempre que possível, respeitar as características individuais dos alunos (ECCHELI, 2008, p 200).

E dessa forma a motivação dos alunos é um importante desafio a ser enfrentado, "pois tem implicações diretas na qualidade do envolvimento do aluno com o processo de ensino e aprendizagem" (ALCARÁ e GUIMARÃES, 2007, p. 177). Segundo Alcará e Guimarães (2007) o aluno motivado busca novos conhecimentos e oportunidades, mostrando-se envolvido com o processo de aprendizagem, envolve-se nas tarefas com entusiasmo e demonstra disposição para novos desafios.

Por outro lado, "um professor motivado, entusiasmado em sua atuação no ensino, tende mais facilmente a influenciar os seus alunos para um processo de aprendizagem eficaz" (GOYA, BZUNECK e GUIMARÃES, 2008, p. 52). E assim, um professor desmotivado tende a desmotivar seus alunos. A esse respeito observou-se que a falta de motivação e interesse em professores e alunos pode contribuir para que estabeleça um círculo vicioso que mantém ambos em estado de "inércia" (ARRUDA, 2001).

Todas as teorias que procuram explicar o processo de motivação partem do princípio de que existe uma necessidade (motivo) que desencadeia uma ação, dando-lhe direção para alcançar um objetivo. Sendo assim, o motivo pode ser considerado um constructo criado para explicar a origem dos comportamentos dirigidos para algum objetivo (WINTERSTEIN, 1992). Senso assim, motivação pode ser definida como "o processo que se desenvolve no interior do indivíduo e o impulsiona a agir, mental ou fisicamente, em função de algo. O indivíduo motivado encontra-se disposto a despender esforços para alcançar seus objetivos" (NÉRICI, 1993, p. 75).

É importante, para os alunos de todos os níveis educacionais, estarem bem motivados para seus estudos. E não é assim somente pelo fato da motivação ser um determinante importante na quantidade de tempo que os alunos gastam estudando, nos seus resultados escolares e nas realizações acadêmicas ao longo do tempo. É também uma causa importante da satisfação imediata em sua vida (bem-estar versus mal-estar) (LENS, MATOS e VANSTEENKISTE, 2008, p 17). O jovem não motivado passa muito tempo na escola realizando tarefas nas quais não está interessado. Isso gera frustração e insatisfação, que pode vir a ser expressa a como um comportamento não social.

Além disso, de acordo com Brophy (1998, p. 11) em sua atuação diária os professores devem: "buscar o desenvolvimento e a manutenção da motivação para aprender com as atividades acadêmicas. Isto é, devem fazer com que os alunos considerem tais atividades significativas e merecedoras de envolvimento, buscando obter com elas os benefícios de aprendizagem.". O aluno motivado procura novos conhecimentos e oportunidades, evidenciando envolvimento com o processo de aprendizagem, participa nas tarefas com entusiasmo e revela disposição para novos desafios (ALCARÁ e GUIMARÃES, 2007).

Assim, a motivação do aluno é "uma variável relevante do processo ensino/aprendizagem, na medida em que o rendimento escolar não pode ser explicado unicamente por conceitos como 
inteligência, contexto familiar e condição socioeconómica" (LOURENÇO e PAIVA, 2010, p. 133). A motivação, de acordo com Lourenço e Paiva (2010) é um elemento fundamental no uso de recursos do indivíduo, de modo a se alcançar um objetivo. Estas características reforçam a justificação da importância que é atribuída à motivação na aprendizagem escolar.

É conhecido que um fator central para o desenvolvimento pessoal e académico dos alunos são os problemas motivacionais, pois podem comprometer gravemente a aprendizagem dos mesmos (MARTINI, 2008). Os alunos, segundo Lourenço e Paiva (2010) têm diversos métodos individuais de avaliação do que fazem ou produzem. Para a maioria deles, o que fazem precisa ser motivante, exigir pouco esforço e ter alguma utilidade. De acordo com Boruchovitch (2009), uma teoria sobre a motivação na aprendizagem aborda a motivação intrínseca e a extrínseca. $\mathrm{O}$ aluno intrinsecamente motivado concretiza a tarefa apenas pelo prazer, porque se interessa por ela e se satisfaz verdadeiramente com a atividade em si. No caso do aluno extrinsecamente motivado realiza-a por causas externas, nomeadamente o receio de punições, o anseio de reconhecimento e de obtenção de compensações, ou ainda por reconhecê-la como necessária, embora não seja do seu agrado.

Desta forma, a motivação é um fator importante no processo de ensino e aprendizagem, sendo que o professor deve tentar manter-se sempre motivado e motivar seu aluno intrínseca e extrinsecamente.

\subsubsection{INDISCIPLINA}

Pirola (2008, p. 41), define indisciplina como:

todo comportamento, gestos e atitudes que nada tem a ver com o processo de ensino almejado pelo(a) professor(a), considerando que professores e alunos precisam ter clareza do processo e do produto das atividades escolares que realizam.

Desta forma, segundo Pirola (2008), a indisciplina está relacionada às concepções que o professor tem sobre o processo educativo, que refletem nas expectativas que tem sobre os alunos e principalmente, na sua prática pedagógica, ou seja, na relação com seu aluno. Partindo desse pressuposto, ela discute como a escola, por vezes, percebe a indisciplina:

A indisciplina tende a ser vista pelos participantes da escola como uma atitude de desrespeito, de intolerância aos acordos firmados, de intransigência, de nãocumprimento de regras capazes de pautar a conduta de um indivíduo ou um grupo. Dessa forma, o aluno indisciplinado não pode ser visto como aquele que questiona, se inquieta e se movimenta na sala, mas como aquele que não tem limites (PIROLA, 2008, p.40).

Além disso, "é senso comum entre os professores que a indisciplina e o desinteresse dos alunos se apresentam como um dos grandes problemas que interferem direta ou indiretamente no processo de ensino-aprendizagem" (SILVA e NAVARRO, 2012, p. 98), sendo assim necessário um questionamento sobre as causas da indisciplina e como combate-la.

Segundo Estrela (2002, p.17) "o conceito de indisciplina relaciona-se intimamente com o de disciplina e tende normalmente a ser definido pela sua negação ou privação ou pela desordem proveniente da quebra das regras estabelecidas". Enquanto que Veiga (2007, p. 15) afirma que "por indisciplina entende-se a transgressão das normas escolares, prejudicando as condições de aprendizagem, o ambiente de ensino ou o relacionamento das pessoas na escola". Igualmente, para Aires (2010, p. 13), a indisciplina "é um fenómeno intrínseco à sociedade e ao seu sistema de ensino e, dada a sua inevitabilidade, tão antigo como a própria escola".

O conceito de indisciplina, de acordo com Garcia (1999b) apresenta uma complexidade que precisa ser considerada. Um entendimento suficientemente amplo do conceito de indisciplina escolar precisa integrar diversos aspectos. Assim,

a noção de indisciplina será considerada através de três de seus principais planos de expressão na escola. De um lado, é possível situá-la no contexto das condutas dos alunos nas diversas atividades pedagógicas, seja dentro ou fora da sala de aula. Em complemento, deve-se considerar a indisciplina sob a dimensão dos 
processos de socialização e relacionamentos que os alunos exercem na escola, na relação com seus pares e com os profissionais da educação, no contexto do espaço escolar - com suas atividades pedagógicas, patrimônio, ambiente, etc. Finalmente, é preciso pensar a indisciplina no contexto do desenvolvimento cognitivo dos estudantes. Sob esta perspectiva, define-se indisciplina como a incongruência entre os critérios e expectativas assumidos pela escola (que supostamente refletem o pensamento da comunidade escolar) em termos de comportamento, atitudes, socialização, relacionamentos e desenvolvimento cognitivo, e aquilo que demonstram os estudantes (GARCIA, 1999b, p. 102).

Velez e Veiga (2010) afirmam que a indisciplina é um fenómeno que tem vindo a aumentar nos últimos anos, bem como os problemas de violência praticados pelas crianças e jovens nas escolas. São problemas complexos que afetam cada vez mais a comunidade escolar. Para estes autores, alguns professores, perante estes fenómenos, revelam estresse e ansiedade quanto ao funcionamento da escola, os pais preocupam-se com o que possa suceder aos seus filhos e os alunos sentem-se inseguros. Devido a uma maior visibilidade e frequência das manifestações destes fenómenos, e de uma maior preocupação evidenciada pelos diversos intervenientes no processo educativo, começou o despertar de um maior interesse de investigadores (VELEZ e VEIGA, 2010).

Segundo Silva (2004, p. 203-204),

A indisciplina - contrariamente à visão biológica, que tende a concebê-la como hiperatividade - é decorrente muito mais do fato de a criança e o adolescente não saberem o que estão fazendo na escola, não valorizá-la, discordarem dos métodos de ensino empregado e da maneira como os professores se relacionam com eles, pelo conteúdo escolar estar aquém ou além do nível de desenvolvimento cognitivo e de aprendizagem, por não terem os valores morais como centrais em sua personalidade (ou ter apenas os de caráter mais privado) e por terem o espaço de recreação prematuramente cerceado e, consequentemente, de desenvolvimento por razões ligadas às condições objetivas de vida.

Assim, de acordo com Ronco, Paula, Silva e Gonçalves (2012) entre os aspectos que geram a indisciplina escolar podemos destacar o aspecto religioso, o aspecto familiar, o aspecto político o aspecto educacional. Além disso, segundo os autores, as manifestações de indisciplina, muitas vezes, podem ser vistas como uma forma de se mostrar para o mundo, mostrar sua existência; em muitos casos o indivíduo tem somente a intenção de ser ouvido por alguém, então para muitos alunos indisciplinados a rebeldia é uma forma de expressão (RONCO, PAULA, SILVA e GONÇALVES, 2012). Desta forma, "professores e instituições de ensino devem se fundamentar no apoio teórico existente para desacelerar e sensibilizar os alunos do seu papel na escola, e consequentemente de seu comportamento escolar" (RONCO, PAULA, SILVA e GONÇALVES, 2012, p. 37), e com isso tentar combater a indisciplina, não com punições severas que nada resolvem, mas sim com "ações que sensibilizem os alunos a melhorarem as suas condutas e terem a satisfação de colherem os frutos dessa opção" (RONCO, PAULA, SILVA e GONÇALVES, 2012, p. 38).

Deste modo, de acordo com Servila e Arbach (2012) é notório como a indisciplina em sala de aula resulta em desgaste emocional do professor que se encontra em relação face a face com os alunos, e a "questão da indisciplina do aluno está atrelada às interações sociais vividas e às relações humanas" (PIROLA e FERREIRA, 2009, p.92). Esse fenômeno não é um traço inerente ao aluno, mas esse aluno se constitui indisciplinado a partir de suas experiências concretas no grupo cultural ao qual pertence (PIROLA e FERREIRA, 2009).

A indisciplina é um traço constituído a partir das interações que se estabelecem no espaço social da escola, "sendo que intervenções no sentido de conquista de disciplina requerem mudanças nas concepções e práticas dos docentes e, em específico, no projeto pedagógico e nas formas de interação com os alunos" (PIROLA e FERREIRA, 2009, p.94). Portanto, compreendemos que a disciplina e a indisciplina escolar "representam maneiras de ser de uma pessoa, desenvolvidas na relação dessa pessoa com outras pessoas do seu meio, que trazem as marcas de certos padrões culturais" (PIROLA e FERREIRA, 2009, p.94). 
Logo, a indisciplina, um fator que influencia negativamente o processo de ensino e aprendizagem deve ser combatida para que alunos e professores possam realizar a tarefa pela qual vão a escola, o ensino e a aprendizagem.

\subsection{BREVE RESUMO DO CAPÍTULO}

Este capítulo apresentou uma revisão sobre o processo de ensino e aprendizagem e sobre a matemática no ensino médio. Também tratou sobre as escolas técnicas federais e sobre as variáveis que influenciam o ensino e a aprendizagem de matemática no ensino médio. Em síntese, um outro resultado que é apresentado do referencial teórico é o levantamento das variáveis que influenciam o processo de ensino e aprendizagem de matemática no ensino médio e que serão estudadas neste trabalho. 


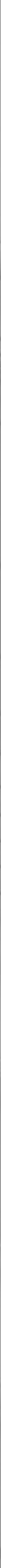


O presente capítulo contempla a apresentação dos passos dados para a realização deste trabalho a fim de fundamentar a caracterização da pesquisa, o método e as técnicas de coleta de dados adotadas.

\subsection{CARACTERIZAÇÃO DA PESQUISA}

A pesquisa desenvolvida caracteriza-se em relação à abordagem do problema como qualitativa, segundo Neves (1996, p. 1), a pesquisa qualitativa costuma ser direcionada ao longo do seu desenvolvimento, não busca enumerar ou medir eventos, e, geralmente, não emprega instrumento estatístico para a análise de dados. Seu foco de interesse é amplo e parte de uma perspectiva diferenciada da adotada pelos métodos quantitativos. Caracteriza-se em relação a natureza como aplicada, uma vez que pretende-se analisar as variáveis que influenciam o ensino e aprendizagem de matemática no ensino médio em uma Escola Técnica Federal.

Quanto aos seus objetivos se classifica como descritiva e exploratória. De acordo com Gil (2002) na pesquisa exploratória, busca-se uma maior familiaridade com o problema e, para isso, são realizadas entrevistas com pessoas envolvidas com o problema, levantamento bibliográfico, análise de exemplos que estimulem a compreensão, entre outros. Enquanto que na pesquisa descritiva, segundo Gil (2002) procura-se descrever as características de um determinado problema ou fenômeno, por meio de relações entre variáveis.

Em relação às estratégias de pesquisa, esta caracteriza-se como uma Pesquisa Bibliográfica e de Levantamento. "A pesquisa bibliográfica abrange toda bibliografia já tornada pública em relação ao tema de estudo" (MARCONI e LAKATOS, 2003, p. 183). Além disso, de acordo com Marconi e Lakatos (2003) sua finalidade é colocar o pesquisador em contato direto com tudo o que foi estudado sobre o assunto. A pesquisa de Levantamento, de acordo com Gil (2002) e Marconi e Lakatos (2003) caracteriza-se pela interrogação direta das pessoas cujo comportamento se deseja conhecer. As conclusões são obtidas por análise quantitativa das informações levantadas junto a uma amostra significativa.

\subsection{MÉTODO}

Segundo Lakatos e Marconi (2010), o método consiste numa série de atividades sistemáticas e racionais para se buscar, de maneira confiável, soluções para um dado problema.

As etapas para o desenvolvimento do trabalho estão apresentadas na Figura 3.1.

Figura 3.1 Etapas sequências do método de pesquisa.

\begin{tabular}{|c|c|}
\hline $\begin{array}{l}1 \text { - Especificação dos Objetivos } \\
\text { É necessário refinar, esclarecer e delimitar o } \\
\text { assunto que será pesquisado }\end{array}$ & $\begin{array}{c}5 \text { - Seleção da amostra } \\
\text { É necessário selecionar uma amostra da } \\
\text { população foco da análise, sendo necessário } \\
\text { para isso estabelecer um plano de amostragem. }\end{array}$ \\
\hline $\begin{array}{l}2 \text { - Operacionalização dos Objetivos e Variáveis } \\
\text { Os conceitos ou variáveis do levantamento } \\
\text { devem ser passíveis de observaçắo }\end{array}$ & $\begin{array}{c}6 \text { - Coleta e verificação dos dados } \\
\text { É uma fase que demanda atenção do pesquisador, } \\
\text { a fim de se evitar um processo de } \\
\text { coleta de dados enviesado. }\end{array}$ \\
\hline empirica e n & \multirow{2}{*}{$\begin{array}{l}7 \text { - Análise e interpretação de dados } \\
\text { Essa etapa relaciona a codificação das respostas, } \\
\text { tabulação dos dados e cálculos estatísticos. } \\
\text { Sendo a mesma, seguida pela interpretação } \\
\text { dos dados, caracterizando-se pela relação entre os } \\
\text { resultados obtidos com outros já conhecidos. }\end{array}$} \\
\hline $\begin{array}{l}3 \text { - Elaboração do instrumento de coleta de dados } \\
\text { A coleta de dados pode ser feita por meio de } \\
\text { questionários, entrevistas ou formulários. }\end{array}$ & \\
\hline $\begin{array}{l}\text { O pesquisador deve realizar um pré-teste } \\
\text { do instrumento de coleta de dados } \\
\text { para validar o instrumento. }\end{array}$ & $\begin{array}{c}8 \text { - Apresentação dos resultados } \\
\text { É a última fase do levantamento, onde o } \\
\text { pesquisador apresenta os resultados } \\
\text { obtidos durante a pesquisa. }\end{array}$ \\
\hline
\end{tabular}

Fonte: Adaptado de Gil (2009, p. 111) apudPinto (2012, p. 82). 
Do ponto de vista da estratégia de pesquisa, inicialmente foi realizado um estudo por meio de revisão bibliográfica, para a apresentação do referencial teórico existente. Este referencial levantou os principais conceitos sobre as variáveis que influenciam o ensino e aprendizagem de matemática no Ensino Médio e apresentou-os, sob a perspectiva de vários autores, da área.

A partir disto, foi apontado um conjunto de variáveis passíveis de serem mensuradas para elaboração de questionário para alunos. Este questionário conta com perguntas fechadas. Ainda, poderá utilizar-se, a partir da delimitação do cenário, da análise documental. Serão utilizadas técnicas estatísticas multivariadas para as análises dos dados coletados. Também será utilizado o diagrama em caixa (boxplot), para retirar os outliers, que são pontos com comportamento diferente dos demais. Estes foram retirados por ter um valor localizado distante de quase todos os outros valores da pesquisa, ou seja, por não apresentarem o mesmo comportamento do restante da amostra pesquisada.

\subsubsection{TÉCNICAS DE ANÁLISES MULTIVARIADAS}

As técnicas de análises multivariadas, de acordo com Pinto (2012, p. 106) tem como objetivo "analisar quando há uma ou mais medidas de cada elemento e as variáveis são analisadas simultaneamente, pois referem-se às relações simultâneas entre dois ou mais fenômenos e seus graus de relacionamentos". O propósito das técnicas de análise multivariadas é investigar elementos que apresentam mais de uma dimensão conjunta, aludindo associações coexistentes entre diversos acontecimentos e suas inter-relações. De acordo com Gouvêa, Prearo e Romero (2012, p. 340), "a necessidade de entender a relação entre diversas variáveis aleatórias faz da análise multivariada uma metodologia com grande potencial de uso", pois pode sustentar perguntas multifacetadas, de modo distinto e terminante, viabilizando a realização de pesquisas significativas e relevantes. É constituída por um conjunto de métodos que podem ser usados quando são feitas várias medições de cada indivíduo ou objeto de uma ou mais amostras.

As técnicas de análises multivariadas avaliam simultaneamente um conjunto de características, considerando-se as correlações existentes e permitindo que inferências sobre o conjunto de características sejam feitas em um nível de significância conhecido (SAKAGUTI, 1994). As técnicas multivariadas são classificadas como técnicas de dependência e ou técnicas de interdependência (MALHOTRA, 2012, p. 347).

De acordo com Faria (2006), há duas condições principais que norteiam a escolha de métodos de pesquisa referentes a similaridades de estímulo. O primeiro é atribuído a característica qualitativa dos dados coletados, que necessitam de estatística não-paramétrica, e o segundo é sobre a qualidade do objeto do estudo, que carece de métodos que possibilitem manter a integridade dos dados.

Conforme a classificação de Malhotra (2012), análises multivariadas se diferenciam entre técnicas de dependência e técnicas de interpendência, o primeiro manifestando uma ou mais variáveis (dependentes) podendo ser explicadas ou preditas por outras (variáveis independentes), o segundo, as variáveis são analisadas simultaneamente sem a orientação de dependência ou independência. Relativo a escala a ser empregada, determina-se a classificação teórica de mensuração entre variáveis métricas e não métricas (GOUVÊA, PREARO e ROMERO 2012, p. 342).

Averiguou-se que a pesquisa possui características de interdependência, tendo como objetivo entender as similaridades entre perfis psicológicos e percepções dos pesquisados. A mensuração será realizada através de variáveis métricas. As análises interdependentes multivariadas escolhidas para este estudo foram o Escalonamento Multidimensional que possibilita a criação de representações geométricas a partir de aderências percebidas. Análise de Conglomerados, que cria agrupamentos a partir de semelhanças e Análise Fatorial Exploratória unifatorial que verifica padrões de intercorrelação, revelando traços latentes (PINTO, 2012, p. 106).

A escolha destas técnicas justificou-se pela necessidade de analisar os dados levantados por meio de questionários aplicados em alunos IFSP (Instituto Federal de Educação, Ciência e Tecnologia de São Paulo ) câmpus Bragança Paulista com foco na similaridade de objetos. Foi utilizado o software SPSS (Statistical Package for The Social Sciences), nas três técnicas de modo a obter-se os dados necessários para análise. 
As técnicas de análise selecionadas são apresentadas nos subitens 3.2.1.1 a 3.2.1.3

\subsubsection{ESCALONAMENTO MULTIDIMENSIONAL (EMD)}

O Escalonamento Multidimensional (EMD) foi criado no início da década de 50 por um grupo de psicometria da Universidade de Princenton. Sendo seu uso estendido para outras áreas de conhecimento como economia, sociologia, marketing e administração. Os laboratórios Bell, dez anos depois, criaram a versão não métrica do EMD, chamada de variação Shepard-Kruskal, que foi influenciada pelo trabalho de Coombs especialmente no que diz respeito aos pontos ideais e aos modelos de desdobramento clássico (SOUZA e BUSSAB, 2003).

Malhotra (2012) assevera que o EMD é um método utilizado para representação espacial e visual das percepções e propensões de indivíduos participantes de uma pesquisa. Semelhanças entre perfis psicológicos e de graus de percepção são interpretadas por meio de ligações geométricas entre pontos em um espaço multidimensional, denominados "mapas espaciais". As linhas do mapa espacial designam o alicerce psicológico e as perspectivas subliminares dos pesquisados para estabelecer determinadas concepções e preferências. Também conhecido como mapeamento perceptual é habitual na literatura como Multidimensional Scaling (MDS) (PEREIRA, 1999, p. 115).

Conforme Souza e Bussab (2003), o EMD tem como objetivo assimilar condições não evidentes apresentadas num modelo de dados empíricos, apresentando-os de forma mais compreensível. As relações entre os objetos do estudo são representadas por meio de pontos distribuídos num espaço dimensional.

O EMD é categorizado como um método de redução de dados com duas variáveis, a métrica e a não métrica. O EMD métrico é utilizado quando as escalas de mensuração são métricas, ou intervalares. Utilizando a suposição de que há uma estrutura, onde as distâncias entre objetos permitem serem calculadas por meio de métrica euclidiana, medindo as preferências e percepções dos sujeitos, e que está disposta num espaço dimensional que produz uma matriz de proximidade. Esta pesquisa optou pela utilização do EMD métrico (SOUZA e BUSSAD, 2003).

Ainda sobre EMD métrico, Pinto (2012) afirma que neste método é utilizado a separação do autovalor da matriz de proximidade, sendo que os resultados são obtidos através da quantidade de autovalores zero; os autovetores indicam o posicionamento das coordenadas dos objetos dentro do mapa, possibilitando a verificação da configuração subjacente.

De acordo com Souza e Bussad (2012), há casos, em que verificar os atributos que possam ser uteis no julgamento dos produtos é uma tarefa excessivamente complexa, ainda mais quando o conjunto de atributos e marcas para o julgamento é muito grande, neste caso produz-se diretamente as matrizes de proximidade. Esta, por sua vez, servirá de entrada para o algoritmo da matriz resposta de distâncias, que será comparada a matriz transformada, de modo a verificar a qualidade do ajuste, e chegando ao melhor, haverá o cálculo das coordenadas e representação dos objetos.

Também há a possibilidade da efetuação do EMD métrico, através de uma matriz de proximidade, por uma medica empírica de conferência subjetiva de pares e objetos. Atestando a afirmação de Malhotra (2012) que alega que a classificação das dimensões é realizada através de um julgamento subjetivo. As proximidades acima citadas classificam-se em: similaridades, quando os objetos encontram-se próximos porque não possuem equivalência e dissimilaridades, se afastados por diferenças. Ante tal fato, os dados da matriz de semelhança, são obtidos de escaladas do tipo razão, intervalar ou no mínimo ordinal. (SOUZA e BUSSAD, 2003)

Hair Jr. et al. (2009) apud Pinto (2012) afirma que o EMD possui a grande vantagem de diminuir a influência do pesquisador, já que não exige a discriminação das variáveis utilizadas no confronto dos objetos. Segue modelo representando um mapa perceptual do EMD com duas dimensões, representado da Figura 3.2. 
Figura 3.2 Exemplo de mapa perceptual do EMD.

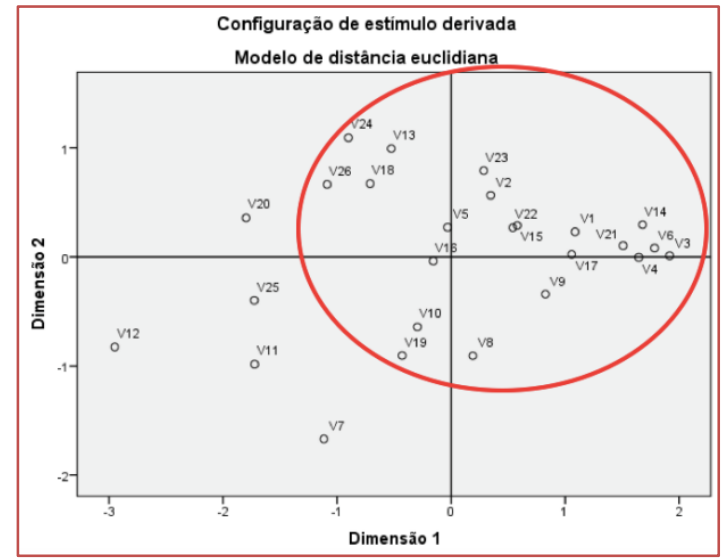

Fonte: Dados da Pesquisa

Ao analisar a Figura 3.2, percebe-se que os sujeitos que apresentam distâncias menores um dos outros, mostram semelhanças entre si, ou seja, maior conexão com conduta a ser estudada. Os objetos que mostram menos aderência, podem ser descartadas por não afetarem o comportamento geral da pesquisa (PINTO, 2012).

Voltando a matriz de dissimilaridades e testes de ajustes, Pinto (2012) mostra que há três medidas de avaliação no da qualidade do ajuste e aderência dos dados analisados, que são:

a) Stress (Standardized Residual Sum oh Squares): demonstra os intervalos das dissimilaridades e dos intervalos originais.

b) SStress ou (Coeficiente de Young): é um cálculo de ajuste que emprega o uso de dados quadráticos. Seus valores de saída estão entre 0 e 1, em pesquisas exploratórias o ajuste é considerado de qualidade quando chega a 0,30.

c) $R Q S\left(R^{2}\right)$ : é uma representação da qualidade de aderência, através de correlação quadrática entre os intervalos originais, e distâncias provenientes dos dados de dissimilaridade, demonstrado por estes.

Foram utilizados parâmetros de 30\% para Stress e SStress e de 60\% para o RQS, de acordo com o recomendado por Malhotra (2012).

\subsubsection{ANÁLISE DE CONGLOMERADOS}

A Análise de Conglomerados, também conhecida como Cluster Analysis, Análise de Agrupamentos, Análise de Segmentação e Análise de Taxionomia, foi utilizada primeiramente por Tyron, em 1939, abrigando algoritmos distintos. É conceituado como um método de análise multivariada, que visa diminuir a dimensionalidade das informações, ao agrupar conjuntos de dados em subconjuntos. Para tanto, aplica um critério fixado que pode mudar de com acordo com o método de agrupamento utilizado (BEM, 2009).

Fávero et al. (2006) afirmam que análise de conglomerados realiza um agrupamento de unidades observacionais, de acordo com critérios pré-determinados de distância entre dados. Também é uma técnica exploratória que visa identificar estruturas de agrupamentos de modo a avaliar a dimensionalidade dos dados, identificar os outlier e fornecer importantes hipóteses a cerca de associações. Em suma, um cluster, pode ser definido como uma variedade de objetos correlacionados uns com os outros, a partir de determinado critério de similaridade pré-fixado, dissimilaridades e objetos de outros grupos. O quadro 3.1 apresenta diversos objetivos atribuídos a análise de conglomerados. 
Quadro 3.1 Objetivos da Aplicação da Técnica de Análise de Conglomerados

\begin{tabular}{|c|c|}
\hline Objetivo & Categoria \\
\hline \multirow{5}{*}{$\begin{array}{c}\text { Agrupar objetos } \\
\text { ou variáveis } \\
\text { semelhantes }\end{array}$} & $\begin{array}{c}\text { Detectar grupos homogêneos nos dados, podendo os grupos ser constituídos por variáveis } \\
\text { ou casos. }\end{array}$ \\
\hline & $\begin{array}{c}\text { Agrupar sujeitos ou variáveis em grupos homogêneos a partir de uma ou mais características } \\
\text { comuns. }\end{array}$ \\
\hline & Agregar objetos com base nas características que eles possuem. \\
\hline & Agrupar indivíduos semelhantes de acordo com a similaridade das variáveis em estudo. \\
\hline & $\begin{array}{l}\text { Identificar um conjunto de grupos que minimize a variação dentro do grupo e maximize a } \\
\text { variação entre os grupos. }\end{array}$ \\
\hline
\end{tabular}

Fonte: Prearo (2012, p. 111).

Conforme exposto por Pinto (2012), todo o foco da análise de conglomerados, encontra-se no conjunto de dados análogos, e para tanto, são utilizadas medidas euclidianas, entre outras. Para a esta pesquisa, utilizou-se os seguintes passos: enumeração das variáveis nos atributos de complexidade e incerteza; escolha da medida euclidiana; definição da aglomeração hierárquica em forma de dendograma; identificação da quantidade de conglomerados necessários; interpretação do dendograma; e ratificação dos resultados através da comparação com os dados obtidos por meio do EMD e da análise fatorial exploratória.

O autor também ressalta o fato de que não há regra definida para a escolha do número de conglomerados a serem analisados, cabendo ao pesquisador determinar a quantidade através do estabelecimento da medida da distância euclidiana e análise de conglomerados não combinados (PINTO, 2012).

A ferramenta principal da análise de conglomerados é a exposição gráfica dos dados. Para tanto, é utilizado o dendrograma, também conhecido como gráfico de árvore ou fenograma. Em suma é a reprodução visual de hierarquias de solução de conglomerados, podendo mostrar uma ou várias soluções. Tal gráfico é caracterizado por sua grande subjetividade, o que exige cuidado durante sua análise (PINTO, 2012).

Neste trabalho, foi empregado um dendograma horizontal, com o eixo y representando os grupos em ordem decrescente de semelhança, e o eixo x, indicando as distâncias entre os grupos. 0 Dendograma está representado na Figura 3.3.

Figura 3.3 Exemplo de Dendograma

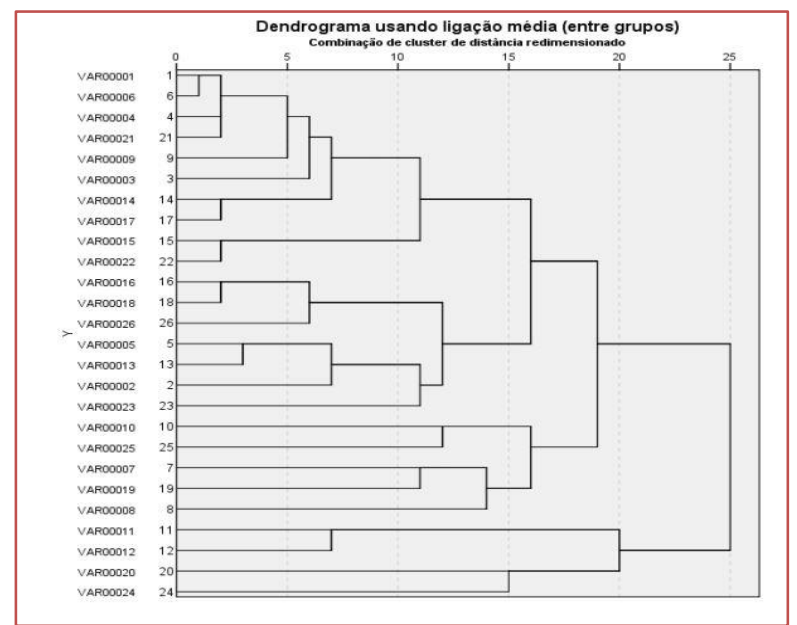

Fonte: Dados da Pesquisa. 
A quantidade de conglomerados utilizados na análise, foi decida com base nas distâncias euclidianas, aqueles que apresentam distância maior que a pré-determinada, não foram empregados, pois as variáveis mais distantes do conglomerado, representam menor capacidade de elucidação da conduta pesquisada.

\subsubsection{ANÁLISE FATORIAL EXPLORATÓRIA}

De acordo com Filho (2010), a análise fatorial possui fundamentos teóricos controversos. Charles Spearman (1904) e Karl Pearson foram os pioneiros da análise fatorial. Sendo que o primeiro verificou a hipótese de que diferentes habilidades poderiam ser oriundas de um elemento geral de inteligência. Spearman estudou as semelhanças em diversos testes psicológicos, e demonstrou que tais correlações poderiam ser explicadas por um fator geral existente em todos os testes, e fatores distintos existentes em cada um. Thurstone (1935) também auxiliou na construção da técnica desenvolvendo a Análise Fatorial Multipla. Hotelling também contribuiu ao apresentar o método de componentes principais que permite o cálculo da única matriz de fatores ortogonais. Tem-se, por tanto, que a desenvolvimento das técnicas de análise fatorial são oriundas de diversas pesquisas (PREARO, 2008; FILHO, 2010).

A análise fatorial abrange diversos métodos estatísticos, tendo como foco principal a definição de estruturas subjacentes de uma matriz. Em suma, a análise fatorial refere-se ao estudo da estrutura de interrelações de determinado número de variáveis, delimitando um conjunto de dimensões similares, denominados fatores. Conforme exposto por Filho (2010) o principal ponto da análise fatorial é a redução de grandes números de variáveis e investigar fatores adjacentes não observados. A análise Fatorial também possibilita ao pesquisador a identificação de dimensões distantes da estrutura e definir o grau em que as variáveis são interpretadas por cada dimensão. Tais dimensões estando explicadas, temos os dois principais objetivos da análise fatorial, que é a redução de dados. Ao se efetuar um resumo dos dados, a análise fatorial adquire dimensões latentes, que ao serem examinadas e assimiladas, discriminam os dados em menor dos que as variáveis originais (FILHO, 2010).

A análise fatorial, das técnicas de análise multivariadas é a que mais contribui para empregos intermediários, em suma, de disposição de dados para serem utilizados por outras técnicas estatísticas, facilitando o entendimento da pesquisa (PREARO, 2008).

De acordo com Filho (2010), a análise fatorial é classificada entre exploratória e confirmatória. Embora diversos autores afirmem que existe apenas a exploratória. Sendo que a técnica exploratória considera apenas o que é determinado pelos dados, sem determinar restrições sobre o número de componentes extraídos. A análise fatorial exploratória pode se adequar a grande maioria dos estudos. Exceto, quando o pesquisador possui uma hipótese preconcebida sobre os dados, com base em pesquisas teóricas ou resultados de estudos anteriores. Nestes casos, é possível testas a hipótese, relativas a questões, como por exemplo: que hipóteses devem ser agrupadas, em um fator, ou determinado número de fatores? Casos, estes em que a análise fatorial realize uma função confirmatória, ao analisar a medida em que os dados satisfazem a questão levantadas (FILHO, 2010). O quadro 3.2 relaciona algumas premissas relacionas a técnica de análise fatorial exploratória. 
Quadro 3.2 Objetivos de Aplicação da Técnica de Análise Fatorial Exploratória.

\begin{tabular}{|c|c|}
\hline Objetivos & Categoria \\
\hline \multirow{9}{*}{$\begin{array}{l}\text { Redução do número } \\
\text { de variáveis para fins } \\
\text { de análise }\end{array}$} & $\begin{array}{l}\text { Resolver o problema das inter-relações e correlações entre um grande número de } \\
\text { variáveis, apresentando-as por meio de um menor número de fatores. Assim, é possível } \\
\text { juntar um maior número de variáveis, representando um conceito mais geral. }\end{array}$ \\
\hline & $\begin{array}{c}\text { Reduzir o número de variáveis requeridas para explicar o fenômeno de interesse e } \\
\text { gerar hipóteses através da análise exploratória dos dados com base nos fatores } \\
\text { emergentes. }\end{array}$ \\
\hline & $\begin{array}{c}\text { Analisar o comportamento de uma variável ou grupos de variáveis em covariação com } \\
\text { outras. }\end{array}$ \\
\hline & $\begin{array}{l}\text { Reduzir dados muito complexos a tamanho manuseável para que o pesquisador possa } \\
\text { interpretar melhor os resultados. }\end{array}$ \\
\hline & $\begin{array}{l}\text { Gerar um reduzido número de variáveis que representam a maior parte da } \\
\text { variabilidade dos dados originais e que possam ser usados em análises subsequentes. }\end{array}$ \\
\hline & $\begin{array}{l}\text { Obter o menor número de variáveis a partir do material original e reproduzir toda a } \\
\text { informação de forma resumida; obter os fatores que reproduzam um padrão separado } \\
\text { de relações entre as variáveis; interpretar de forma lógica o padrão de relações entre } \\
\text { as variáveis. }\end{array}$ \\
\hline & $\begin{array}{l}\text { Investigar quais variáveis formam subconjuntos coerentes e relativamente } \\
\text { independentes uns dos outros. }\end{array}$ \\
\hline & $\begin{array}{l}\text { Identificar o maior número possível de variáveis hipotéticas (fatores) que possam } \\
\text { explicar a maior percentagem possível da covariância entre as variáveis. }\end{array}$ \\
\hline & $\begin{array}{l}\text { Identificar a estrutura latente de um grupo de variáveis, reduzindo os atributos de um } \\
\text { grande número de variáveis em um pequeno número de fatores. }\end{array}$ \\
\hline
\end{tabular}

Fonte: Prearo (2008, p. 27).

No Quadro 3.2, é possível verificar certa discordância entra alguns autores, em relação ao número de objetos por variável. Sendo que alguns defendem de 5 a 20 casos, e alguns 300 casos (PREARO, 2008).

Segundo Filho (2010), a realização da análise fatorial, exige o seguimento de quatro etapas, que são detalhadas a seguir:

a) Entrada de Dados (BASE): os dados inseridos para a efetuação da análise fatorial, se transformam num conjunto de valores de variáveis para cada objeto ou indivíduo da amostra. Em realidade, é possível realizar análise fatorial em qualquer matriz que realize cálculo de similaridade. Sendo que a medida da similaridade não precisa ser necessariamente uma correlação.

b) Cálculo de Correlações: são utilizadas duas abordagens para o cálculo da matriz de correlação análise fatorial $R$ e análise fatorial $Q$ - A análise fatorial $R$ realiza os cálculos das correlações entre as variáveis, e na análise fatorial $Q$, o cálculo é obtido entre os casos. Sendo que na análise fatorial $R$, busca-se realizar um agrupamento de variáveis de acordo com fatores pré-estabelecidos. Todas as variáveis podem ser correlacionadas de duas em duas.

c) Extração de Fatores Iniciais: há uma grande variedade de métodos complexos para extração de fatores da matriz de correlação, sendo que o método de extração de componentes principais será o utilizado nesta pesquisa. O objetivo da extração de fatores é encontrar elementos que componham uma combinação linear de variáveis originais ou da matriz de correlação. Ou seja, variáveis relacionadas entre si, iram somar-se para formar um fator. Formando assim uma matriz residual, que passará pelo menos processo até formar um pequeno conjunto de aglomerados que permaneça sem explicação. 
d) Rotação: Com o objetivo de auxiliar na interpretação de dados muitas vezes complexos, é necessário a rotação da matriz. Há a rotação ortogonal ou Varimax, que mantém os fatores não correlacionadas e a rotação oblíqua, tornando os fatores correlacionados entre si. O objetivo principal é discriminar aqueles fatores que apresentam variáveis tanto com baixa, quanto com alta correlação. A título de curiosidade, a utilização da rotação de matrizes, exige tantos cálculos complexos, que esta só passou a ser realizada após a invenção de computadores e softwares específicos. A rotação determina diversas disposições Entre elas: Quais os fatores coletados pela análise, e quantos são. E quais variáveis originais constituem os fatores extraídos pela análise.

\subsection{OBJETO DE ESTUDO}

A amostra deste estudo foi não probabilística com julgamento e é composta por alunos da faixa etária entre 14 e 18 anos do Instituto Federal de Educação, Ciência e Tecnologia de São Paulo (IFSP), campus Bragança Paulista.

De acordo com o Plano de Desenvolvimento Institucional (PDI) (2014) do Instituto Federal de Educação, Ciência e Tecnologia de São Paulo, a partir de 2011, o IFSP câmpus Bragança Paulista passou a oferecer a modalidades de ensino Técnico Integrado ao Ensino Médio.

Ainda de acordo com este documento, o câmpus Bragança Paulista do IFSP oferece, atualmente, cursos superiores de tecnologia nas áreas de Informática e Indústria, além do curso de Licenciatura em Matemática. No ensino técnico profissionalizante oferece os cursos técnicos concomitante em Mecatrônica e integrados ao ensino médio de Informática, Mecânica e Eletroeletrônica (PDI, 2014, p. 58).

\subsection{PROCEDIMENTOS}

A partir da análise da literatura disponível foram levantadas algumas variáveis principais que influenciam o ensino e a aprendizagem de matemática. A partir destas variáveis foi elaborado um questionário fechado para os alunos. Neste questionário, os mesmos devem responder as perguntas divididas em dois blocos, que são:

a) Bloco I são perguntas para caracterizar o perfil da amostra; e,

b) Bloco II são perguntas referentes às variáveis levantadas que são classificadas em uma escala de Likert, que de acordo com Vieira (2009) é uma série de itens com o mesmo número de alternativas, organizados para medir um conceito. As demais escalas utilizam a mesma estrutura. Neste caso a escala visando analisar as variáveis que influenciam o ensino e a aprendizagem de matemática possui cinco alternativas, onde:

1) Nunca;

2) Raramente;

3) Eventualmente;

4) Frequentemente;

5) Sempre.

A partir das considerações realizadas, o questionário utilizado na pesquisa, pode ser verificado no Apêndice A.

Embora, o questionário tenha sido preparado para a população pesquisada, fez-se necessário um estudo piloto, ou seja, a aplicação desse instrumento de pesquisa para uma amostra da população a ser estudada de modo a validá-lo. "Um teste piloto caracteriza-se pelo caráter experimental e é aplicado a uma pequena amostra de participantes" (MARIUCI, FERRI e FELICETTI, 2012, p. 3), assim, o objetivo do teste piloto neste estudo foi avaliar aspectos funcionais, tais como pertinência, organização, clareza das questões, de modo a corrigir e/ou melhorar eventuais problemas, antes da aplicação definitiva. Assim, o feedback que o teste piloto proporcionou permitiu observar se a redação das questões estava clara a todos os questionados, bem como se as questões tinham o mesmo sentido para todos. 
A pesquisa foi respondida por todos os alunos matriculados no Ensino Médio Integrado do IFSP câmpus Bragança Paulista, sendo que foram respondidos 150 questionários de um total de 174 alunos matriculados. Os 24 alunos que não responderam faltaram nos dias em que a coleta de dados foi realizada.

\subsection{CARACTERIZAÇÃO DA AMOSTRA}

A Figura 3.4 apresenta o sexo dos respondentes desta pesquisa. Pode-se observar, através desta figura, que $56,3 \%$ do grupo de estudantes são do sexo masculino enquanto que $43,7 \%$ são do sexo feminino.

Figura 3.4 Sexo dos respondentes da pesquisa.

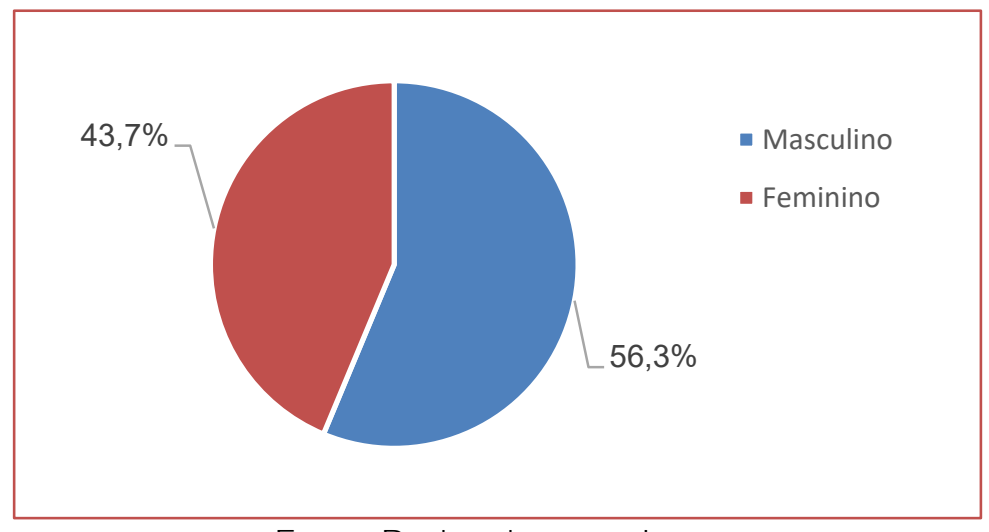

Fonte: Dados da pesquisa.

A Figura 3.5 apresenta a faixa etária dos respondentes deste questionário. Em relação a idade pode-se comprovar, ao analisar a figura 3.5 , que $84,8 \%$ da totalidade da amostra engloba as idades de 15,16 e 17 anos.

Figura 3.5 Idade dos respondentes da pesquisa.

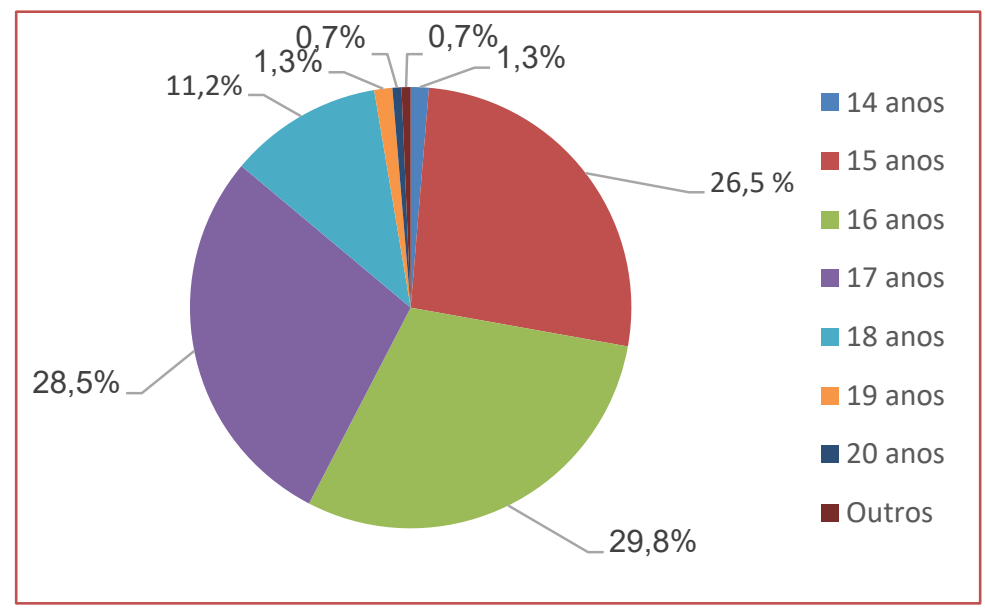

Fonte: Dados da pesquisa.

No que diz respeito a escolaridade da mãe, expressa na Figura 3.6 nota-se que $32,5 \%$ da totalidade concluíram Ensino Fundamental II, 32,5\% concluíram Ensino Médio e 32,5\% concluíram o Ensino Superior. 
Figura 3.6 Grau de Escolaridade da mãe.

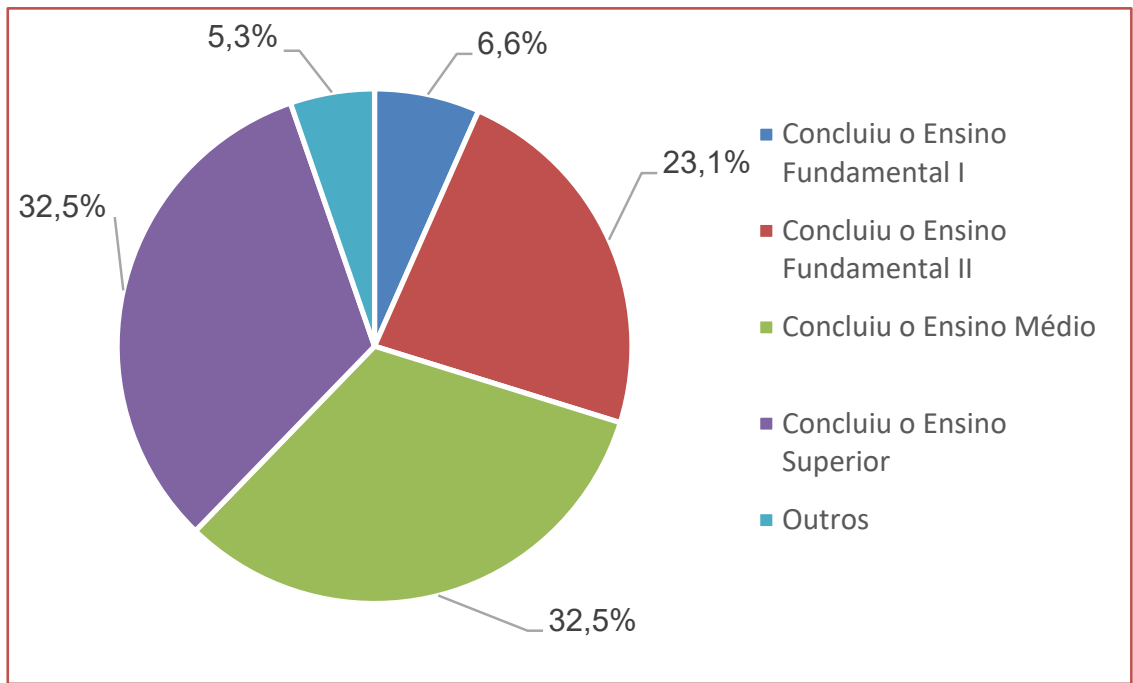

Fonte: Dados da pesquisa.

Na Figura 3.7, correspondendo a escolaridade do pai destes estudantes, verifica-se que 17,2\% concluíram Ensino Fundamental II, 38,4\% concluíram o Ensino Médio e 27,8\% terminaram o Curso Superior.

Figura 3.7 Grau de Escolaridade do pai.

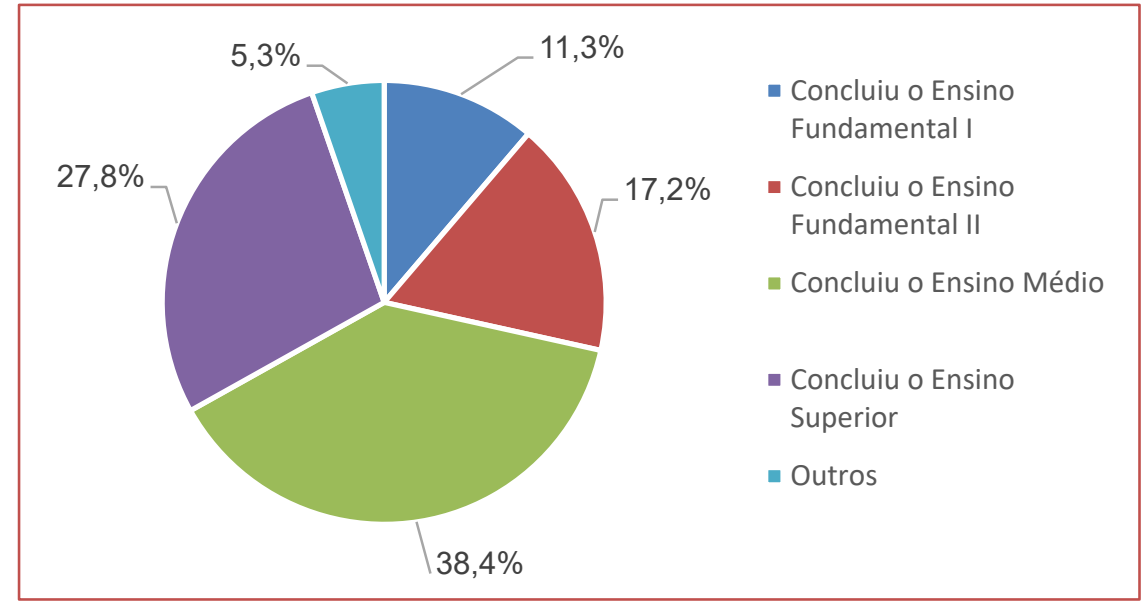

Fonte: Dados da pesquisa.

A Figura 3.8 mostra se os alunos pretendem cursar o Ensino Superior. Pode-se observar, através desta figura, que 95,4\% do grupo de estudantes responderam sim e, portanto pretendem cursar o Ensino Superior. 
Figura 3.8 Pretende cursar Ensino Superior.

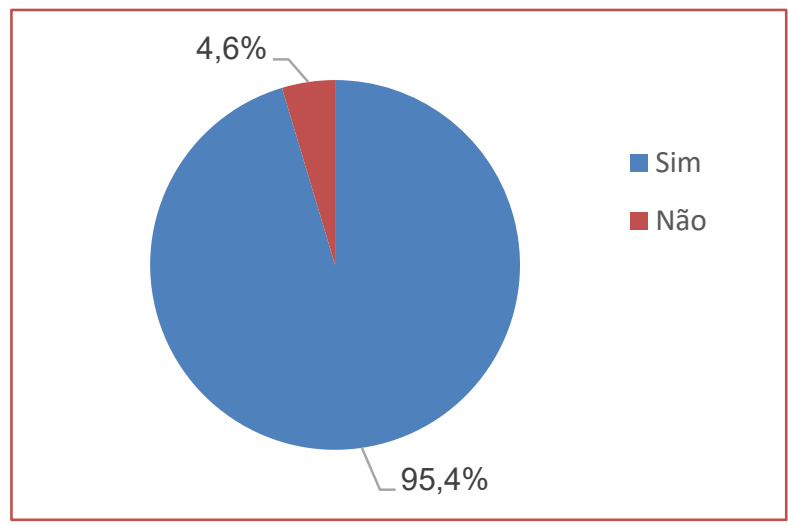

Fonte: Dados da pesquisa.

\subsection{BREVE RESUMO DO CAPÍTULO}

Neste capítulo foram apresentadas as classificações desta pesquisa aplicada, que têm como base a pesquisa bibliográfica e levantamento. A pesquisa é exploratória com abordagem qualitativa, desenvolvida por meio da aplicação de questionários, sendo analisados por meio de técnicas estatísticas multivariadas. Também é apresentada a caracterização da amostra pesquisada. 


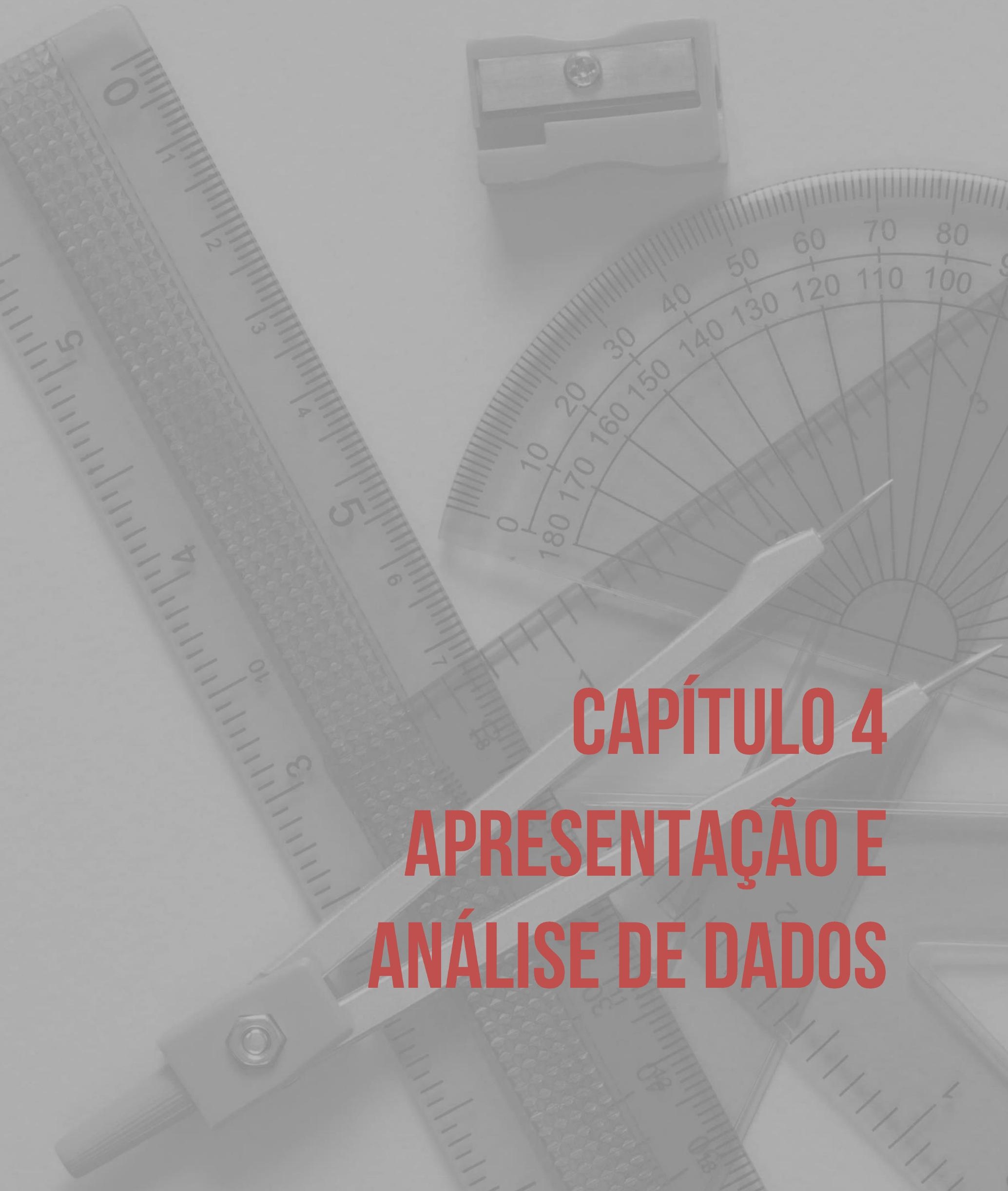


Neste capítulo são apresentados os resultados da pesquisa seguidos de uma análise crítica.

\subsection{ANÁLISE DOS RESULTADOS}

Conforme afirmado anteriormente, as análises dos dados coletados são realizadas por três métodos estatísticos de análise multivariada: o Escalonamento Multidimensional (EMD), a Análise de Conglomerado e a Análise Fatorial Exploratória.

As variáveis levantadas que influenciam o ensino e a aprendizagem de matemática no Ensino Médio foram inseridas no software estatístico IBM SPSS para processamento das análises, conforme Quadro 4.1.

Quadro 4.1 Legenda das variáveis.

\begin{tabular}{|c|c|}
\hline Código & Questão \\
\hline V1 & Entender o porquê de estudar matemática. \\
\hline V2 & Apreciar estudar matemática. \\
\hline V3 & Achar importante seu professor ser formado em matemática. \\
\hline V4 & Achar que a formação do professor influencia no processo de ensino e aprendizagem. \\
\hline V5 & Se achar motivado para estudar matemática. \\
\hline V6 & Achar seu professor motivado para ensinar matemática. \\
\hline V7 & Acreditar que a sua indisciplina atrapalha a aprendizagem de matemática. \\
\hline V8 & Achar que a indisciplina de seus colegas atrapalha a sua aprendizagem de matemática. \\
\hline V9 & Achar o material utilizado pelo professor importante para a aprendizagem. \\
\hline V10 & Achar que se fosse utilizado outro material poderia ser mais fácil aprender matemática. \\
\hline V11 & Ter um sentimento de impotência ao estudar matemática. \\
\hline V12 & Gostar de matemática. \\
\hline V13 & Ter prazer em estudar matemática. \\
\hline V14 & Achar que estudar Matemática é fundamental para seu futuro. \\
\hline V15 & Realizar as atividades propostas pelo professor em sala de aula. \\
\hline V16 & Estudar matemática fora da sala de aula. \\
\hline V17 & Acreditar que os conteúdos estudados em matemática influenciam seu futuro. \\
\hline V18 & Ter um método para estudar matemática. \\
\hline V19 & Utilizar meios tecnológicos para aprender matemática. \\
\hline V20 & Buscar algum profissional fora da sala de aula para aprender matemática \\
\hline V21 & $\begin{array}{c}\text { Acreditar que o modo como professor de Matemática trabalha para se adaptar a maneira de } \\
\text { aprender do aluno é importante }\end{array}$ \\
\hline V22 & Participar das atividades propostas pelo professor de matemática. \\
\hline V23 & Fazer perguntas para o professor quando não entende o que foi explicado. \\
\hline V24 & Comparar suas anotações com a de seus colegas. \\
\hline V25 & Não dar atenção quando o professor esta explicando a matéria e pensar em outras coisas. \\
\hline V26 & Revisar suas anotações da aula em outro momento. \\
\hline
\end{tabular}

Fonte: Dados da pesquisa. 
Estas variáveis podem ser classificadas como os itens que influenciam o ensino e aprendizagem de matemática no Ensino Médio a partir do levantamento bibliográfico realizado, de acordo com o Quadro 4.2.

Quadro 4.2 Classificação das variáveis a partir do levantamento bibliográfico.

\begin{tabular}{|c|c|}
\hline $\begin{array}{c}\text { Item que influencia o ensino e aprendizagem de } \\
\text { matemática }\end{array}$ & Variáveis \\
\hline $\begin{array}{c}\text { Formação do professor } \\
\text { V3, V4 }\end{array}$ & V15, V23 \\
\hline Relação interpessoal entre professor e aluno & V2, V5, V13 \\
\hline Motivação do aluno & V6, V21 \\
\hline Motivação do professor & V7, V8, V25 \\
\hline Indisciplina & V9, V10, \\
\hline Material didático & V1, V11, V12, V17 \\
\hline Relação sociocultural & V14, V16, V22, V26 \\
\hline Dedicação do aluno a disciplina & V18, V19, V20, V24 \\
\hline Metodologia para estudo de matemática & \\
\hline
\end{tabular}

Fonte: Dados da pesquisa.

Para a análise dos dados gerais do trabalho (população) os outliers, que são pontos com comportamento diferente dos demais, foram retirados através do diagrama em caixa (boxplot) simples como é possível ver na Figura 4.1. Os outliers foram retirados por ter um valor localizado distante de quase todos os outros valores da pesquisa, ou seja, por não apresentarem o mesmo comportamento do restante da amostra pesquisada. O método do diagrama em caixa (boxplot) foi escolhido por revelar o centro dos dados, a dispersão dos dados, a distribuição dos dados e a presença de outliers.

Figura 4.1 Diagrama em caixa dos respondentes da pesquisa.

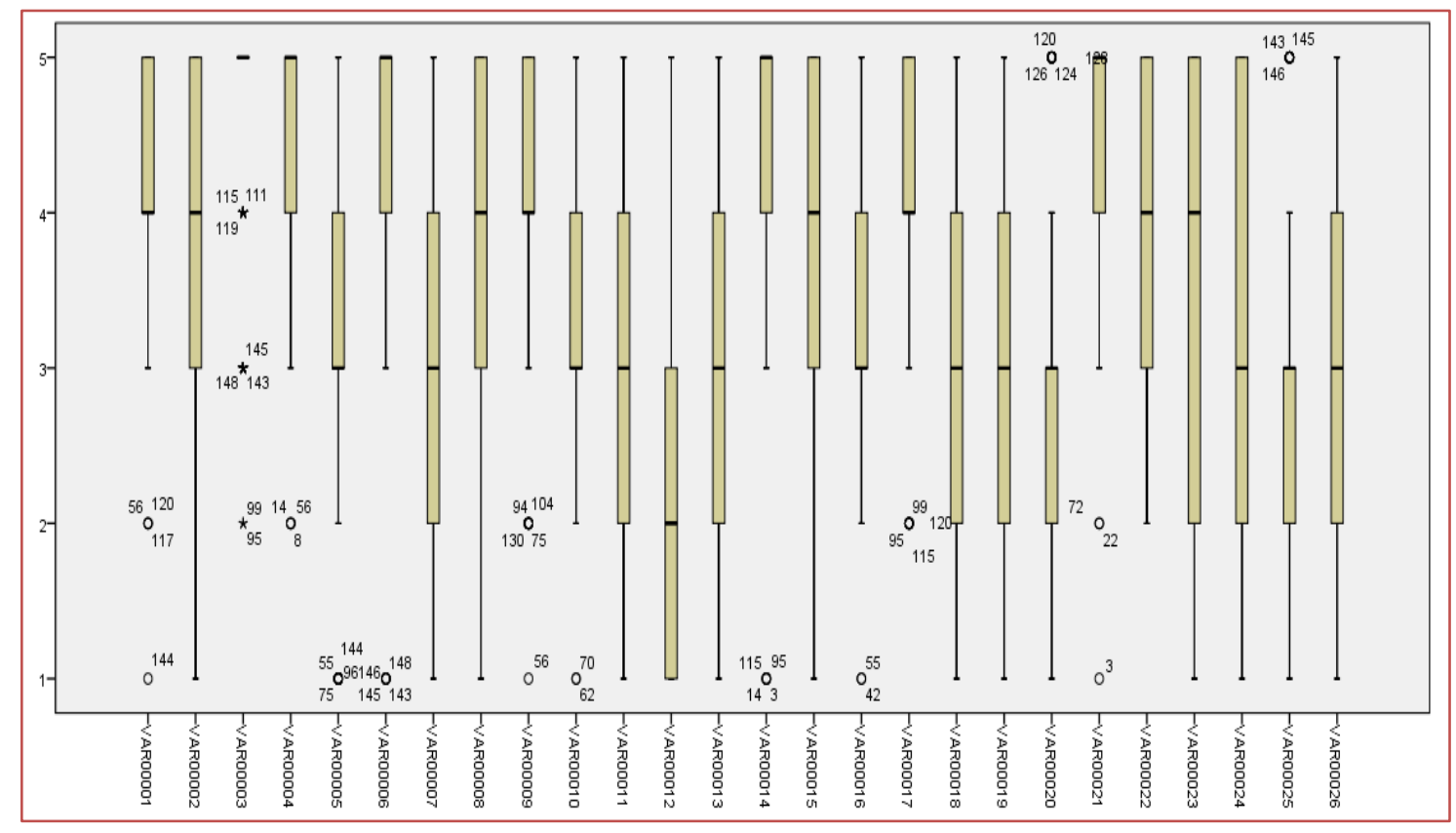

Fonte: Dados da pesquisa. 
Os outliers retirados para aumentar a confiança da pesquisa foram: $3,8,11,14,22,24,42,55,56$, 62, 70, 72, 75, 94, 95, 96, 99, 104, 115, 117, 119, 120, 126, 128, 130, 143, 144, 145, 146 e 148, conforme a Figura 4.1. A partir disto, como já explicado, as análises estatísticas da população geral foram realizadas sem os outliers, apenas com os demais 120 respondes da pesquisa.

As análises estatísticas por turmas foram realizadas com os outliers, pois sem estes algumas turmas ficariam com um número de respondentes muito pequeno. Também foi realizada a análise estatística dos outliers.

\subsection{ANÁLISES MULTIVARIADAS DO 1 ํ ANO DO CURSO TÉCNICO INTEGRADO AO ENSINO MÉDIO DE INFORMÁTICA}

A partir da análise do Quadro 4.4 com relação às variáveis desta pesquisa, é possível verificar que os níveis de adequação do ajuste ao se aplicar o EMD estão dentro de níveis adequados de ajuste (aderência), pois o referido estudo trata-se de uma pesquisa exploratória.

Quadro 4.3 Níveis de aderência do EMD (variáveis) 1ำ ano do curso Técnico Integrado ao Ensino Médio de Informática.

\begin{tabular}{|c|c|}
\hline Índice & Nível \\
\hline $\begin{array}{l}\text { S-stress (Coeficiente de Young do Escalonamento } \\
\text { Multidimensional) }\end{array}$ & $\begin{array}{l}0,001000 \\
\text { Melhoria do ajuste na } 4^{\underline{a}} \text { interação }-0,00038\end{array}$ \\
\hline Stress (Standardized Residual Sum of Squares) & 0,13975 \\
\hline RSQ - R² (Correlação quadrática) & 0,91683 \\
\hline
\end{tabular}

Fonte: Dados da pesquisa.

É importante ressaltar que o nível de aderência está adequado com o uso da análise do Escalonamento Multidimensional (EMD), pois o trabalho tem objetivo exploratório e neste caso mensura-se percepções de pessoas, no caso alunos do $1^{\circ}$ ano do curso Técnico Integrado ao Ensino Médio de Informática, tem seus níveis de aderência podendo variar até algo próximo a uma escala de 0,30000, apresentando níveis adequados na qualidade do ajuste com fator de $30 \%$ para o nível de SStress e Stress. Enquanto que no RSQ, os níveis de adequação da qualidade do ajuste devem ser superiores a 0,60000, o que denota um mínimo de 60\% de qualidade dos dados.

Figura 4.2 Mapa perceptual de similaridade (variáveis) do $1^{\circ}$ ano do curso Técnico Integrado ao Ensino Médio de Informática - Distâncias euclidianas.

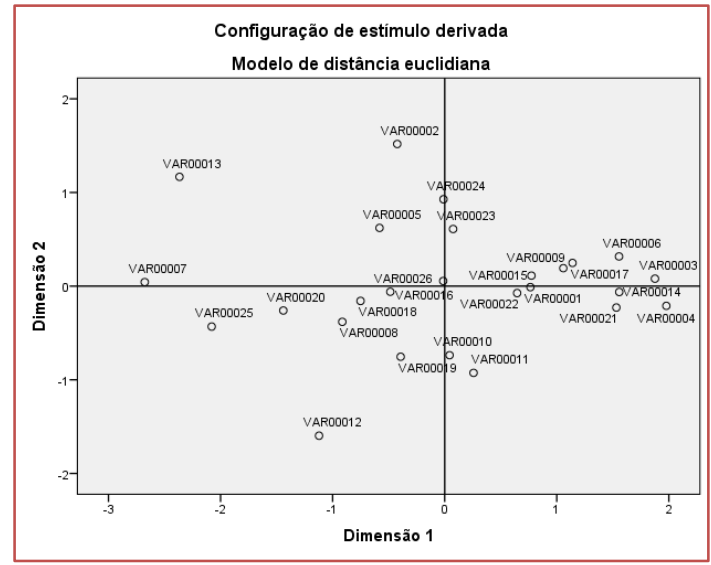

Fonte: Dados da pesquisa. 
Ao realizar uma análise no mapa perceptual de similaridade do EMD apresentado na Figura 4.2 nota-se que as variáveis (7), (12) e (13), que se referem, respectivamente, a "Acreditar que a sua indisciplina atrapalha a aprendizagem de matemática", "Gostar de matemática" e "ter prazer em estudar matemática" apresentam menor aderência dos alunos, ou seja, possuem menor inserção ao contexto do ensino e aprendizagem de matemática no Ensino Médio.

Este fato que também pode ser confirmado pela análise de conglomerados no dendograma da Figura 4.3, subsidiado pelos coeficientes (distâncias euclidianas), apresentadas na Tabela 4.1. A análise do dendograma reforça que as variáveis (7) - "acreditar que a sua indisciplina atrapalha a aprendizagem de matemática" e (13) - "ter prazer em estudar matemática" apresentam menor aderência ao explicar o comportamento das variáveis para Configuração de Estímulos Derivados Modelo de Distância Euclidiana Dimensão 1. Desta forma, o seu grau de similaridade com as demais variáveis é baixo, o qual pode ser verificado ao ver que as variáveis citadas estão compreendidas nos últimos conglomerados formados e que possuem maior distância euclidiana em relação às demais.

A maior distância euclidiana é apresentada no coeficiente da Tabela 4.1, a qual aponta que as variáveis (7) e (13), além da variável (25) - "não dar atenção quando o professor esta explicando a matéria e pensar em outras coisas" - são incorporadas nos últimos conglomerados formados.

Tabela 4.1 Resultados dos conglomerados 1ํano do curso Técnico Integrado ao Ensino Médio de Informática.

\begin{tabular}{|c|c|c|c|c|c|c|}
\hline \multirow{2}{*}{ Estágio } & \multicolumn{2}{|c|}{ Cluster combinado } & \multirow{2}{*}{ Coeficientes } & \multicolumn{2}{|c|}{ O cluster de estágio é exibido primeiro } & \multirow{2}{*}{$\begin{array}{l}\text { Próximo } \\
\text { estágio }\end{array}$} \\
\hline & Cluster 1 & Cluster 2 & & Cluster 1 & Cluster 2 & \\
\hline 1 & 4 & 6 & 14,000 & 0 & 0 & 3 \\
\hline 2 & 14 & 17 & 17,000 & 0 & 0 & 11 \\
\hline 3 & 3 & 4 & 19,000 & 0 & 1 & 14 \\
\hline 4 & 15 & 23 & 22,000 & 0 & 0 & 13 \\
\hline 5 & 21 & 22 & 23,000 & 0 & 0 & 10 \\
\hline 6 & 20 & 26 & 25,000 & 0 & 0 & 17 \\
\hline 7 & 2 & 5 & 26,000 & 0 & 0 & 19 \\
\hline 8 & 16 & 18 & 29,000 & 0 & 0 & 9 \\
\hline 9 & 8 & 16 & 29,500 & 0 & 8 & 17 \\
\hline 10 & 9 & 21 & 30,500 & 0 & 5 & 13 \\
\hline 11 & 1 & 14 & 32,500 & 0 & 2 & 14 \\
\hline 12 & 10 & 11 & 33,000 & 0 & 0 & 15 \\
\hline 13 & 9 & 15 & 34,000 & 10 & 4 & 16 \\
\hline 14 & 1 & 3 & 34,111 & 11 & 3 & 16 \\
\hline 15 & 10 & 19 & 38,500 & 12 & 0 & 18 \\
\hline 16 & 1 & 9 & 40,300 & 14 & 13 & 23 \\
\hline 17 & 8 & 20 & 43,500 & 9 & 6 & 18 \\
\hline 18 & 8 & 10 & 48,733 & 17 & 15 & 21 \\
\hline 19 & 2 & 24 & 53,000 & 7 & 0 & 22 \\
\hline 20 & 13 & 25 & 55,000 & 0 & 0 & 24 \\
\hline 21 & 8 & 12 & 57,875 & 18 & 0 & 22 \\
\hline 22 & 2 & 8 & 61,593 & 19 & 21 & 23 \\
\hline 23 & 1 & 2 & 68,795 & 16 & 22 & 25 \\
\hline 24 & 7 & 13 & 69,500 & 0 & 20 & 25 \\
\hline 25 & 1 & 7 & 105,130 & 23 & 24 & 0 \\
\hline
\end{tabular}

Fonte: Dados da pesquisa. 
Figura 4.3 Dendograma (variáveis) 1o ano do curso Técnico Integrado ao Ensino Médio de Informática.

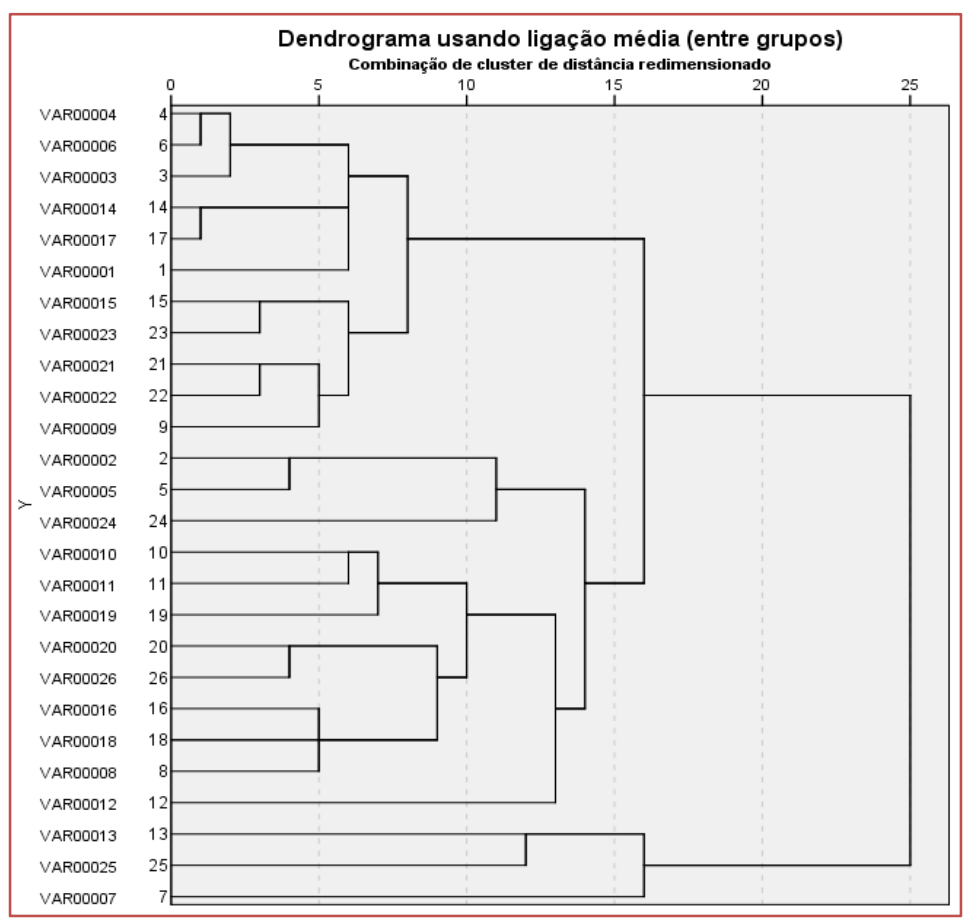

Fonte: Dados da pesquisa.

Também foi realizada uma análise fatorial exploratória para buscar a melhor disposição de itens por fatores. Foi realizada análise para um único fator com determinante próximo à zero $(0,01)$, KMO maior que 0,732 e teste de esfericidade de Bartlett significativa, $p<0,0001$. Foi utilizado o método de Extração Análise de Componente Principal e o método de Rotação Varimax com Normalização de Kaiser.

A análise fatorial exploratória mostrou que a variável (7) está mais distante das demais (Tabela 4.2), como já apontado nas outras análises.

Tabela 4.2 Resultados dos fatores $1^{\circ}$ ano do curso Técnico Integrado ao Ensino Médio de Informática.

\begin{tabular}{|c|c|}
\hline Fator & Variável \\
\hline 1,46295 & V12 \\
\hline 1,24797 & V10 \\
\hline 1,14998 & V19 \\
\hline 1,11384 & V26 \\
\hline 0,97406 & V11 \\
\hline 0,91886 & V13 \\
\hline 0,78419 & V3 \\
\hline 0,73291 & V2 \\
\hline 0,69134 & V14 \\
\hline 0,45707 & V17 \\
\hline 0,45706 & V5 \\
\hline 0,39906 & V15 \\
\hline 0,30799 & V9 \\
\hline 0,06173 & V8 \\
\hline$-0,05788$ & V21 \\
\hline$-0,10687$ & V16 \\
\hline$-0,16435$ & V22 \\
\hline$-0,29597$ & V20 \\
\hline$-0,52122$ & V24 \\
\hline$-0,81284$ & V4 \\
\hline$-0,99927$ & V18 \\
\hline$-1,21013$ & V1 \\
\hline$-1,21013$ & V25 \\
\hline$-1,75933$ & V6 \\
\hline$-1,80401$ & V23 \\
\hline$-1,81701$ & V7 \\
\hline
\end{tabular}

Fonte: Dados da pesquisa 


\subsection{ANÁLISES MULTIVARIADAS DO 1 응 ANO DO CURSO TÉCNICO INTEGRADO AO ENSINO MÉDIO DE MECÂNICA}

Com relação às variáveis desta pesquisa, a partir da análise do Quadro 4.5, verifica-se que os níveis de adequação do ajuste ao se aplicar O EMD estão dentro de níveis adequados de ajuste (aderência), pois o referido estudo trata-se de uma pesquisa exploratória.

Quadro 4.4 Níveis de aderência do EMD (variáveis) do 1o ano do curso Técnico Integrado ao Ensino Médio de Mecânica.

\begin{tabular}{|c|c|}
\hline Índice & Nível \\
\hline S-stress & 0,001000 \\
& Melhoria do ajuste na $4^{\underline{a} \text { interação }-0,00058}$ \\
\hline Stress & 0,15514 \\
\hline RSQ & 0,87630 \\
\hline
\end{tabular}

Fonte: Dados da pesquisa.

É importante ressaltar que o nível de aderência está adequado com o uso da análise do Escalonamento Multidimensional (EMD), pois o trabalho tem objetivo exploratório e neste caso mensura-se percepções de pessoas, no caso alunos do $1^{\circ}$ ano do curso Técnico Integrado ao Ensino Médio de Mecânica, tem seus níveis de aderência podendo variar até algo próximo a uma escala de 0,30000, apresentando níveis adequados na qualidade do ajuste com fator de $30 \%$ para o nível de SStress e Stress. Enquanto que no RSQ, os níveis de adequação da qualidade do ajuste devem ser superiores a 0,60000, o que denota um mínimo de 60\% de qualidade dos dados.

Figura 4.4 Mapa perceptual de similaridade (variáveis) do $1^{\circ}$ ano do curso Técnico Integrado ao Ensino Médio de Mecânica - Distâncias euclidianas

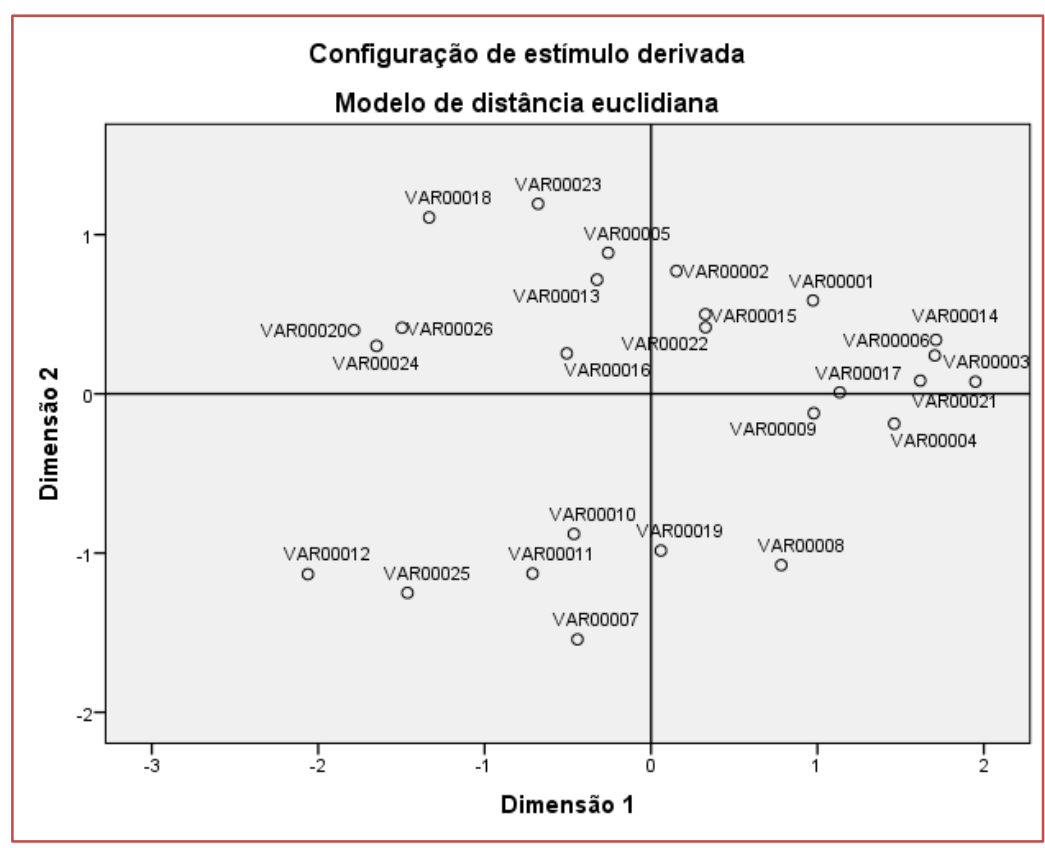

Fonte: Dados da pesquisa

Ao realizar uma análise no mapa perceptual de similaridade do EMD apresentado na Figura 4.4 é possível notar que as variáveis (12) e (25), que se referem, respectivamente, a "gostar de 
matemática" e "não dar atenção quando o professor esta explicando a matéria e pensa em outras coisas" apresentam menor aderência dos alunos, ou seja, possuem menor inserção ao contexto do ensino e aprendizagem de matemática no Ensino Médio. As variáveis (12) e (25) apresentam menor aderência, não fazendo parte do grupo de variáveis que reúne aquelas com maior similaridade com o atributo analisado, no caso, as variáveis: (1), (2), (3), (4), (5), (6), (7), (9), (11), (13), (14), (15), (16), (17), (18), (19), (20), (21), (22), (23), (24) e (26) conforme apresentado no mapa perceptual da Figura 4.4 .

Este fato que também pode ser confirmado pela análise de conglomerados no dendograma da Figura 4.5, subsidiado pelos coeficientes (distâncias euclidianas), apresentadas na Tabela 4.3. A análise do dendograma reforça que as variáveis (7) - "acreditar que a sua indisciplina atrapalha a aprendizagem de matemática" (12) - "gostar de matemática" e (25) - "não dar atenção quando o professor esta explicando a matéria e pensar em outras coisas" apresentam menor aderência ao explicar o comportamento das variáveis para Configuração de Estímulos Derivados Modelo de Distância Euclidiana Dimensão 1. Desta forma, o seu grau de similaridade com as demais variáveis é baixo, o qual pode ser verificado ao ver que as variáveis citadas estão compreendidas nos últimos conglomerados formados e que possuem maior distância euclidiana em relação às demais. A maior distância euclidiana é apresentada no coeficiente da Tabela 4.3, a qual aponta que as variáveis (7), (12) e (25) são incorporadas nos últimos conglomerados formados.

Figura 4.5 Dendograma (variáveis) do 1ํano do curso Técnico Integrado ao Ensino Médio de Mecânica.

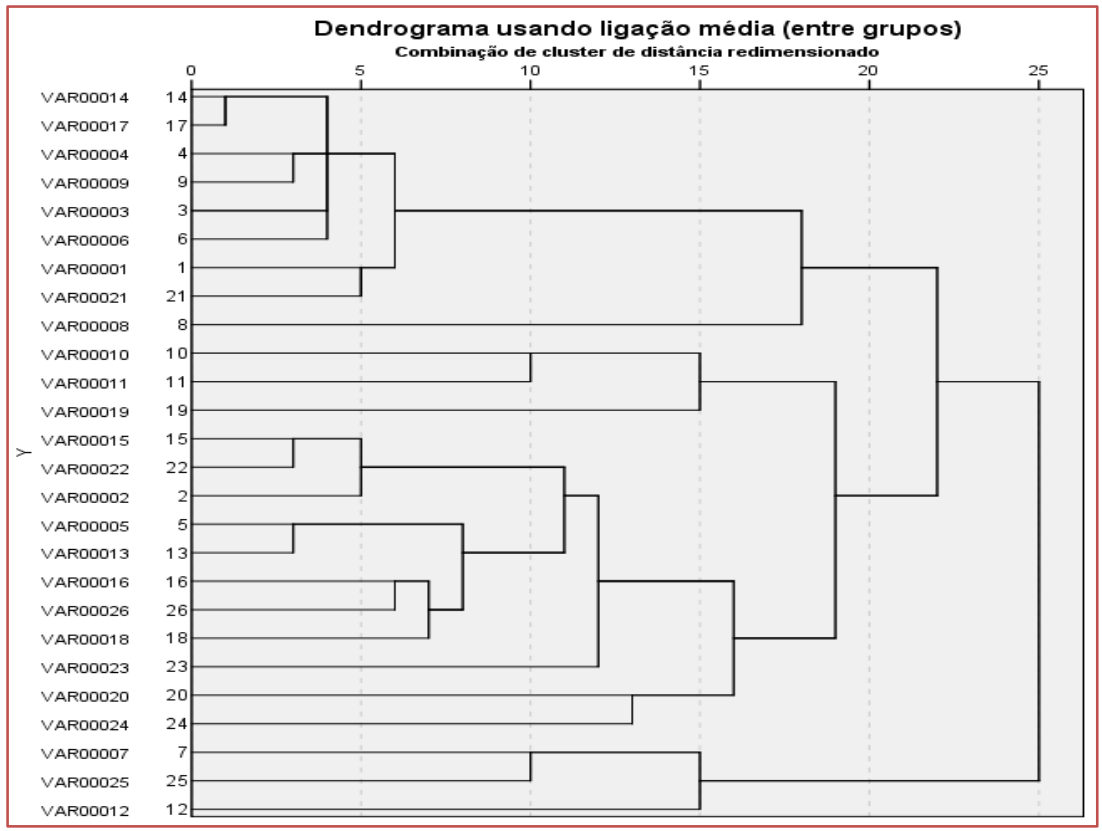

Fonte: Dados da pesquisa. 
Tabela 4.3 Resultados dos conglomerados do 1ํano do curso Técnico Integrado ao Ensino Médio de Mecânica.

\begin{tabular}{|c|c|c|c|c|c|c|}
\hline \multirow[t]{2}{*}{ Estágio } & \multicolumn{2}{|c|}{ Cluster combinado } & \multirow[t]{2}{*}{ Coeficientes } & \multicolumn{2}{|c|}{ O cluster de estágio é exibido primeiro } & \multirow{2}{*}{$\begin{array}{l}\text { Próxim } \\
\text { estágic }\end{array}$} \\
\hline & Cluster 1 & Cluster 2 & & Cluster 1 & Cluster 2 & \\
\hline 1 & 14 & 17 & 14,000 & 0 & 0 & 6 \\
\hline 2 & 15 & 22 & 26,000 & 0 & 0 & 9 \\
\hline 3 & 5 & 13 & 27,000 & 0 & 0 & 13 \\
\hline 4 & 4 & 9 & 27,000 & 0 & 0 & 6 \\
\hline 5 & 3 & 6 & 30,000 & 0 & 0 & 7 \\
\hline 6 & 4 & 14 & 32,000 & 4 & 1 & 7 \\
\hline 7 & 3 & 4 & 35,250 & 5 & 6 & 11 \\
\hline 8 & 1 & 21 & 38,000 & 0 & 0 & 11 \\
\hline 9 & 2 & 15 & 40,000 & 0 & 2 & 16 \\
\hline 10 & 16 & 26 & 42,000 & 0 & 0 & 12 \\
\hline 11 & 1 & 3 & 43,333 & 8 & 7 & 22 \\
\hline 12 & 16 & 18 & 51,000 & 10 & 0 & 13 \\
\hline 13 & 5 & 16 & 56,167 & 3 & 12 & 16 \\
\hline 14 & 10 & 11 & 62,000 & 0 & 0 & 20 \\
\hline 15 & 7 & 25 & 66,000 & 0 & 0 & 19 \\
\hline 16 & 2 & 5 & 69,067 & 9 & 13 & 17 \\
\hline 17 & 2 & 23 & 72,500 & 16 & 0 & 21 \\
\hline 18 & 20 & 24 & 81,000 & 0 & 0 & 21 \\
\hline 19 & 7 & 12 & 90,000 & 15 & 0 & 25 \\
\hline 20 & 10 & 19 & 93,000 & 14 & 0 & 23 \\
\hline 21 & 2 & 20 & 94,722 & 17 & 18 & 23 \\
\hline 22 & 1 & 8 & 109,125 & 11 & 0 & 24 \\
\hline 23 & 2 & 10 & 114,364 & 21 & 20 & 24 \\
\hline 24 & 1 & 2 & 127,778 & 22 & 23 & 25 \\
\hline 25 & 1 & 7 & 146,942 & 24 & 19 & 0 \\
\hline
\end{tabular}

Fonte: Dados da pesquisa

Também foi realizada uma análise fatorial exploratória para buscar a melhor disposição de itens por fatores. Foi realizada análise para um único fator com determinante próximo à zero $(0,01)$, KMO maior que 0,737 e teste de esfericidade de Bartlett significativa, $p<0,0001$. Foi utilizado o método de Extração Análise de Componente Principal e o método de Rotação Varimax com Normalização de Kaiser. A análise fatorial exploratória (Tabela 4.4) mostrou que as variáveis (4) e (6) estão mais distantes das demais, diferente das outras análises. 
Tabela 4.4 Resultados dos fatores do 1ํano do curso Técnico Integrado ao Ensino Médio de Mecânica.

\begin{tabular}{|c|c|}
\hline Fator & Variável \\
\hline 2,08963 & V1 \\
\hline 2,08963 & V2 \\
\hline 1,46912 & V11 \\
\hline 1,37297 & V23 \\
\hline 0,70299 & V25 \\
\hline 0,52173 & V26 \\
\hline 0,48979 & V22 \\
\hline 0,31639 & V5 \\
\hline 0,27451 & V17 \\
\hline 0,22988 & V16 \\
\hline 0,08129 & V15 \\
\hline 0,03575 & V7 \\
\hline 0,01561 & V14 \\
\hline$-0,09673$ & V9 \\
\hline$-0,21623$ & V12 \\
\hline$-0,32186$ & V8 \\
\hline$-0,41168$ & V21 \\
\hline$-0,71764$ & V3 \\
\hline$-0,78019$ & V20 \\
\hline$-1,21773$ & V18 \\
\hline$-1,24821$ & V24 \\
\hline$-1,74771$ & V19 \\
\hline$-2,01641$ & V4 \\
\hline$-2,36888$ & V6 \\
\hline
\end{tabular}

Fonte: Dados da pesquisa

\subsection{ANÁLISES MULTIVARIADAS DO 2 ANO DO CURSO TÉCNICO INTEGRADO AO ENSINO MÉDIO DE MECÂNICA}

Com a análise do Quadro 4.6, em relação às variáveis desta pesquisa, verifica-se que os níveis de adequação do ajuste ao se aplicar o EMD estão dentro de níveis adequados de ajuste (aderência), pois o referido estudo trata-se de uma pesquisa exploratória. 
Quadro 4.5 Níveis de aderência do EMD (variáveis) do 2ํano do curso Técnico Integrado ao Ensino Médio de Mecânica.

\begin{tabular}{|cc|}
\hline Índice & Nível \\
\hline S-stress & 0,001000 \\
& Melhoria do ajuste na $4^{\text {a }}$ interação $-0,00074$ \\
\hline Stress & 0,16622 \\
\hline RSQ & 0,90109 \\
\hline
\end{tabular}

Fonte: Dados da pesquisa.

É importante ressaltar que o nível de aderência está adequado com o uso da análise do Escalonamento Multidimensional (EMD), pois o trabalho tem objetivo exploratório e neste caso mensura-se percepções de pessoas, no caso alunos do $2^{\circ}$ ano do curso Técnico Integrado ao Ensino Médio de Mecânica, tem seus níveis de aderência podendo variar até algo próximo a uma escala de 0,30000, apresentando níveis adequados na qualidade do ajuste com fator de $30 \%$ para o nível de SStress e Stress. Enquanto que no RSQ, os níveis de adequação da qualidade do ajuste devem ser superiores a 0,60000, o que denota um mínimo de 60\% de qualidade dos dados.

Figura 4.6 Mapa perceptual de similaridade (variáveis) do $2^{\circ}$ ano do curso Técnico Integrado ao Ensino Médio de Mecânica - Distâncias euclidianas.

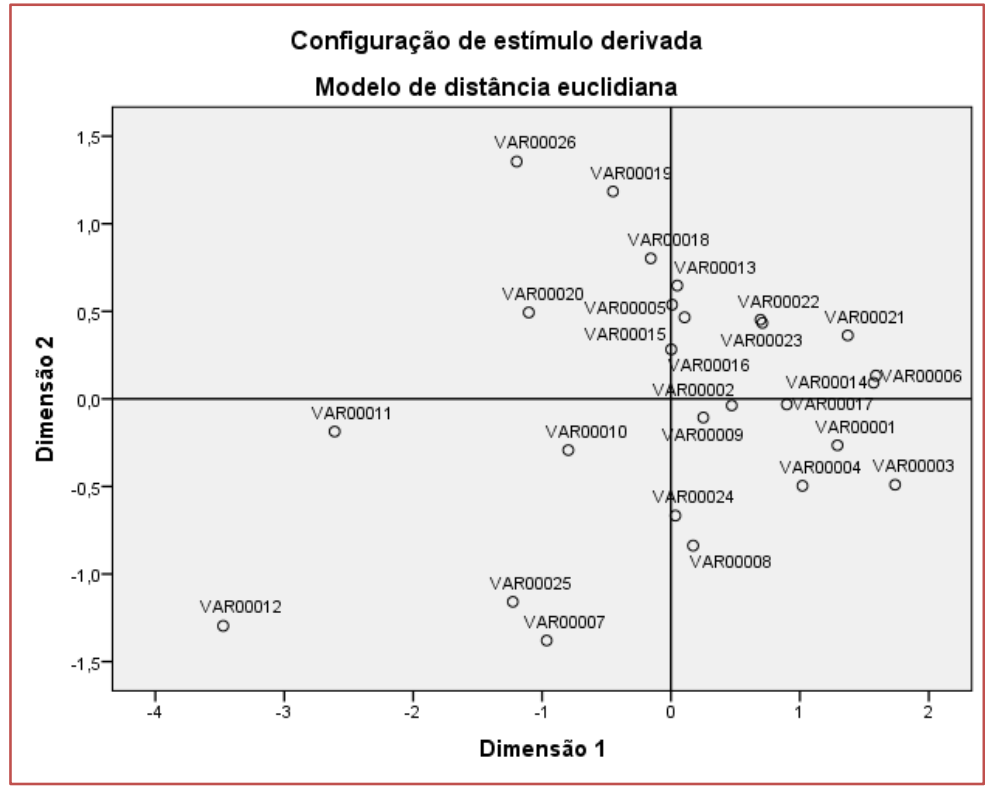

Fonte: Dados da pesquisa.

Ao realizar uma análise no mapa perceptual de similaridade do EMD apresentado na Figura 4.6 é possível notar que as variáveis (7), (11), (12) e (25), que se referem, respectivamente, a "acreditar que a sua indisciplina atrapalha a aprendizagem de matemática", "ter um sentimento de impotência ao estudar matemática", "gostar de matemática" e "não dar atenção quando o professor esta explicando a matéria e pensar em outras coisas" apresentam menor aderência dos alunos, ou seja, possuem menor inserção ao contexto do ensino e aprendizagem de matemática no Ensino Médio, conforme apresentado no mapa perceptual da Figura 4.5.

Este fato que também pode ser confirmado pela análise de conglomerados no dendograma da Figura 4.7, subsidiado pelos coeficientes (distâncias euclidianas), apresentadas na Tabela 4.5. A análise do dendograma reforça que as variáveis (7) "acreditar que a sua indisciplina atrapalha a aprendizagem de matemática ", (11) "ter um sentimento de impotência ao estudar matemática", (12) 
"gostar de matemática" e (25) "não dar atenção quando o professor esta explicando a matéria e pensar em outras coisas" apresentam menor aderência ao explicar o comportamento das variáveis para Configuração de Estímulos Derivados Modelo de Distância Euclidiana Dimensão 1. Desta forma, o seu grau de similaridade com as demais variáveis é baixo, o qual pode ser verificado ao ver que as variáveis citadas estão compreendidas nos últimos conglomerados formados e que possuem maior distância euclidiana em relação às demais. A maior distância euclidiana é apresentada no coeficiente da Tabela 4.5, a qual aponta que as variáveis (7), (11), (12) e (25) são incorporadas nos últimos conglomerados formados.

Figura 4.7 Dendograma (variáveis) do $2^{\circ}$ ano do curso Técnico Integrado ao Ensino Médio de Mecânica.

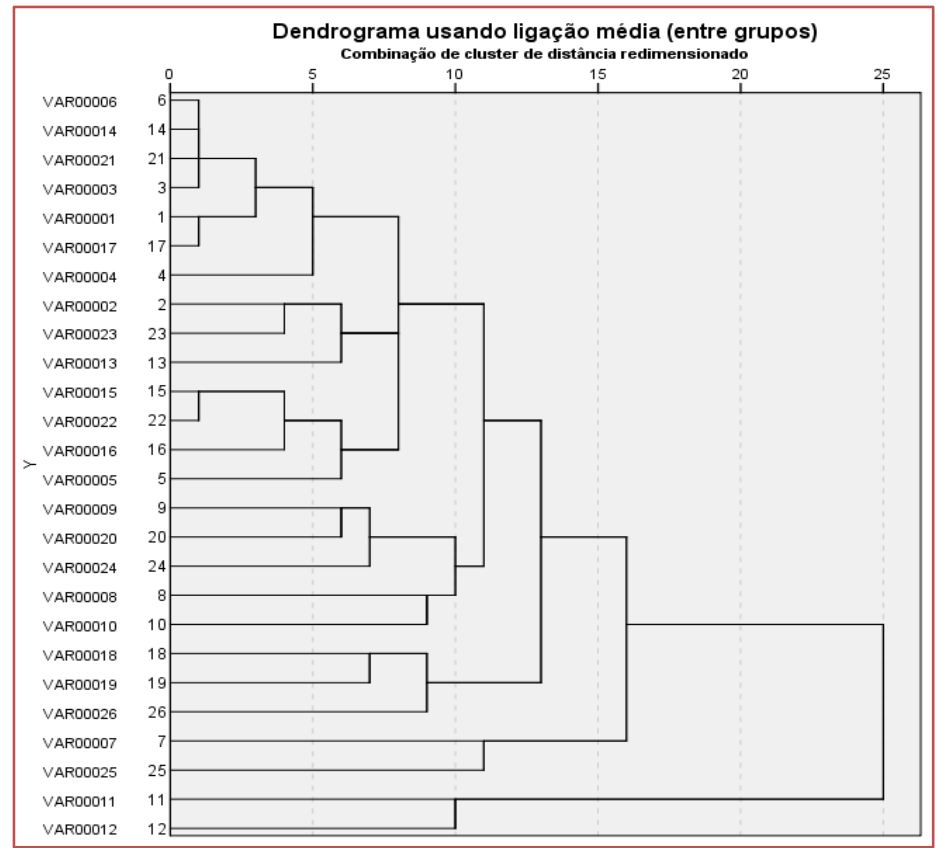

Fonte: Dados da pesquisa. 
Tabela 4.5 Resultados dos conglomerados.

\begin{tabular}{|c|c|c|c|c|c|c|}
\hline \multirow[t]{2}{*}{ Estágio } & \multicolumn{2}{|c|}{ Cluster combinado } & \multirow[t]{2}{*}{ Coeficientes } & \multicolumn{2}{|c|}{ O cluster de estágio é exibido primeiro } & \multirow{2}{*}{$\begin{array}{l}\text { Próximo } \\
\text { estágio }\end{array}$} \\
\hline & Cluster 1 & Cluster 2 & & Cluster 1 & Cluster 2 & \\
\hline 1 & 6 & 14 & 12,000 & 0 & 0 & 4 \\
\hline 2 & 1 & 17 & 14,000 & 0 & 0 & 6 \\
\hline 3 & 15 & 22 & 17,000 & 0 & 0 & 7 \\
\hline 4 & 6 & 21 & 17,000 & 1 & 0 & 5 \\
\hline 5 & 3 & 6 & 17,333 & 0 & 4 & 6 \\
\hline 6 & 1 & 3 & 27,250 & 2 & 5 & 9 \\
\hline 7 & 15 & 16 & 32,500 & 3 & 0 & 12 \\
\hline 8 & 2 & 23 & 33,000 & 0 & 0 & 11 \\
\hline 9 & 1 & 4 & 37,000 & 6 & 0 & 16 \\
\hline 10 & 9 & 20 & 43,000 & 0 & 0 & 14 \\
\hline 11 & 2 & 13 & 44,500 & 8 & 0 & 15 \\
\hline 12 & 5 & 15 & 45,333 & 0 & 7 & 15 \\
\hline 13 & 18 & 19 & 49,000 & 0 & 0 & 18 \\
\hline 14 & 9 & 24 & 50,500 & 10 & 0 & 19 \\
\hline 15 & 2 & 5 & 56,833 & 11 & 12 & 16 \\
\hline 16 & 1 & 2 & 57,000 & 9 & 15 & 22 \\
\hline 17 & 8 & 10 & 64,000 & 0 & 0 & 19 \\
\hline 18 & 18 & 26 & 66,500 & 13 & 0 & 23 \\
\hline 19 & 8 & 9 & 68,667 & 17 & 14 & 22 \\
\hline 20 & 11 & 12 & 69,000 & 0 & 0 & 25 \\
\hline 21 & 7 & 25 & 75,000 & 0 & 0 & 24 \\
\hline 22 & 1 & 8 & 76,757 & 16 & 19 & 23 \\
\hline 23 & 1 & 18 & 87,772 & 22 & 18 & 24 \\
\hline 24 & 1 & 7 & 106,364 & 23 & 21 & 25 \\
\hline 25 & 1 & 11 & 163,583 & 24 & 20 & 0 \\
\hline
\end{tabular}

Fonte: Dados da pesquisa.

Também foi realizada uma análise fatorial exploratória para buscar a melhor disposição de itens por fatores. Foi realizada análise para um único fator com determinante próximo à zero $(0,01)$, KMO maior que 0,730 e teste de esfericidade de Bartlett significativa, $p<0,0001$. Foi utilizado o método de Extração Análise de Componente Principal e o método de Rotação Varimax com Normalização de Kaiser. A análise fatorial exploratória (Tabela 4.6) mostrou que as variáveis (7) e (11) estão mais distantes das demais, diferente das outras análises. Enquanto que as variáveis (12) e (25) estão mais próximas entre si, como nas demais análises. 
Tabela 4.6 Resultados dos fatores do $2^{\circ}$ ano do curso Técnico Integrado ao Ensino Médio de Mecânica.

\begin{tabular}{|c|c|}
\hline Fator & Variável \\
\hline 1,28363 & V9 \\
\hline 1,26175 & V10 \\
\hline 1,23097 & V24 \\
\hline 1,22279 & V11 \\
\hline 1,04256 & V17 \\
\hline 1,03504 & V1 \\
\hline 0,83918 & V6 \\
\hline 0,78947 & V21 \\
\hline 0,7145 & V26 \\
\hline 0,61825 & V13 \\
\hline 0,31088 & V20 \\
\hline 0,18492 & V14 \\
\hline 0,13529 & V15 \\
\hline$-0,04792$ & V7 \\
\hline$-0,13967$ & V22 \\
\hline$-0,31134$ & V3 \\
\hline$-0,48607$ & V19 \\
\hline$-0,49808$ & V16 \\
\hline$-0,74223$ & V5 \\
\hline$-0,84682$ & V23 \\
\hline$-1,30205$ & V12 \\
\hline$-1,63237$ & V4 \\
\hline$-1,67072$ & V2 \\
\hline$-2,1637$ & V18 \\
\hline
\end{tabular}

Fonte: Dados da pesquisa.

\subsection{ANÁLISES MULTIVARIADAS DO 3 ANO DO CURSO TÉCNICO INTEGRADO AO ENSINO MÉDIO DE MECÂNICA}

A partir da análise do Quadro 4.7, em relação às variáveis desta pesquisa, verifica-se que os níveis de adequação do ajuste ao se aplicar o EMD estão dentro de níveis adequados de ajuste (aderência), pois o referido estudo trata-se de uma pesquisa exploratória. 
Quadro 4.6 Níveis de aderência do EMD (variáveis) do 3o ano do curso Técnico Integrado ao Ensino Médio de Mecânica.

\begin{tabular}{|cc|}
\hline Índice & Nível \\
\hline S-stress & 0,001000 \\
& Melhoria do ajuste na $4^{\text {a }}$ interação $-0,00054$ \\
\hline Stress & 0,16036 \\
\hline RSQ & 0,86318 \\
\hline
\end{tabular}

Fonte: Dados da pesquisa

É importante ressaltar que o nível de aderência está adequado com o uso da análise do Escalonamento Multidimensional (EMD), pois o trabalho tem objetivo exploratório e neste caso mensura-se percepções de pessoas, no caso alunos do $3^{\circ}$ ano do curso Técnico Integrado ao Ensino Médio de Mecânica, tem seus níveis de aderência podendo variar até algo próximo a uma escala de 0,30000, apresentando níveis adequados na qualidade do ajuste com fator de $30 \%$ para o nível de SStress e Stress. Enquanto que no RSQ, os níveis de adequação da qualidade do ajuste devem ser superiores a 0,60000, o que denota um mínimo de 60\% de qualidade dos dados.

Figura 4.8 Mapa perceptual de similaridade (variáveis) do $3^{\circ}$ ano do curso Técnico Integrado ao Ensino Médio de Mecânica - Distâncias euclidianas.

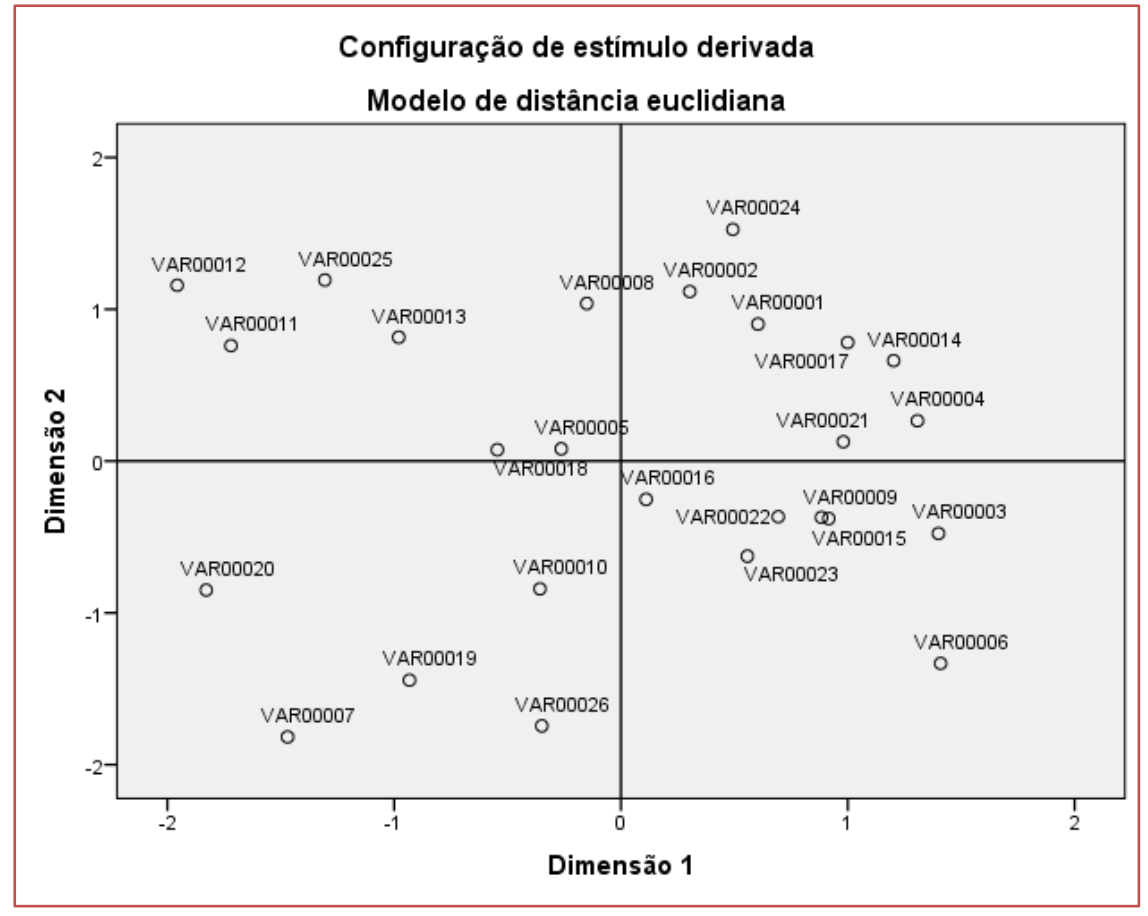

Fonte: Dados da pesquisa.

Ao realizar uma análise no mapa perceptual de similaridade do EMD apresentado na Figura 4.8 é possível notar que as variáveis (7), (11), (12), (20) e (25), que se referem, respectivamente, a "acreditar que a sua indisciplina atrapalha a aprendizagem de matemática", "ter um sentimento de impotência ao estudar matemática", "gostar de matemática", "buscar algum profissional fora da sala de aula para aprender matemática" e "não dar atenção quando o professor esta explicando a matéria e pensar em outras coisas" apresentam menor aderência dos alunos, ou seja, possuem menor inserção ao contexto do ensino e aprendizagem de matemática no Ensino Médio. 
Este fato que também pode ser confirmado pela análise de conglomerados no dendograma da Figura 4.9, subsidiado pelos coeficientes (distâncias euclidianas), apresentadas na Tabela 4.7. A análise do dendograma reforça que as variáveis (7) "acreditar que a sua indisciplina atrapalha a aprendizagem de matemática", (12) "gostar de matemática" e (25) "não dar atenção quando o professor esta explicando a matéria e pensar em outras coisas" apresentam menor aderência ao explicar o comportamento das variáveis para Configuração de Estímulos Derivados Modelo de Distância Euclidiana Dimensão 1. Desta forma, o seu grau de similaridade com as demais variáveis é baixo, o qual pode ser verificado ao ver que as variáveis citadas estão compreendidas nos últimos conglomerados formados e que possuem maior distância euclidiana em relação às demais. A maior distância euclidiana é apresentada no coeficiente da Tabela 4.7, a qual aponta que as variáveis (7), (12) e (25) são incorporadas nos últimos conglomerados formados.

Tabela 4.7 Resultados dos conglomerados do 3ํㅡㄹ ano do curso Técnico Integrado ao Ensino Médio de Mecânica.

\begin{tabular}{|c|c|c|c|c|c|c|}
\hline \multirow[t]{2}{*}{ Estágio } & \multicolumn{2}{|c|}{ Cluster combinado } & \multirow[t]{2}{*}{ Coeficientes } & \multicolumn{2}{|c|}{ O cluster de estágio é exibido primeiro } & \multirow{2}{*}{$\begin{array}{l}\text { Próximo } \\
\text { estágio }\end{array}$} \\
\hline & Cluster 1 & Cluster 2 & & Cluster 1 & Cluster 2 & \\
\hline 1 & 14 & 17 & 6,000 & 0 & 0 & 4 \\
\hline 2 & 16 & 22 & 19,000 & 0 & 0 & 6 \\
\hline 3 & 3 & 9 & 21,000 & 0 & 0 & 7 \\
\hline 4 & 4 & 14 & 22,000 & 0 & 1 & 8 \\
\hline 5 & 2 & 5 & 28,000 & 0 & 0 & 11 \\
\hline 6 & 15 & 16 & 28,500 & 0 & 2 & 10 \\
\hline 7 & 3 & 21 & 31,500 & 3 & 0 & 8 \\
\hline 8 & 3 & 4 & 34,778 & 7 & 4 & 14 \\
\hline 9 & 10 & 19 & 37,000 & 0 & 0 & 15 \\
\hline 10 & 15 & 23 & 38,000 & 6 & 0 & 14 \\
\hline 11 & 1 & 2 & 41,000 & 0 & 5 & 13 \\
\hline 12 & 12 & 25 & 46,000 & 0 & 0 & 25 \\
\hline 13 & 1 & 13 & 48,333 & 11 & 0 & 16 \\
\hline 14 & 3 & 15 & 49,333 & 8 & 10 & 17 \\
\hline 15 & 10 & 20 & 51,500 & 9 & 0 & 18 \\
\hline 16 & 1 & 18 & 54,750 & 13 & 0 & 19 \\
\hline 17 & 3 & 6 & 60,100 & 14 & 0 & 21 \\
\hline 18 & 10 & 26 & 64,333 & 15 & 0 & 22 \\
\hline 19 & 1 & 11 & 66,600 & 16 & 0 & 20 \\
\hline 20 & 1 & 8 & 74,167 & 19 & 0 & 21 \\
\hline 21 & 1 & 3 & 87,377 & 20 & 17 & 23 \\
\hline 22 & 7 & 10 & 94,250 & 0 & 18 & 24 \\
\hline 23 & 1 & 24 & 95,556 & 21 & 0 & 24 \\
\hline 24 & 1 & 7 & 117,326 & 23 & 22 & 25 \\
\hline 25 & 1 & 12 & 123,583 & 24 & 12 & 0 \\
\hline
\end{tabular}

Fonte: Dados da pesquisa. 
Figura 4.9 Dendograma (variáveis) do $3^{\circ}$ ano do curso Técnico Integrado ao Ensino Médio de Mecânica.

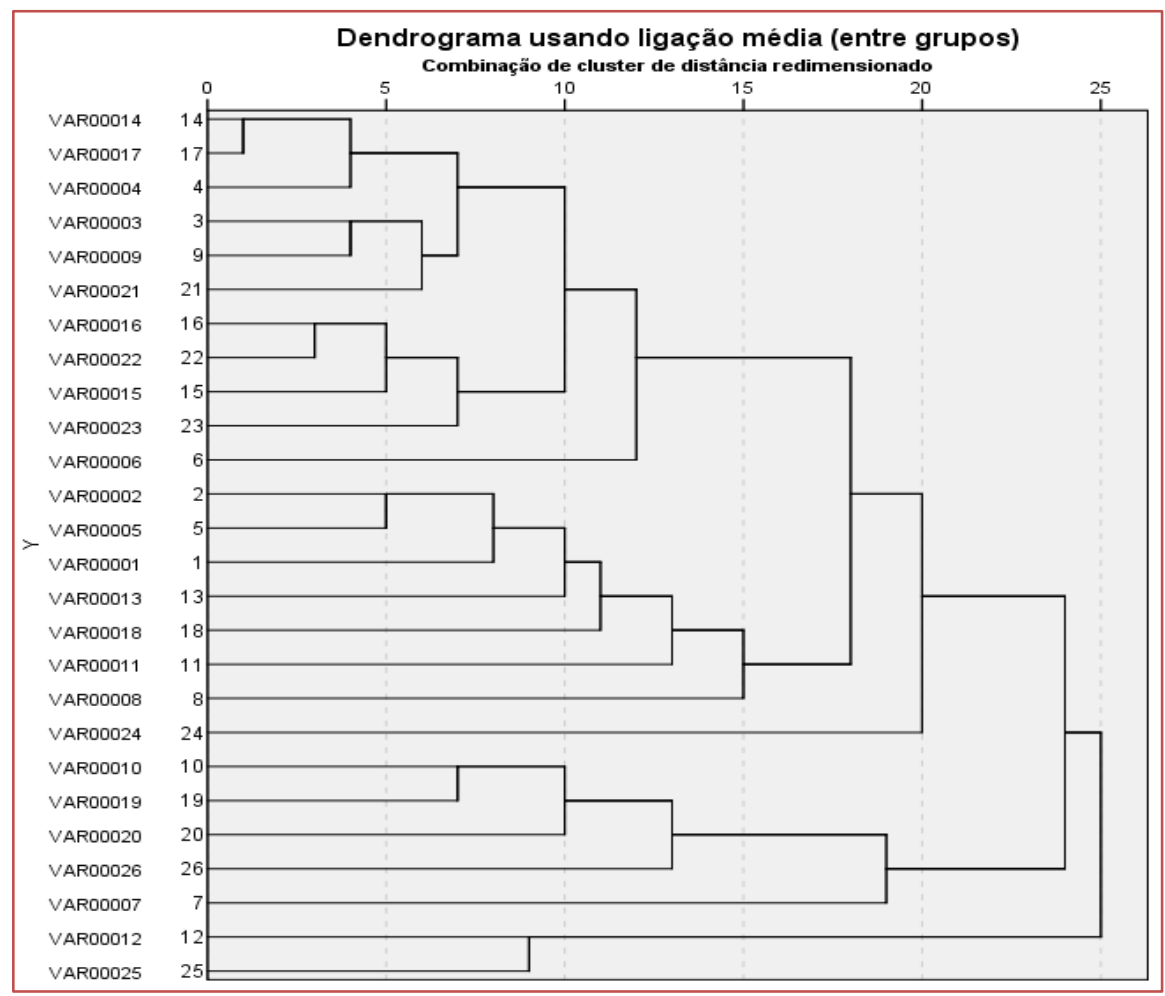

Fonte: Dados da pesquisa.

Também foi realizada uma análise fatorial exploratória para buscar a melhor disposição de itens por fatores. Foi realizada análise para um único fator com determinante próximo à zero $(0,01)$, KMO maior que 0,736 e teste de esfericidade de Bartlett significativa, $p<0,0001$. Foi utilizado o método de Extração Análise de Componente Principal e o método de Rotação Varimax com Normalização de Kaiser. A análise fatorial exploratória (Tabela 4.8) mostrou que as variáveis (12), (20) e (25) estão mais distantes das demais, diferente das outras análises. Enquanto que as variáveis (7) e (11) estão mais próximas, como nas demais análises. 
Tabela 4.8 Resultados dos fatores do 3ํano do curso Técnico Integrado ao Ensino Médio de Mecânica.

\begin{tabular}{|c|c|}
\hline Fator & Variável \\
\hline 1,54487 & V9 \\
\hline 1,54487 & V5 \\
\hline 1,49451 & V11 \\
\hline 1,30301 & V7 \\
\hline 1,06853 & V2 \\
\hline 1,05804 & V6 \\
\hline 1,05418 & V19 \\
\hline 0,78598 & V23 \\
\hline 0,68251 & V21 \\
\hline 0,61371 & V25 \\
\hline 0,38198 & V1 \\
\hline 0,12056 & V22 \\
\hline 0,02807 & V17 \\
\hline$-0,15965$ & V4 \\
\hline$-0,16394$ & V15 \\
\hline$-0,3379$ & V18 \\
\hline$-0,64282$ & V26 \\
\hline$-0,64282$ & V24 \\
\hline$-0,90017$ & V10 \\
\hline$-0,91327$ & V8 \\
\hline$-0,91327$ & V12 \\
\hline$-0,99223$ & $\mathrm{~V} 13$ \\
\hline$-1,09554$ & V20 \\
\hline$-1,38758$ & V14 \\
\hline$-1,6504$ & V3 \\
\hline$-1,76394$ & V16 \\
\hline
\end{tabular}

Fonte: Dados da pesquisa.

\subsection{ANÁLISES MULTIVARIADAS DO 3 ANO DO CURSO TÉCNICO INTEGRADO AO ENSINO MÉDIO DE ELETROELETRÔNICA}

A partir da análise do Quadro 4.8, em relação às variáveis desta pesquisa, verifica-se que os níveis de adequação do ajuste ao se aplicar o EMD estão dentro de níveis adequados de ajuste (aderência), pois o referido estudo trata-se de uma pesquisa exploratória. 
Quadro 4.7 Níveis de aderência do EMD (variáveis) do 3o ano do curso Técnico Integrado ao Ensino Médio de Eletroeletrônica.

\begin{tabular}{|c|c|}
\hline Índice & Nível \\
\hline S-stress & 0,001000 \\
& Melhoria do ajuste na $4^{\text {a }}$ interação $-0,00051$ \\
\hline Stress & 0,13070 \\
\hline RSQ & 0,92813 \\
\hline
\end{tabular}

Fonte: Dados da pesquisa.

É importante ressaltar que o nível de aderência está adequado com o uso da análise do Escalonamento Multidimensional (EMD), pois o trabalho tem objetivo exploratório e neste caso mensura-se percepções de pessoas, no caso alunos do $3^{\circ}$ ano do curso Técnico Integrado ao Ensino Médio de Eletroeletrônica, tem seus níveis de aderência podendo variar até algo próximo a uma escala de 0,30000, apresentando níveis adequados na qualidade do ajuste com fator de $30 \%$ para o nível de SStress e Stress. Enquanto que no RSQ, os níveis de adequação da qualidade do ajuste devem ser superiores a 0,60000, o que denota um mínimo de 60\% de qualidade dos dados.

Figura 4.10 Mapa perceptual de similaridade (variáveis) do 3o ano do curso Técnico Integrado ao Ensino Médio de Eletroeletrônica - Distâncias euclidianas.

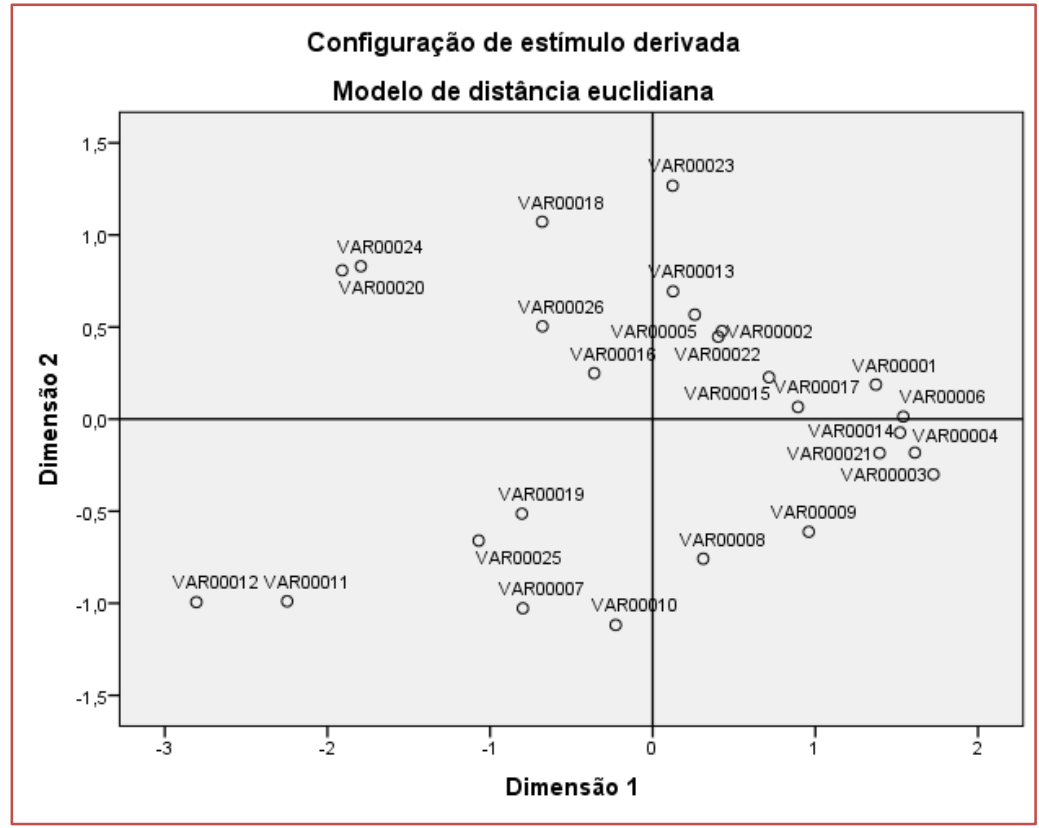

Fonte: Dados da pesquisa.

Ao realizar uma análise no mapa perceptual de similaridade do EMD apresentado na Figura 4.10 é possível notar que as variáveis (11), (12), (20) e (24), que se referem, respectivamente a "ter um sentimento de impotência ao estudar matemática", "gostar de matemática", "buscar algum profissional fora da sala de aula para aprender matemática" e "comparar suas anotações com a de seus colegas" apresentam menor aderência dos alunos, ou seja, possuem menor inserção ao contexto do ensino e aprendizagem de matemática no Ensino Médio.

Este fato, que também pode ser confirmado pela análise de conglomerados no dendograma da Figura 4.11, subsidiado pelos coeficientes (distâncias euclidianas), apresentadas na Tabela 4.9. A análise do dendograma reforça que as variáveis (11) "ter um sentimento de impotência ao estudar matemática", (12) "gostar de matemática", (20) "buscar algum profissional fora da sala de aula para 
aprender matemática" e (24) "comparar suas anotações com a de seus colegas" apresentam menor aderência ao explicar o comportamento das variáveis para Configuração de Estímulos Derivados Modelo de Distância Euclidiana Dimensão 1. Desta forma, o seu grau de similaridade com as demais variáveis é baixo, o qual pode ser verificado ao ver que as variáveis citadas estão compreendidas nos últimos conglomerados formados e que possuem maior distância euclidiana em relação às demais. A maior distância euclidiana é apresentada no coeficiente da Tabela 4.9, a qual aponta que as variáveis (11), (12), (20) e (24) são incorporadas nos últimos conglomerados formados.

Tabela 4.9 Resultados dos conglomerados do 3o ano do curso Técnico Integrado ao Ensino Médio de Eletroeletrônica.

\begin{tabular}{|c|c|c|c|c|c|c|}
\hline \multirow[t]{2}{*}{ Estágio } & \multicolumn{2}{|c|}{ Cluster combinado } & \multirow[t]{2}{*}{ Coeficientes } & \multicolumn{2}{|c|}{ O cluster de estágio é exibido primeiro } & \multirow{2}{*}{$\begin{array}{c}\text { Próximo } \\
\text { estágio }\end{array}$} \\
\hline & Cluster 1 & Cluster 2 & & Cluster 1 & Cluster 2 & \\
\hline 1 & 1 & 6 & 3,873 & 0 & 0 & 5 \\
\hline 2 & 16 & 18 & 4,243 & 0 & 0 & 10 \\
\hline 3 & 14 & 17 & 4,243 & 0 & 0 & 11 \\
\hline 4 & 4 & 21 & 4,359 & 0 & 0 & 5 \\
\hline 5 & 1 & 4 & 4,410 & 1 & 4 & 8 \\
\hline 6 & 15 & 22 & 4,472 & 0 & 0 & 14 \\
\hline 7 & 5 & 13 & 4,583 & 0 & 0 & 13 \\
\hline 8 & 1 & 9 & 5,242 & 5 & 0 & 9 \\
\hline 9 & 1 & 3 & 5,485 & 8 & 0 & 11 \\
\hline 10 & 16 & 26 & 5,599 & 2 & 0 & 18 \\
\hline 11 & 1 & 14 & 5,749 & 9 & 3 & 14 \\
\hline 12 & 11 & 12 & 5,916 & 0 & 0 & 24 \\
\hline 13 & 2 & 5 & 5,951 & 0 & 7 & 15 \\
\hline 14 & 1 & 15 & 7,027 & 11 & 6 & 22 \\
\hline 15 & 2 & 23 & 7,099 & 13 & 0 & 18 \\
\hline 16 & 7 & 19 & 7,280 & 0 & 0 & 19 \\
\hline 17 & 10 & 25 & 7,416 & 0 & 0 & 21 \\
\hline 18 & 2 & 16 & 7,418 & 15 & 10 & 22 \\
\hline 19 & 7 & 8 & 8,199 & 16 & 0 & 21 \\
\hline 20 & 20 & 24 & 8,246 & 0 & 0 & 24 \\
\hline 21 & 7 & 10 & 8,550 & 19 & 17 & 23 \\
\hline 22 & 1 & 2 & 8,692 & 14 & 18 & 23 \\
\hline 23 & 1 & 7 & 9,511 & 22 & 21 & 25 \\
\hline 24 & 11 & 20 & 10,008 & 12 & 20 & 25 \\
\hline 25 & 1 & 11 & 11,646 & 23 & 24 & 0 \\
\hline
\end{tabular}

Fonte: Dados da pesquisa 
Figura 4.11 Dendograma (variáveis) do 3o ano do curso Técnico Integrado ao Ensino Médio de Eletroeletrônica.

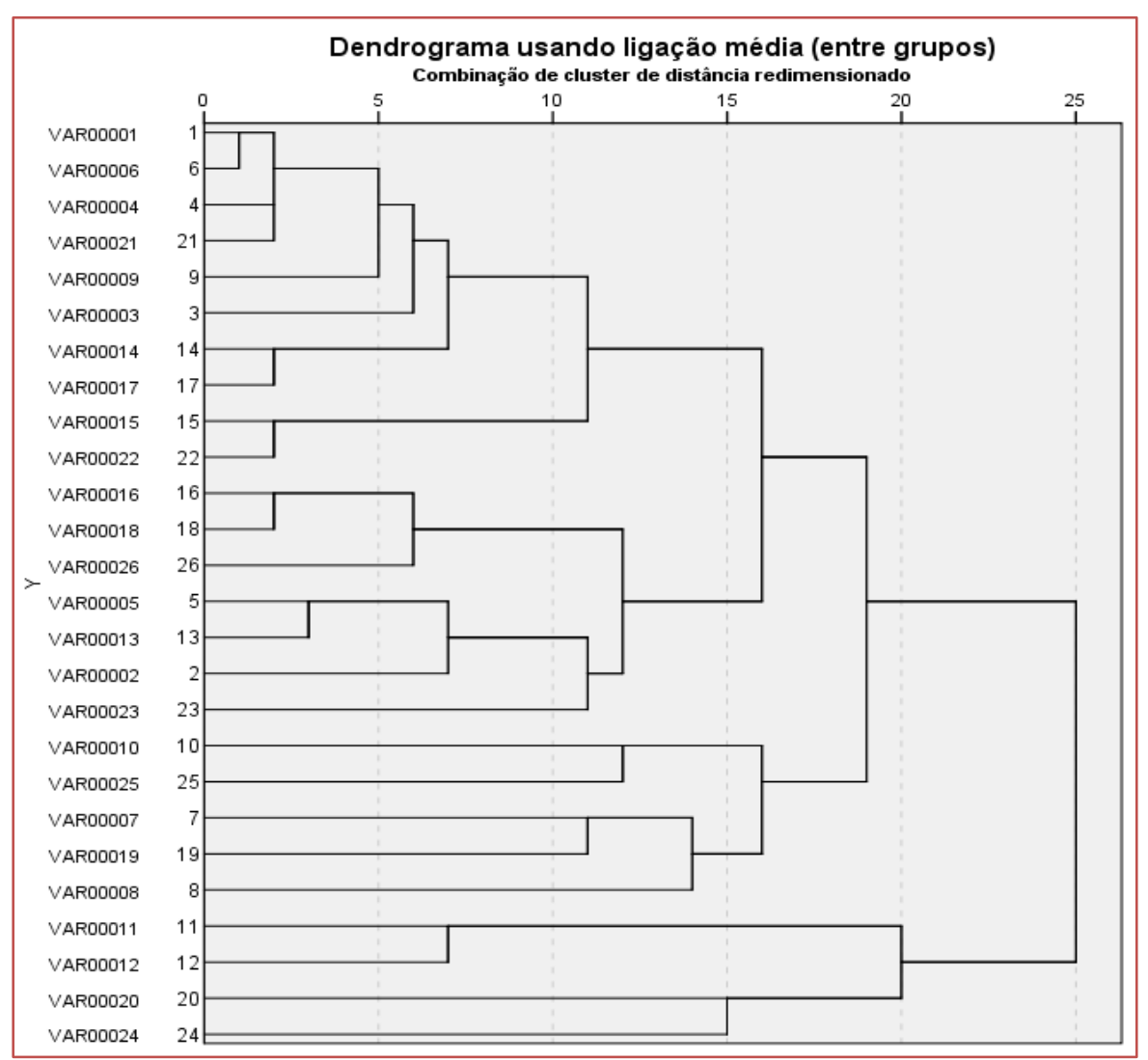

Fonte: Dados da pesquisa

Também foi realizada uma análise fatorial exploratória para buscar a melhor disposição de itens por fatores. Foi realizada análise para um único fator com determinante próximo à zero $(0,01)$, KMO maior que 0,729 e teste de esfericidade de Bartlett significativa, $p<0,0001$. Foi utilizado o método de Extração Análise de Componente Principal e o método de Rotação Varimax com Normalização de Kaiser. A análise fatorial exploratória (Tabela 4.10) mostrou que a variável (20) está mais distante das demais, diferente das outras análises. Ao passo que as variáveis (11), (12) e (24) estão mais próximas, como nas demais análises. 
Tabela 4.10 Resultados dos fatores do 3ํano do curso Técnico Integrado ao Ensino Médio de Eletroeletrônica.

\begin{tabular}{|c|c|}
\hline Fator & Variável \\
\hline 1,57007 & V23 \\
\hline 1,31869 & V18 \\
\hline 0,95417 & V14 \\
\hline 0,91191 & V13 \\
\hline 0,8462 & V17 \\
\hline 0,83735 & V3 \\
\hline 0,69543 & V5 \\
\hline 0,68155 & V6 \\
\hline 0,66794 & V21 \\
\hline 0,58262 & V4 \\
\hline 0,52855 & V16 \\
\hline 0,49953 & V1 \\
\hline 0,3804 & V22 \\
\hline 0,14761 & V2 \\
\hline 0,04755 & V20 \\
\hline$-0,07151$ & V8 \\
\hline$-0,09231$ & V15 \\
\hline$-0,16872$ & V9 \\
\hline$-0,34893$ & V26 \\
\hline$-1,02993$ & V7 \\
\hline$-1,04558$ & V11 \\
\hline$-1,34182$ & V12 \\
\hline$-1,41347$ & V24 \\
\hline$-1,47298$ & V19 \\
\hline$-1,58501$ & V25 \\
\hline$-2,09932$ & V10 \\
\hline
\end{tabular}

\subsection{ANÁLISES MULTIVARIADAS DA POPULAÇÃO DE ALUNOS DO ENSINO MÉDIO DO IFSP CAMPUS BRAGANÇA PAULISTA}

A partir da análise do Quadro 4.9, em relação às variáveis desta pesquisa, verifica-se que os níveis de adequação do ajuste ao se aplicar o EMD estão dentro de níveis adequados de ajuste (aderência), pois o referido estudo trata-se de uma pesquisa exploratória.

Quadro 4.8 Níveis de aderência do EMD (variáveis) da população de alunos do Ensino Médio do IFSP campus Bragança Paulista.

\begin{tabular}{|c|c|}
\hline Índice & Nível \\
\hline S-stress & 0,001000 \\
& Melhoria do ajuste na $5^{\text {a }}$ interação $-0,00064$ \\
\hline Stress & 0,15340 \\
\hline RSQ & 0,89996 \\
\hline
\end{tabular}

Fonte: Dados da pesquisa.

É importante ressaltar que o nível de aderência está adequado com o uso da análise do Escalonamento Multidimensional (EMD), pois o trabalho tem objetivo exploratório e neste caso mensura-se percepções de pessoas, no caso alunos do curso Técnico Integrado ao Ensino Médio do IFSP campus Bragança Paulista, tem seus níveis de aderência podendo variar até algo próximo a uma escala de 0,30000, apresentando níveis adequados na qualidade do ajuste com fator de $30 \%$ 
para o nível de SStress e Stress. Enquanto que no RSQ, os níveis de adequação da qualidade do ajuste devem ser superiores a 0,60000, o que denota um mínimo de 60\% de qualidade dos dados.

Figura 4.12 Mapa perceptual de similaridade (variáveis) da população de alunos do Ensino Médio do IFSP campus Bragança Paulista - Distâncias euclidianas,

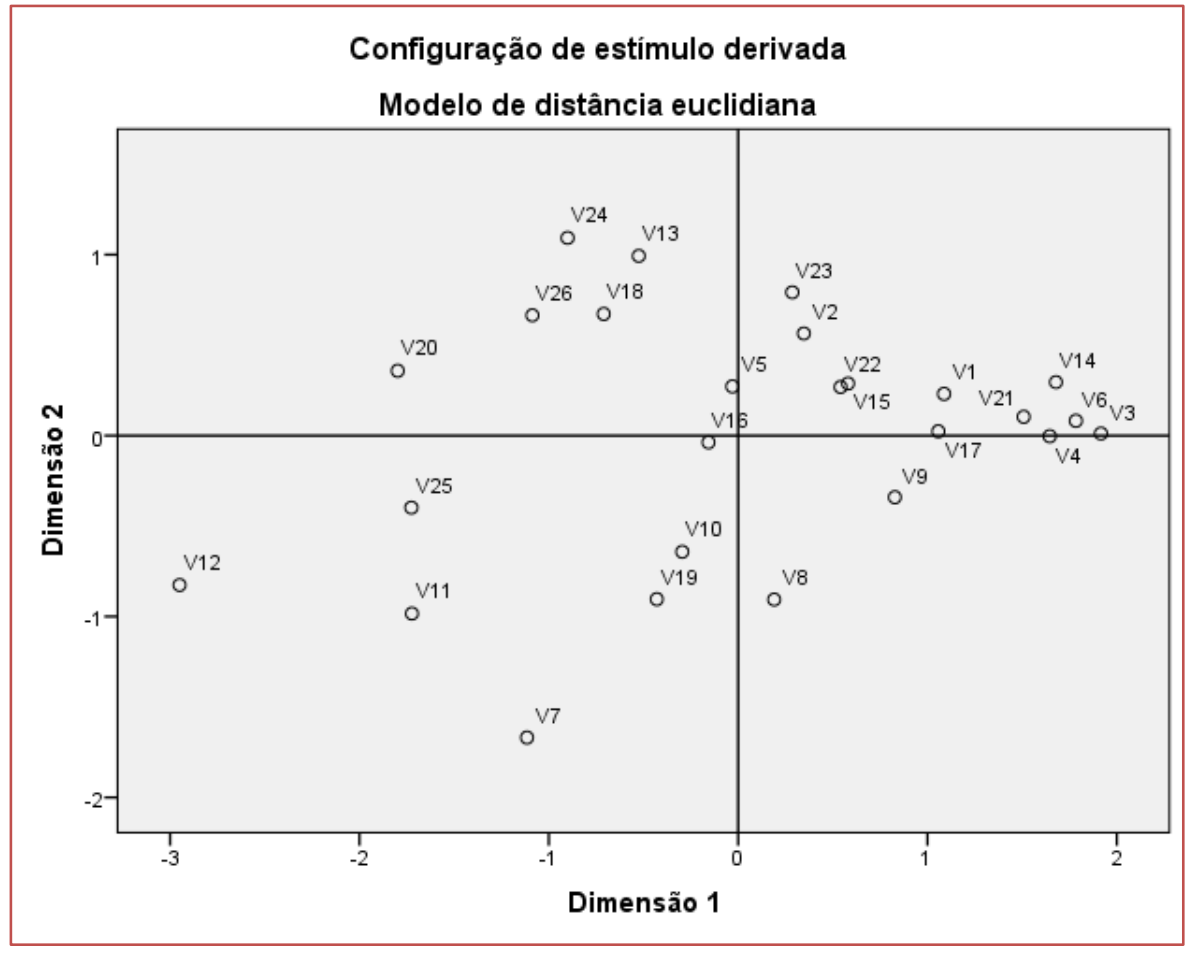

Fonte: Dados da pesquisa.

Ao realizar uma análise no mapa perceptual de similaridade do EMD apresentado na Figura 4.12 é possível notar que as variáveis (7), (11), (12), (20) e (25), que se referem, respectivamente a "acreditar que a sua indisciplina atrapalha a aprendizagem de matemática", "ter um sentimento de impotência ao estudar matemática", "gostar de matemática", "buscar algum profissional fora da sala de aula para aprender matemática" e "não dar atenção quando o professor esta explicando a matéria e pensar em outras coisas" apresentam menor aderência dos alunos, ou seja, possuem menor inserção ao contexto do ensino e aprendizagem de matemática no Ensino Médio.

Este fato, que também pode ser confirmado pela análise de conglomerados no dendograma da Figura 4.13, subsidiado pelos coeficientes (distâncias euclidianas), apresentadas na Tabela 4.11. A análise do dendograma reforça que as variáveis (7) "acreditar que a sua indisciplina atrapalha a aprendizagem de matemática", (11) "ter um sentimento de impotência ao estudar matemática", (12) "gostar de matemática", (20) "buscar algum profissional fora da sala de aula para aprender matemática" e (25) "não dar atenção quando o professor esta explicando a matéria e pensar em outras coisas", apresentam menor aderência ao explicar o comportamento das variáveis para Configuração de Estímulos Derivados Modelo de Distância Euclidiana Dimensão 1. Desta forma, o seu grau de similaridade com as demais variáveis é baixo, o qual pode ser verificado ao ver que as variáveis citadas estão compreendidas nos últimos conglomerados formados e que possuem maior distância euclidiana em relação às demais. A maior distância euclidiana é apresentada no coeficiente da Tabela 4.11, a qual aponta que as variáveis (7), (11), (12), e (25) são incorporadas nos últimos conglomerados formados. 
Tabela 4.11 Resultados dos conglomerados da população de alunos do Ensino Médio do IFSP campus Bragança Paulista.

\begin{tabular}{|c|c|c|c|c|c|c|}
\hline \multirow[t]{2}{*}{ Estágio } & \multicolumn{2}{|c|}{ Cluster combinado } & \multirow[t]{2}{*}{ Coeficientes } & \multicolumn{2}{|c|}{ O cluster de estágio é exibido primeiro } & \multirow{2}{*}{$\begin{array}{l}\text { Próximo } \\
\text { estágio }\end{array}$} \\
\hline & Cluster 1 & Cluster 2 & & Cluster 1 & Cluster 2 & \\
\hline 1 & 14 & 17 & 8,660 & 0 & 0 & 4 \\
\hline 2 & 15 & 22 & 10,488 & 0 & 0 & 9 \\
\hline 3 & 3 & 6 & 11,045 & 0 & 0 & 5 \\
\hline 4 & 1 & 14 & 12,141 & 0 & 1 & 10 \\
\hline 5 & 3 & 4 & 12,275 & 3 & 0 & 6 \\
\hline 6 & 3 & 21 & 12,806 & 5 & 0 & 8 \\
\hline 7 & 5 & 13 & 13,077 & 0 & 0 & 11 \\
\hline 8 & 3 & 9 & 13,409 & 6 & 0 & 10 \\
\hline 9 & 15 & 16 & 13,709 & 2 & 0 & 12 \\
\hline 10 & 1 & 3 & 13,737 & 4 & 8 & 18 \\
\hline 11 & 2 & 5 & 14,704 & 0 & 7 & 15 \\
\hline 12 & 15 & 23 & 15,692 & 9 & 0 & 14 \\
\hline 13 & 20 & 26 & 16,823 & 0 & 0 & 20 \\
\hline 14 & 15 & 18 & 16,887 & 12 & 0 & 15 \\
\hline 15 & 2 & 15 & 17,376 & 11 & 14 & 18 \\
\hline 16 & 10 & 19 & 17,692 & 0 & 0 & 20 \\
\hline 17 & 12 & 25 & 18,682 & 0 & 0 & 19 \\
\hline 18 & 1 & 2 & 19,080 & 10 & 15 & 21 \\
\hline 19 & 11 & 12 & 19,317 & 0 & 17 & 24 \\
\hline 20 & 10 & 20 & 19,360 & 16 & 13 & 22 \\
\hline 21 & 1 & 8 & 20,138 & 18 & 0 & 23 \\
\hline 22 & 10 & 24 & 21,244 & 20 & 0 & 23 \\
\hline 23 & 1 & 10 & 21,850 & 21 & 22 & 25 \\
\hline 24 & 7 & 11 & 22,770 & 0 & 19 & 25 \\
\hline 25 & 1 & 7 & 24,672 & 23 & 24 & 0 \\
\hline
\end{tabular}

Fonte: Dados da pesquisa. 
Figura 4.13 Dendograma (variáveis) da população de alunos do Ensino Médio do IFSP campus Bragança Paulista.

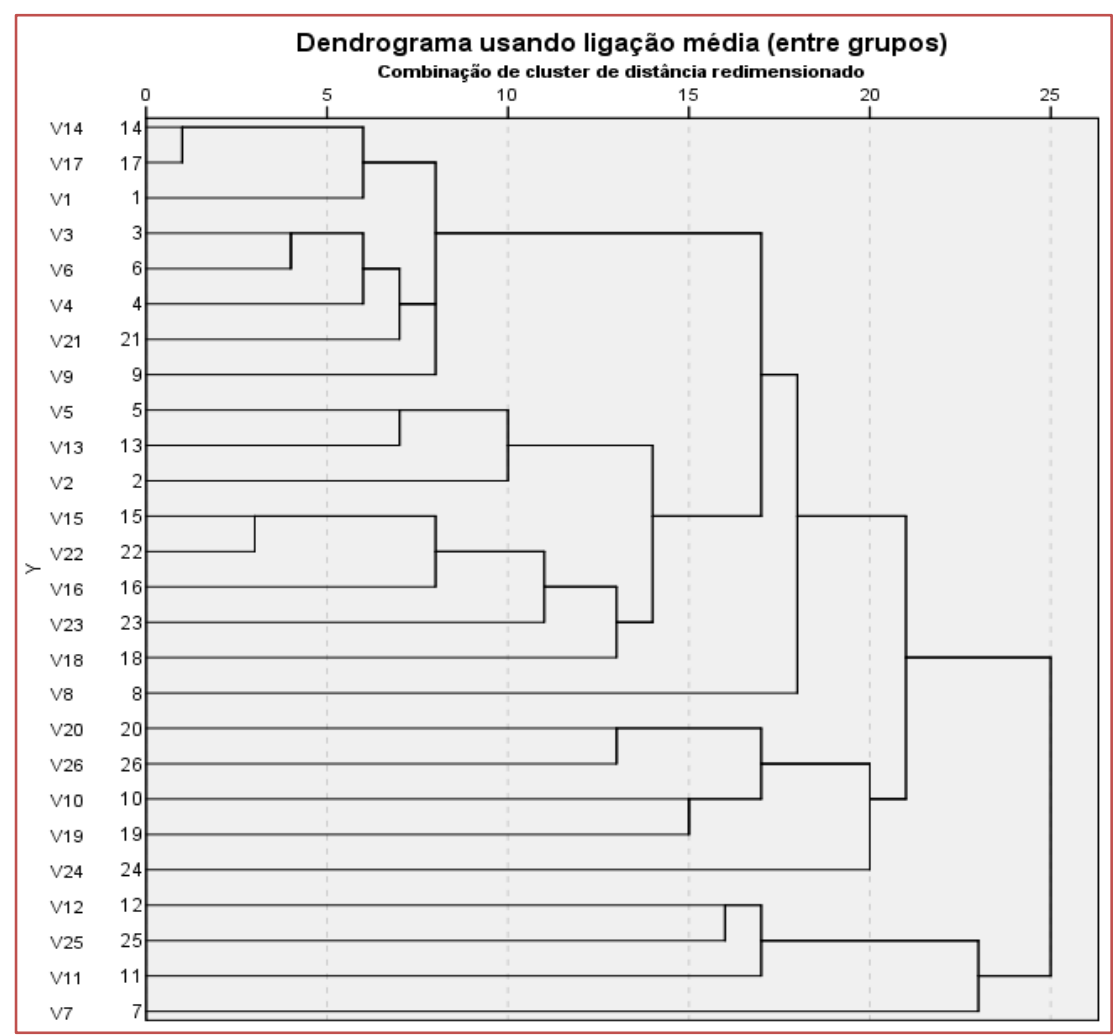

Fonte: Dados da pesquisa.

Também foi realizada uma análise fatorial exploratória para buscar a melhor disposição de itens por fatores. Foi realizada análise para um único fator com determinante próximo à zero $(0,01)$, KMO maior que 0,734 e teste de esfericidade de Bartlett significativa, $p<0,0001$. Foi utilizado o método de Extração Análise de Componente Principal e o método de Rotação Varimax com Normalização de Kaiser. A análise fatorial exploratória (Tabela 4.12) mostrou que as variáveis (11), (12) e (25) estão mais distantes das demais, diferente das outras análises. Enquanto que as variáveis (7), e (20) estão mais próximas, como nas demais análises. 
Tabela 4.12 Resultados dos fatores da população de alunos do Ensino Médio do IFSP campus Bragança Paulista.

\begin{tabular}{|c|c|}
\hline Fator & Variável \\
\hline 2,06395 & V1 \\
\hline 2,06395 & V2 \\
\hline 1,64393 & V4 \\
\hline 1,57895 & V18 \\
\hline 0,62695 & V13 \\
\hline 0,60187 & V22 \\
\hline 0,51049 & V23 \\
\hline 0,40598 & V26 \\
\hline 0,18476 & V25 \\
\hline 0,15909 & V21 \\
\hline$-0,05435$ & V10 \\
\hline$-0,15089$ & V19 \\
\hline$-0,20723$ & V6 \\
\hline$-0,36855$ & V17 \\
\hline$-0,54682$ & V7 \\
\hline$-0,56659$ & V20 \\
\hline$-0,71708$ & V14 \\
\hline$-0,79281$ & V15 \\
\hline$-0,91341$ & V12 \\
\hline$-1,4171$ & V16 \\
\hline$-1,62296$ & V11 \\
\hline$-1,72445$ & V24 \\
\hline$-1,89364$ & V8 \\
\hline$-1,98395$ & V9 \\
\hline$-2,25126$ & V5 \\
\hline$-2,68187$ & V3 \\
\hline
\end{tabular}

Fonte: Dados da pesquisa.

\subsection{ANÁLISES MULTIVARIADAS DOS OUTLIERS DA PESQUISA}

A partir da análise do Quadro 4.10, em relação às variáveis desta pesquisa, verifica-se que os níveis de adequação do ajuste ao se aplicar o EMD estão dentro de níveis adequados de ajuste (aderência), pois o referido estudo trata-se de uma pesquisa exploratória. 
Quadro 4.9 Níveis de aderência do EMD (variáveis) dos outliers da pesquisa.

\begin{tabular}{|c|c|}
\hline Índice & Nível \\
\hline S-stress & 0,001000 \\
\hline Stress & Melhoria do ajuste na $4^{\underline{a} \text { interação }-0,00010}$ \\
\hline RSQ & 0,21901 \\
\hline
\end{tabular}

Fonte: Dados da pesquisa.

É importante ressaltar que o nível de aderência está adequado com o uso da análise do Escalonamento Multidimensional (EMD), pois o trabalho tem objetivo exploratório e neste caso mensura-se percepções de pessoas, no caso os outliers desta pesquisa, tem seus níveis de aderência podendo variar até algo próximo a uma escala de 0,30000, apresentando níveis adequados na qualidade do ajuste com fator de 30\% para o nível de SStress e Stress. Enquanto que no RSQ, os níveis de adequação da qualidade do ajuste devem ser superiores a 0,60000, o que denota um mínimo de $60 \%$ de qualidade dos dados.

Figura 4.14 Mapa perceptual de similaridade (variáveis) dos outliers da pesquisa - Distâncias euclidianas

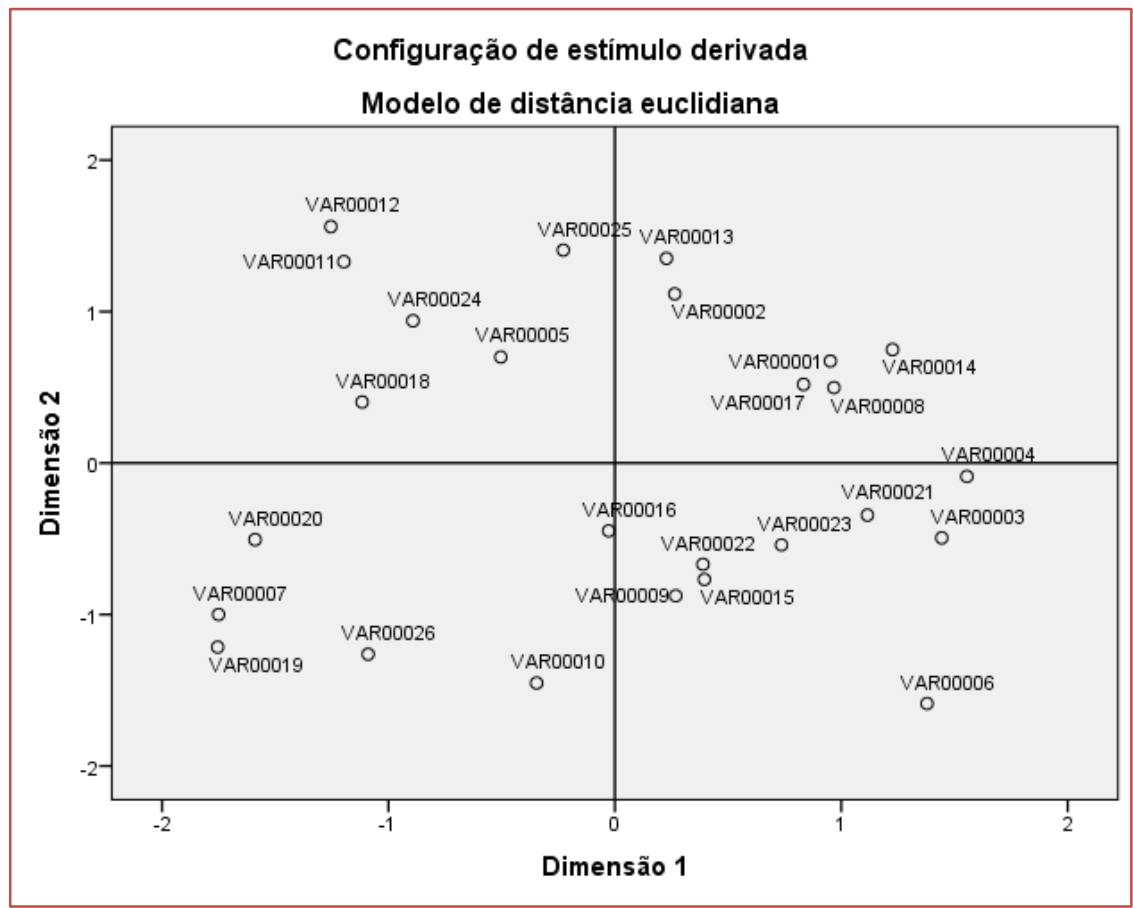

Fonte: Dados da pesquisa

Ao realizar uma análise no mapa perceptual de similaridade do EMD apresentado na Figura 4.14 é possível notar que a variável (6) "Achar seu professor motivado para ensinar matemática" apresenta menor aderência dos outliers, ou seja, possuem menor inserção ao contexto do ensino e aprendizagem de matemática no Ensino Médio.

Já na análise de conglomerados no dendograma da Figura 4.15, subsidiado pelos coeficientes (distâncias euclidianas), apresentadas na Tabela 4.13 mostra que as variáveis (7), (19), (20) e (26), que são respectivamente "acreditar que a sua indisciplina atrapalha a aprendizagem de matemática", "utilizar meios tecnológicos para aprender matemática", "buscar algum profissional fora da sala de aula para aprender matemática" e "revisar suas anotações da aula em outro momento", 
apresentam menor aderência ao explicar o comportamento das variáveis para Configuração de Estímulos Derivados Modelo de Distância Euclidiana Dimensão 1. Desta forma, o seu grau de similaridade com as demais variáveis é baixo, o qual pode ser verificado ao ver que as variáveis citadas estão compreendidas nos últimos conglomerados formados e que possuem maior distância euclidiana em relação às demais. A maior distância euclidiana é apresentada no coeficiente da Tabela 4.13, a qual aponta que as variáveis (7), (19), (20) e (26) são incorporadas nos últimos conglomerados formados.

Tabela 4.13 Resultados dos conglomerados dos outliers da pesquisa.

\begin{tabular}{|c|c|c|c|c|c|c|}
\hline \multirow[t]{2}{*}{ Estágio } & \multicolumn{2}{|c|}{ Cluster combinado } & \multirow[t]{2}{*}{ Coeficientes } & \multicolumn{2}{|c|}{ O cluster de estágio é exibido primeiro } & \multirow{2}{*}{$\begin{array}{l}\text { Próximo } \\
\text { estágio }\end{array}$} \\
\hline & Cluster 1 & Cluster 2 & & Cluster 1 & Cluster 2 & \\
\hline 1 & 14 & 17 & 17,000 & 0 & 0 & 10 \\
\hline 2 & 15 & 22 & 27,000 & 0 & 0 & 3 \\
\hline 3 & 15 & 16 & 33,500 & 2 & 0 & 6 \\
\hline 4 & 3 & 4 & 34,000 & 0 & 0 & 11 \\
\hline 5 & 5 & 18 & 42,000 & 0 & 0 & 17 \\
\hline 6 & 15 & 23 & 43,667 & 3 & 0 & 17 \\
\hline 7 & 9 & 10 & 45,000 & 0 & 0 & 20 \\
\hline 8 & 1 & 2 & 49,000 & 0 & 0 & 13 \\
\hline 9 & 20 & 26 & 54,000 & 0 & 0 & 15 \\
\hline 10 & 13 & 14 & 56,500 & 0 & 1 & 13 \\
\hline 11 & 3 & 21 & 58,000 & 4 & 0 & 16 \\
\hline 12 & 11 & 12 & 60,000 & 0 & 0 & 18 \\
\hline 13 & 1 & 13 & 61,167 & 8 & 10 & 19 \\
\hline 14 & 8 & 25 & 66,000 & 0 & 0 & 19 \\
\hline 15 & 19 & 20 & 67,000 & 0 & 9 & 22 \\
\hline 16 & 3 & 6 & 70,333 & 11 & 0 & 20 \\
\hline 17 & 5 & 15 & 72,750 & 5 & 6 & 21 \\
\hline 18 & 11 & 24 & 77,000 & 12 & 0 & 24 \\
\hline 19 & 1 & 8 & 81,800 & 13 & 14 & 21 \\
\hline 20 & 3 & 9 & 93,000 & 16 & 7 & 23 \\
\hline 21 & 1 & 5 & 98,643 & 19 & 17 & 23 \\
\hline 22 & 7 & 19 & 103,000 & 0 & 15 & 25 \\
\hline 23 & 1 & 3 & 111,513 & 21 & 20 & 24 \\
\hline 24 & 1 & 11 & 134,965 & 23 & 18 & 25 \\
\hline 25 & 1 & 7 & 142,295 & 24 & 22 & 0 \\
\hline
\end{tabular}

Fonte: Dados da pesquisa 
Figura 4.15 Dendograma (variáveis) dos outliers da pesquisa

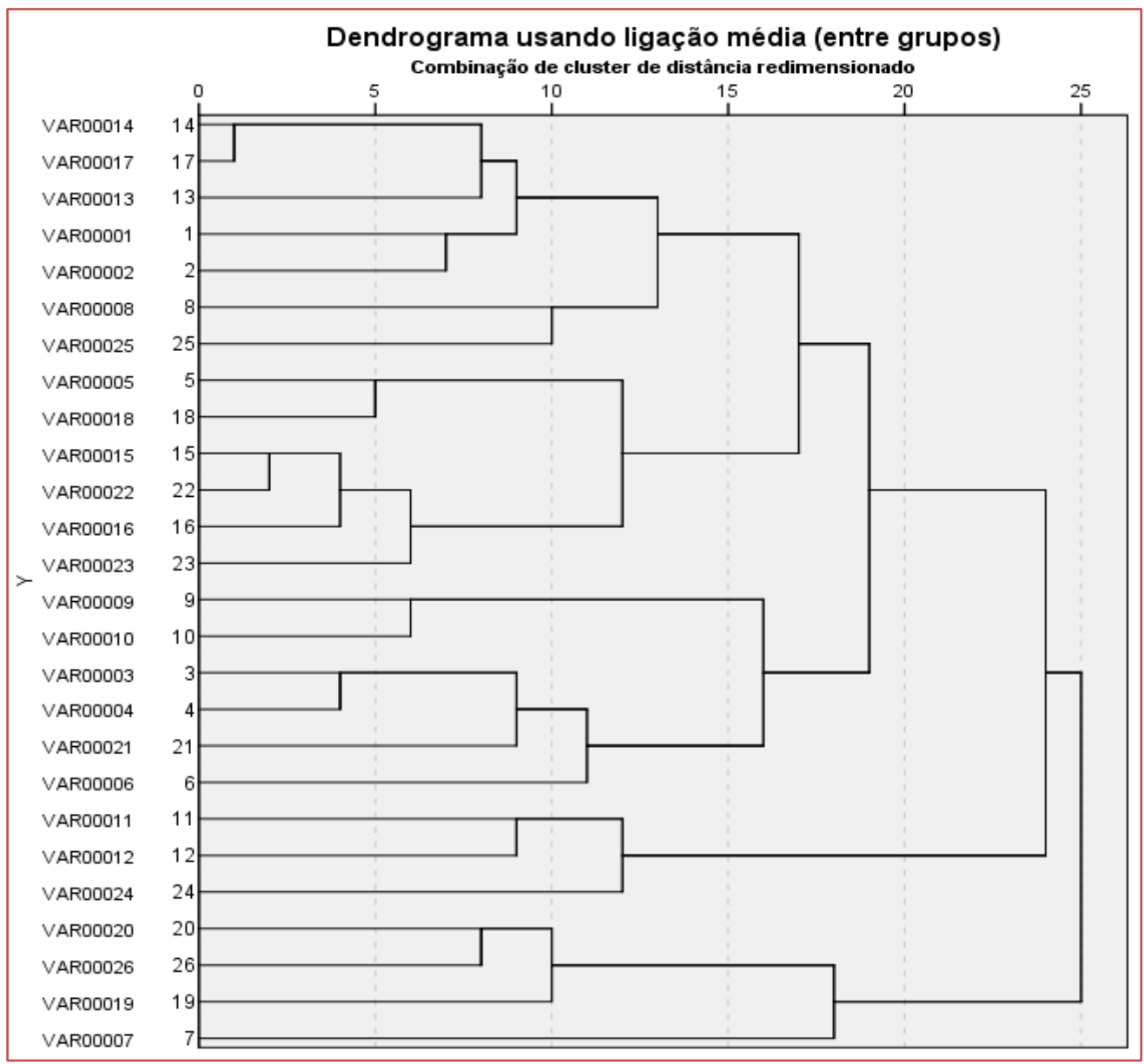

Fonte: Dados da pesquisa

Também foi realizada uma análise fatorial exploratória para buscar a melhor disposição de itens por fatores. Foi realizada análise para um único fator com determinante próximo à zero $(0,01)$, KMO maior que 0,731 e teste de esfericidade de Bartlett significativa, $p<0,0001$. Foi utilizado o método de Extração Análise de Componente Principal e o método de Rotação Varimax com Normalização de Kaiser. A análise fatorial exploratória (Tabela 4.14) mostrou que as variáveis (15) e (16) estão mais distantes das demais, diferente das outras análises. 
Tabela 4.14 Resultados dos fatores dos outliers da pesquisa.

\begin{tabular}{|c|c|}
\hline Fator & Variável \\
\hline 1,5674 & V15 \\
\hline 1,55138 & V24 \\
\hline 1,50265 & V23 \\
\hline 1,08099 & V11 \\
\hline 1,04095 & V20 \\
\hline 0,9675 & V22 \\
\hline 0,93925 & V3 \\
\hline 0,5034 & V25 \\
\hline 0,47306 & V2 \\
\hline 0,445 & V6 \\
\hline 0,1808 & V17 \\
\hline 0,16009 & V21 \\
\hline$-0,0262$ & V1 \\
\hline$-0,15431$ & V4 \\
\hline$-0,40672$ & V26 \\
\hline$-0,46707$ & V13 \\
\hline$-0,52206$ & V19 \\
\hline$-0,59513$ & V18 \\
\hline$-0,6253$ & V10 \\
\hline$-0,70667$ & V12 \\
\hline$-0,8349$ & V14 \\
\hline$-1,05345$ & V5 \\
\hline$-1,27946$ & V9 \\
\hline$-1,42018$ & V8 \\
\hline$-1,48219$ & V7 \\
\hline$-1,66984$ & V16 \\
\hline
\end{tabular}

Fonte: Dados da pesquisa.

\subsection{CONCLUSÕES DAS ANÁLISES DAS TÉCNICAS DE ANÁLISES MULTIVARIADAS}

As análises do Quadro 4.11 apontam que os métodos de análise multivariada - Escalonamento Multidimensional (EMD), Análise de Conglomerados e Análise Fatorial Exploratória -, não tiveram caráter confirmatório como se estabelecia no planejamento da pesquisa, assim adota-se após essas análises um caráter complementar dos métodos, proporcionando uma maior amplitude na seleção das variáveis que irão compor o instrumento final de análise das variáveis que influenciam o ensino e aprendizagem de matemática no Ensino Médio. Portanto, em decorrência destas análises pode-se verificar as variáveis que possuem maior aderência do comportamento dos atributos. 
Quadro 4.10 Variáveis com menor aderência EMD, Análise de Conglomerado e Análise Fatorial Exploratória.

\begin{tabular}{|c|c|c|c|}
\hline \multirow{3}{*}{ Turma } & \multicolumn{3}{|c|}{ Método de Análise Multivariada } \\
\hline & EMD & $\begin{array}{c}\text { Análise de } \\
\text { Conglomerado }\end{array}$ & $\begin{array}{l}\text { Análise Fatorial } \\
\text { Exploratória }\end{array}$ \\
\hline & Variável (is) & Variável (is) & Variável (is) \\
\hline $\begin{array}{c}\text { 1ํ ano Técnico Integrado ao Ensino } \\
\text { Médio de Informática }\end{array}$ & 7,12 e 13 & 7 e 13 & 7 e 25 \\
\hline $\begin{array}{c}\text { 1a ano Técnico Integrado ao Ensino } \\
\text { Médio de Mecânica }\end{array}$ & 12 e 25 & 7,12 e 25 & 4 e 6 \\
\hline $\begin{array}{c}2^{0} \text { ano Técnico Integrado ao Ensino } \\
\text { Médio de Mecânica }\end{array}$ & $7,11,12$ e 25 & $7,11,12$ e 25 & 7 e 11 \\
\hline $\begin{array}{c}\text { 3o ano Técnico Integrado ao Ensino } \\
\text { Médio de Mecânica }\end{array}$ & $7,11,12,20$ e 25 & 7,12 e 25 & 12,20 e 25 \\
\hline $\begin{array}{c}\text { 3º ano Técnico Integrado ao Ensino } \\
\text { Médio de Eletroeletrônica }\end{array}$ & $11,12,20$ e 24 & $11,12,20$ e 24 & 20 \\
\hline População pesquisada & $7,11,12,20$ e 25 & $7,11,12$ e 25 & 11,12 e 25 \\
\hline Outliers & 6 & $7,19,20$ e 26 & 15 e 16 \\
\hline
\end{tabular}

Fonte: Dados da pesquisa.

A partir do Quadro 4.11 com base nos métodos, verifica-se que as variáveis com maior confirmação ou repetibilidade para a população pesquisada são as variáveis (7), (11), (12) e (25) que se referem, respectivamente, a "acreditar que a sua indisciplina atrapalha a aprendizagem de matemática", "ter um sentimento de impotência ao estudar matemática", "gostar de matemática" e "não dar atenção quando o professor esta explicando a matéria e pensar em outras coisas".

Analisando o Quadro $4.11 \mathrm{com}$ base nos métodos em relação aos $1^{\circ}$ anos, verifica-se que as variáveis com maior confirmação ou repetibilidade são as variáveis (7), (12) e (25) que se referem, respectivamente a "acreditar que a sua indisciplina atrapalha a aprendizagem de matemática", "gostar de matemática" e "não dar atenção quando o professor esta explicando a matéria e pensar em outras coisas", porém ao compararmos as três análises (Quadro 4.11) percebemos que estas turmas não tem um comportamento muito uniforme. Ao comparar os $1^{\circ}$ anos com o $2^{\circ}$ ano, de acordo com o Quadro (4.9) percebemos que o $2^{\circ}$ ano tem um comportamento mais uniforme, sendo que as variáveis (7) - "acreditar que a sua indisciplina atrapalha a aprendizagem de matemática" e (11) - "ter um sentimento de impotência ao estudar matemática" se repetem nas três análises. Por outro lado, percebemos que as variáveis (7), (12) e (25) são apontadas nas três análises para os $1^{\text {o }}$ anos e o $2^{\circ}$ ano, o que espelha o resultado ao realizar uma análise da população pesquisada.

Ao analisar o Quadro (4.11) com base nos métodos em relação aos 3o anos, verifica-se que as variáveis com maior confirmação ou repetibilidade são as variáveis (11) e (12) que se referem, respectivamente a "ter um sentimento de impotência ao estudar matemática", "gostar de matemática" e ao compararmos as análises podemos perceber que estas turmas tem um comportamento mais uniforme com relação as variáveis que influenciam o ensino e a aprendizagem de matemática no Ensino Médio. Também é interessante notar que no $3^{\circ}$ ano Técnico Integrado ao Ensino Médio de Mecânica as variáveis (12) - "gostar de matemática" e (25) - "não dar atenção quando o professor esta explicando a matéria e pensar em outras coisas" se repetem nas três análises. Já no $3^{\text {o }}$ ano Técnico Integrado ao Ensino Médio de Eletroeletrônica a variável (20) "buscar algum profissional fora da sala de aula para aprender matemática" se repete nas três análises.

Ao comparar-se os $1^{\circ}$ anos com os $3^{\circ}$ anos percebe-se que os $3^{\circ}$ anos tem um comportamento mais uniforme que os $1^{\circ}$ anos, mas a variável (12) - "gostar de matemática" foi apontada nas análises em 
ambas as turmas, o que se espelha no comportamento de toda população pesquisada. Comparando o $2^{\circ}$ ano com os $3^{\circ}$ anos percebemos que as duas salas têm um comportamento mais uniforme em relação as análises e que a variável (11) - "ter um sentimento de impotência ao estudar matemática" foi apontada nas análises em ambas as turmas.

Ao analisar os outliers é possível perceber que nas três análises não há um padrão das variáveis apontadas e que estas variáveis são diferentes das variáveis apontadas na análise geral da população e nas análises das turmas.

\subsection{BREVE RESUMO DO CAPÍTULO}

Neste capítulo foram apresentadas as análises e discussões dos dados referentes as variáveis que influenciam o ensino e a aprendizagem de matemática no Ensino Médio por meio das seguintes técnicas estatísticas multivariadas: Escalonamento Multidimensional, Análise de Conglomerado e Análise Fatorial Exploratória. 


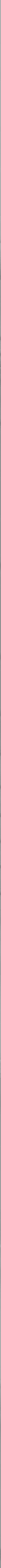


Este capítulo final tem como objetivo sistematizar as conclusões e considerações finais deste estudo. Inicia-se pelas principais conclusões do trabalho, seguidas das considerações finais sobre a proposta desenvolvida. O capítulo é finalizado com as limitações da pesquisa e sugestões de trabalhos futuros.

\subsection{CONCLUSÕES}

A partir das análises e discussões dos resultados são estabelecidas as conclusões deste trabalho.

Para o desenvolvimento deste trabalho estabeleceu-se como problema de pesquisa: "Quais variáveis influenciam o ensino e a aprendizagem de matemática no Ensino Médio em uma Escola Técnica Federal?". A partir da problemática investigada foi atingido o objetivo geral estabelecido, ou seja, foram identificadas e analisadas as variáveis que contribuem e influenciam o ensino e a aprendizagem de matemática no Ensino Médio em uma Escola Técnica Federal. Os objetivos específicos delimitados a partir do objetivo geral do trabalho foram atingidos, tendo em vista o seguinte:

$\mathrm{Na}$ literatura foram levantados os aspectos teóricos relativos ao ensino e aprendizagem de matemática em geral e no ensino médio, além de especificamente em uma Escola Técnica Federal;

A partir do referencial teórico foram levantados e apontados os possíveis aspectos que influenciam o ensino e a aprendizagem de matemática e a partir disto foi elaborado um instrumento de pesquisa que contou com 26 questões. Também foram descritos os aspectos estudados neste trabalho para compreensão de cada um e de sua influência no processo de ensino e aprendizagem de matemática no Ensino Médio. O instrumento de coleta de dados também contou com 5 questões para a caracterização da amostra pesquisada. Esta amostra forram todos os alunos matriculados no Ensino Médio do IFSP - câmpus Bragança Paulista, sendo que apenas os alunos que estavam ausentes no dia da coleta de dados não responderam o questionário;

As análises da pesquisa dos dados obtidos a partir da aplicação de questionários com os alunos no âmbito da escola pesquisada foram realizadas com três técnicas estatísticas multivariadas, o Escalonamento Multidimensional (EMD), a Análise de Conglomerados e a Análise Fatorial Exploratória e os dados foram analisados por turma, para a população em geral e para os outliers desta pesquisa. Essas técnicas subsidiaram a triagem das variáveis mais relevantes e com maior aderência pelos alunos nos atributos analisados e a partir disto percebeu-se que 5 variáveis mostraram menor relevância, sendo que desta forma restaram 20 variáveis que mostraram maior relevância e aderência para a amostra pesquisada. Em decorrência da aplicação das técnicas foi possível fazer uma triagem do número de variáveis significativas.

Conclui-se, portanto, que a proposta deste trabalho foi atingida.

\subsection{CONSIDERAÇÕES FINAIS}

Diante do exposto, após o delineamento e execução são estabelecidas às considerações finais deste trabalho, que são:

O processo de ensino e aprendizagem é muito complexo e por isso é muito importante que este seja estudado constantemente de maneira a ser sempre aprimorado, melhorando e facilitando o ensino para o professor e a aprendizagem para os alunos. A matemática é uma disciplina escolar, mas se encontra presente na vida do ser humano desde seu nascimento, porém normalmente só é vista de maneira formal na escola, sendo assim muito importante saber o que pode influenciar seu processo de ensino e aprendizagem. O Ensino Médio é a etapa final da educação básica e deve preparar o aluno para o mercado de trabalho, para sua vida e para continuar estudando, portando precisa oferecer uma educação de qualidade para que os alunos possam efetivamente ter uma oportunidade de escolha e decidir o que querem para seu futuro. As Escolas Técnicas Federais fazem parte da rede pública de ensino, entretanto vivem uma situação diferente das demais escolas públicas, sendo assim importante ser pesquisada. 
Após o levantamento bibliográfico foram apontados os itens que podem influenciar o ensino e a aprendizagem de matemática no Ensino Médio em uma Escola Técnica Federal e a partir destes foi elaborado um questionário para o levantamento de dados para a pesquisa.

Embora existam muitas variáveis que influenciam o ensino e a aprendizagem de matemática no Ensino Médio em uma Escola Técnica Federal, o trabalho conseguiu por meio das técnicas de análise multivariadas - Escalonamento Multidimensional, Análise de Conglomerados e Análise Fatorial Exploratória - identificar aquelas que são mais relevantes, que após a análise se enquadram em duas categorias - indisciplina e relação sócio cultural - dos itens que podem influenciar o ensino e a aprendizagem de matemática.

A partir destas variáveis levantadas é possível para professores, alunos e demais envolvidos no processo de ensino aprendizagem refletir sobre os aspectos que podem influenciar, positiva ou negativamente, o processo de ensino e aprendizagem e assim buscar sempre a melhor maneira para que este processo seja eficiente e eficaz, proporcionando ao aluno a melhor educação possível. Percebe-se que as hipóteses levantadas foram comprovadas.

Concluiu-se também que na análise dos outliers não há um padrão, para as três análises realizadas, das variáveis apontadas e que estas variáveis são diferentes das variáveis apontadas na análise geral da população e nas análises por turma.

\subsection{LIMITAÇÕES DA PESQUISA}

Esse trabalho se limitou a analisar as variáveis que influenciam o ensino e a aprendizagem de matemática no Ensino Médio em uma Escola Técnica Federal, não sendo objetivo do trabalho analisar as variáveis que influenciam o ensino e a aprendizagem de matemática em outros âmbitos.

Outra limitação foi pesquisar apenas alunos de uma Escola Técnica Federal, que são apenas uma parte do número de alunos do Ensino Médio na rede pública de ensino.

\subsection{PROPOSTA DE TRABALHOS FUTUROS}

Em decorrência da pesquisa realizada e das variáveis levantadas sugere-se que em trabalhos futuros:

Seja pesquisado no âmbito das escolas públicas de modo geral e das escolas privadas;

Realizar uma pesquisa análoga a esta com alunos do Ensino Fundamental;

Realizar uma pesquisa envolvendo a percepção do professor a respeito das varáveis que influenciam o ensino e a aprendizagem de matemática; e,

Analisar outras variáveis que influenciam o ensino e a aprendizagem de matemática no ensino médio que não foram pesquisadas neste trabalho. 


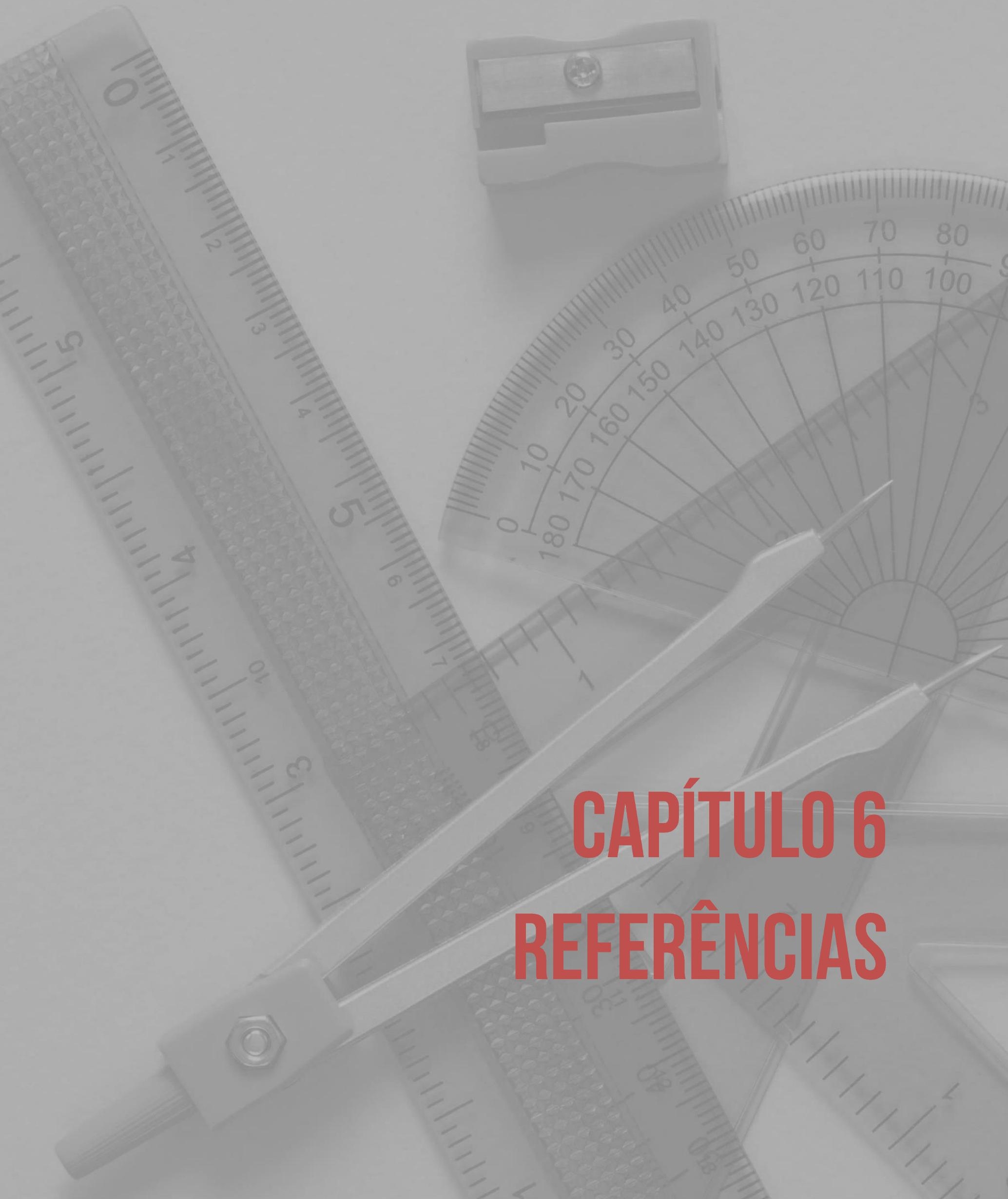




\section{REFERÊNCIAS}

[1]. AIRES, L. Disciplina na Sala de Aulas: um guia de boas práticas para professores do $3^{\circ}$ ciclo do Ensino Básico e Ensino Secundário. Lisboa: Edições Silabo, 2010. 96p

[2]. ABREU, M. C; MASSETO, M. T. O professor universitário em sala de aula: prática e princípios teóricos. São Paulo: MG Ed. Associados, 1996. In: SANTOS, Sandra C. dos. O Processo de Ensino-Aprendizagem e a Relação ProfessorAluno: aplicação dos "sete princípios para a boa prática na educação de ensino superior". Caderno de Pesquisas em Administração, São Paulo, v. 08, n. 1 2001. Disponível em: <http://regeusp.com.br/arquivos/v08-1art07.pdf >. Acesso em: 1 mai. 2015.

[3]. ALCARÁ, Adriana R.; GUIMARÃES, Sueli E. R. A Instrumentalidade como uma estratégia motivacional. Psicologia Escolar Educacional, Paraná, v. 11, n. 1, 2007. p. 177-178.

[4]. ARRUDA, S. M. Entre a Inércia e a Busca: reflexões sobre a formação em serviço de professores de física do ensino médio. 2001. 238 f. Tese (Doutorado em Educação). Universidade de São Paulo, São Paulo-SP. Disponível em: $<$ http://www.teses.usp.br/teses/disponiveis/48/4813 3/tde-05032002-132057/publico/TDE.pdf>. Acesso em: 28 mar. 2015.

[5]. BAKER, J. A. Contributions of teacher: child relationships to positive school adjustment during elementary school. Journal of School Psychology. 2008. p. 211-229. Disponível em: $<$ https://www.gse.harvard.edu/sites/default/files/uk/ Teacher-Child-Relationship.pdf>. Acesso em: 28 mar. 2015

[6]. BARBOSA, Altemir José Gonçalves; CAMPOS, Renata Araújo; VALENTIM, Tássia Azevedo. A Diversidade em Sala de Aula e a Relação Professor-Aluno. Estudos psicologia. v.28, n.4, Campinas. 2011. p. 453-461. Disponível em: <http://www.scielo.br/pdf/estpsi/ v28n4/06.pdf>. Acesso em: 1 mai. 2015.

[7]. BEM, Judite Sanson de; GIACOMINI, Nelci Maria Richter. Gastos em cultura no Rio Grande do Sul e a delimitação de área homogêneas em municípios selecionados no ano de 2007. In: Anais... ENCONTRO NACIONAL DA ASSOCIAÇÃO BRASILEIRA DE ESTUDOS REGIONAIS E URBANOS, VII., 2007, São Paulo, p. 1-18. Disponível em: <http://aplicativos.fipe.org.br/enaber/pdf/90.pdf>. Acesso em: 14 nov. 2015.

[8]. BIRCH, S. H.; LADD, G. W. The TeacherChild Relationship and Children's Early School Adjustment. Journal of School Psychology. 1997. p. 61-79. Disponível em: <http://www.sciencedirect.com/science/article/pii/S 0022440596000295>. Acesso em: 28 mar. 2015.

[9]. BRASIL. Constituição da Republica Federativa do Brasil (1988). Lex: Legislação
Federal e Educação. Disponível em: <http://www.planalto.gov.br/ccivil_03/constituicao /constituicaocompilado.htm>. Acesso em: 28 ago. 2014.

[10]. L L Lei № 9.349, de 20 de dezembro de 1996. Lex: Lei de Diretrizes e Bases da Educação Nacional. Disponível em: <http://www.planalto.gov.br/ccivil_03/leis/19394.htm >. Acesso em: 28 ago. 2014.

[11]

Lei $\mathrm{n}$ ․ 11.274 , de 6 de fevereiro de 2006. Altera a redação dos arts. 29, 30, 32 e 87 da Lei no 9.394, de 20 de dezembro de 1996, que estabelece as diretrizes e bases da educação nacional, dispondo sobre a duração de 9 (nove) anos para o ensino fundamental, com matrícula obrigatória a partir dos 6 (seis) anos de idade. Disponível <http://www.planalto.gov.br/ccivil_03/_Ato2004006/2006/Lei/L11274.htm\#art3>. Acesso em: 10 mar. 2015.

[12]. Ministério da Educação. Secretaria de Educação Fundamental. Parâmetros Curriculares Nacionais: matemática. Brasília, 1997.

[13] Ministério da Educação. Secretaria de Educação Média e Tecnológica. Parâmetros Curriculares Nacionais (Ensino Médio). Brasília: MEC, 2000. Disponível em: $<$ http://portal.mec.gov.br /seb/arquivos /pdf/ciencian.pdf>. Acesso em: 17 ago. 2014.

[14]. Ministério da Educação. Diretrizes Curriculares Nacionais para o Ensino Médio. Parecer: CEB 15/98, Junho, 1998.

[15]. Ministério da Educação. Sistema Nacional de Educação Básica - SAEB. Brasília,

[16]. 2001.

[17]. Parecer CNE/CP 9/2001, de 17 de janeiro de 2002. Estabelece as Diretrizes Curriculares Nacionais para a formação de professores da educação básica, em nível superior, curso de licenciatura, de graduação plena. Diário oficial da União, poder executivo, Brasília, DF, 18 jan.2002. Seção 1, p.31.

[18]. _ Proposta em Discussão: Políticas Públicas para a Educação Profissional e Tecnológica. Brasília: Secretaria de Educação Profissional e Tecnológica, Ministério da Educação, 2004.

[19]. BROPHY, J. Research on Motivation in Education: past, present, and future. In: T. Urdan (Ed.). Advances in Motivation and Achievement: achievement contexts. v.11, p.1-44. Greenwich: $1998 . \quad$ Disponível em: <http://publish.uwo.ca/ gardner/docs/GardnerPubli c Lecture1.pdf>. Acesso em: 28 mar. 2015.

[20]. BORUCHOVITCH, Evely; ALENCAR, Eunice M. L. Soriano de; FLEITH, Denise de Souza; FONSECA, Marília Saldanha da. Motivação do 
Aluno para Aprender: fatores inibidores segundo gestores e coordenadores pedagógicos. ETD Educação Temática Digital, Campinas, SP, v. 15, n. 3, 2013. p. 425-442. Disponível em: <https://www.fe.unicamp.br/revistas/ged/etd/article/ view/5529>. Acesso em: 1 mai. 2015.

[21]. BORUCHOVITCH, E. A Motivação do Aluno. Rio de Janeiro: Editora Vozes, 2009. 184 p.

[22]. BULLOUGH, R. V.. Becoming a Teacher: self and the social location of teacher education. In: B. J. Biddle, T. L. Good e I. F. Goodson (Eds.), International handbook of teachers and teaching. Dordrecht: Kluwer Academic Publishers. 1997, p. 79-134. Disponível em: <http://link.springer.com/chapter/10.1007\%2F97894-011-4942-6_3\#page-1>. Acesso em: 28 mar. 2015.

[23]. BEHRENS, M. A. O Paradigma Emergente e a Prática Pedagógica. 3. ed. Curitiba: Champagnat: 2003, 120 p.

[24]. CERON, Jussara Cristina Mayer. Educação Matemática: desafios para o cotidiano de professoras alfabetizadoras das séries iniciais do ensino fundamental. 2004. 187 f. Dissertação (Mestrado em Educação). Faculdades Integradas Católicas de Palmas (FACIPAL), Palmas - PR.

[25]. CHACÓN, I. Matemática emocional: os afetos na aprendizagem matemática. Porto Alegre: Artmed: 2003. 255p.

[26]. CODO, Wanderley. Educação: carinho e trabalho. Petrópolis, RJ: Vozes; Brasília: Confederação Nacional dos Trabalhadores em Educação / Universidade de Brasília - Laboratório de Psicologia do Trabalho, 1999. 432p.

[27]. D’AMBROSIO, Ubiratan. Etnomatemática: elo entre as tradições e a modernidade. Belo Horizonte: Autêntica, 2001. 110p.

[28]. ECCHELI, Simone Deperon. A Motivação como Prevenção da Indisciplina. Educação em Revista. Curitiba, n. 32, 2008. p. 199-213. Disponível em: <http://www.scielo.br/ scielo.php?script=sci_arttext\&pid=S010406020080 00200014\&Ing=en\&nrm=iso $>$. Acesso em: 1 mai. 2015.

[29]. ESTRELA, M. T. Relação Pedagógica, Disciplina e Indisciplina na Aula. Porto: Porto Editora, 2002. 160p.

[30]. ESCOTT, Clarice Monteiro; MORAES, Márcia Amaral Correa de . História da Educação Profissional no Brasil: as políticas públicas e o novo cenário de formação de professores nos institutos federais de educação, ciência e tecnologia. Anais... IX Seminário Nacional de Estudos e Pesquisas "História, Sociedade e Educação no Brasil”, João Pessoa, 2012. Disponível em: <http://www.histedbr.fe.unicamp.br/acer_histedbr/s eminario/seminario9 /PDFs/2.51.pdf>. Acesso em: 10 de abr. 2015.
[31]. FARIA, Cleyciane Alves de. Aplicação do escalonamento multidimensional ao julgamento e classificação de conceitos emocionais. 2006. 243 f. Dissertação de Mestrado em Psicologia. Universidade Federal de Uberlândia, Uberlândia, MG.

[32]. FÁVERO, Luiz Paulo Lopes et al. Análise Fatorial e Análise de Conglomerados para Determinação de Clusters em Empresas de Internet no Brasil. In: International Conference on Information Systems and Technology Management. São Paulo, SP, 2005. 16 p.

[33]. FETZER, Fernanda. As Quatro Operações Aritméticas: ensino e aprendizagem numa perspectiva conceitual. Anais... XIII Conferencia Interamericana de Educación Matemática (CIAEMIACME), Recife, Brasil, 2011, p. 37-53. Disponível em: $\quad<$ http://www.lematec.noip.org/CDS/XIIICIAEM/artigos/632.pdf>. Acesso em: 18 mar. 2015.

[34]. FILHO, Dalson Brito Figueiredo; SILVA JÚNIOR, José Alexandre da. Visão além do alcance: uma introdução à análise fatorial. Opinião Pública, v. 16, n. 1, 2010. p. 164-185.

[35]. FIORENTINI, Dario; LORENZATO, Sérgio. A Educação Matemática como Campo Profissional e Científico. p. 3-13 In: FIORENTINI, Dario; LORENZATO, Sérgio. Investigação em Educação Matemática: percursos teóricos e metodológicos 3ed. rev. Campinas, SP: Autores associados, 2009, $226 \mathrm{p}$.

[36]. FIORENTINI, Dario, MIORIM, Maria Ângela. Uma Reflexão sobre o Uso de Materiais Concretos e Jogos no Ensino da Matemática. Boletim SBEM-SP. São Paulo, ano 4, n.7, 1990. p. 5-10. Disponível em: <http://drbassessoria.com.br/1Umareflexaosobreousodemater iaisconcretosejogosnoEnsinodaMatematica.pdf>. Acesso em: 1 mai. 2015.

[37]. FREIRE, Paulo. Pedagogia do Oprimido. 36. ed. Rio de Janeiro: Edições Paz e Terra, 2003. $256 p$.

[38]. GARCÍA, Carlos Marcelo. Formação de Professores: para uma mudança educativa. Porto: Porto Editora, 1999a. 272p.

[39]. GARCIA, J. Indisciplina na escola: uma reflexão sobre a dimensão preventiva. Revista Paranaense de Desenvolvimento, Curitiba, n. 95, p. 101-108, jan./abr. 1999b.

[40]. GIMENO, José; PÉREZ, Gómez Angel I. Compreender e Transformar o Ensino. 4. ed. Porto Alegre, RS: Artes Médicas, 1998. 400p.

[41]. GIL, Antonio Carlos. Como Elaborar Projeto de Pesquisa. 4. ed. São Paulo: Atlas, 2002. $175 p$.

[42]. GODOY, Elenilton Vieira. A Matemática no Ensino Médio: a trajetória brasileira desde a década de 80 e as organizações curriculares de outros países. Revista Práxis educacional. v. 6, n. 
9. Vitória da Conquista, 2010. p. 1-24. Disponível em: $\quad<$ http://periodicos.uesb.br/index.php/ praxis/article/viewFile/428/455>. Acesso em: 2 fev. 2015.

[43]. GOYA, Alcides; BZUNECK, José Aloyseo; GUIMARAES, Sueli Édi Rufini. Crenças de Eficácia de Professores e Motivação de Adolescentes para Aprender Física. Psicologia Escolar Educacional, vol. 12, n.1. 2008. p. 51-67. Disponível em: $<$ http://www.scielo.br/pdf/pee/v12n1/v12n1a05.pdf >. Acesso em: 1 mai. 2015.

[44]. GOUVÊA, Maria Aparecida; PREARO, Leandro Campi; ROMEIRO, Maria do Carmo. Avaliação da adequação de aplicação de técnicas multivariadas em estudos do comportamento do consumidor em teses e dissertações de duas instituições de ensino superior. Revista de Administração, v. 47, n. 2, 2012. P. 336-355.

[45]. HAMRE, B.K.; PIANTA, R.C.; DOWNER, J.T.; MASHBURN, S.J. Teachers' Perceptions of Conflict with Young Students: looking beyond problem behaviors. Social Development, v. 17, 2008. p. 118-134. Disponível em: <http://onlinelibrary.wiley.com/doi/10.1111/j.14679507.2007.00418.x/abstract?deniedAccessCustomi sedMessage $=$ \&userlsAuthenticated $=$ false $>$. Acesso em: 8 mai. 2015.

[46]. HARGREAVES, Andy. Revisiting Voice. Educational Researcher, v. 25, n. 1, p12-19 Sage Publications 1996.

[47]. Instituto Nacional de Estudos e Pesquisas Educacionais Anísio Teixeira. Índice de Desenvolvimento da Educação Básica (IDEB) 2005/2017. Disponível em: <http://ideb.inep.gov.br/resultado/resultado/resulta doBrasil. seam?cid=2870786 $>$. Acesso em: 17 ago. 2018.

[48]. LAKATOS, Eva Maria; MARCONI, Marina de Andrade. Metodologia Científica. 2. ed. São Paulo: Atlas, 2010. 247p.

[49]. LAKATOS, Eva Maria; MARCONI, Marina de Andrade. Fundamentos de metodologia científica. 5. ed. São Paulo: Atlas. 2003. 310 p. Disponível em:<http://docente. ifrn.edu.br/olivianeta/disciplinas/copy_of_historiai/historia-ii/china-e-india>. Acesso em 2 jun. 2015.

[50]. LEITE, Dante Moreira. Educação e Relações Interpessoais. In: PATTO, M. H. S. Introdução à Psicologia Escolar. São Paulo: T. A. Queiróz, 1993. p.234-257. Disponível em: <https://books.google.com.br/books?hl=pt$B R \& \mid r=\& i d=k r d 6 z h q i h 88 C \& o i=f n d \& p g=$

PA11\&dq $=$ PATTO,+ M. + H. + S. + Introdu $\%$ C3\%A7\%C $3 \% \mathrm{~A} 30+\% \mathrm{C} 3 \% \mathrm{~A} 0+$ psicologia + escolar.$\&$ ots $=\mathrm{DTiiZ}$ B5nha\&sig=UG2LQLFZitlJ6A7K6Vf6frnxZPk\#v=one page\&q=PATTO\%2C\%20M.\%2OH. \%20S.\%2OIntro du\%C3\%A7\%C3\%A30\%20\%C3\%A0\%20psicologia \%20escolar.\&f=false>. Acesso em: 28 mar. 2015.

[51]. LENS, Willy; MATOS, Lennia; VANSTEENKISTE, Marten. Professores como
Fontes de Motivação dos Alunos: o quê e o porquê da aprendizagem do aluno. Revista Educação, Porto Alegre, v. 31, n. 1. p. 17-20, 2008 Disponível em: $\quad<$ http://revistaseletronicas.pucrs. br/ojs/index.php/faced/article/view/2752 >. Acesso em: 28 mar. 2015.

[52]. LIMA, M.S.L. Estágio e Aprendizagem da Profissão Docente. Brasília: Liber Livro, 2012. $171 \mathrm{p}$.

[53]. LOPES, Claudivan Sanches. A Violência no Espaço Escolar e a Relação Professor-Aluno. Dissertação (Mestrado em Educação). Universidade Estadual de Maringá, Maringá, 2001. Disponível em: < http://observatoriogeograficoamericalatina.org.mx/e gal11/Geografiasoci

oeconomica/Geografiacultural/13.pdf>. Acesso em: 28 mar. 2015.

[54]. LOPES, Celi Espasandin. Os Desafios e as Perspectivas para a Educação Matemática no Ensino Médio. In: A Educação Matemática no Ensino Médio. Anais... Sessão Trabalho Encomendado - Associação Nacional de PósGraduação e Pesquisa em Educação, Goiania, $2011 . \quad$ Disponível em: <http://www.ufrrj.br/emanped/noticia/docs/TextosG T 19Anped2011_Trab Encomendado.pdf>. Acesso em: 28 ago. 2014

[55]. LOURENCO, Abílio Afonço; PAIVA, Maria Olímpia A. de. A Motivação Escolar e o Processo de Aprendizagem. Ciências cognitivas [online]. v. 15, n. 2, 2010. p. 132-141.

[56]. MALHOTRA, Naresh K. Pesquisa de marketing: uma orientação aplicada. 6. ed. Porto Alegre: Bookman, 2012. 736p.

[57]. MARX, K.; ENGELS, F. A Ideologia Alemã. São Paulo: Grijalbo, 1977. 616p.

[58]. MARTINI, M.L. Promovendo a Motivação do Aluno: contribuições da teoria da atribuição de causalidade. Psicologia Escolar Educacional. Campinas, v. 12, n. 2, 480 p., Dez. 2008. Disponível em: $<$ http://www.scielo.br/scielo.php?script=sci_arttext \&pid=S1413-

$85572008000200022 \& \operatorname{lng}=e n \& n r m=i s o>$. Acesso em: 15 mai. 2015.

[59]. MARIUCI, Sérgio; FERRI, Maricia da Silva; FELICETTI, Vera Lúcia. Uma Sombra na Educação Brasileira: do ensino regular ao paralelo. Anais... IX ANPED SUL, Caxias do Sul, 2012. Disponível em: <http://www.ucs.br/etc/conferencias/index.php/anp edsul/9anpedsul/ paper/viewFile/506/115>. Acesso em: 10 de nov. 2015

[60]. MELLO, GUIOMAR NAMO DE. Formação Inicial de Professores para a Educação Básica: uma (re)visão radical. São Paulo Perspectiva. [online], São Paulo, v. 14, n. 1, p. 98110, mar. 2000. Disponível em: < http://www.scielo.br/pdf/spp/v14n1/9807.pdf> Acesso em: 1 mai. 2015. 
[61]. MIGUEL, J. C.. O ensino de Matemática na Perspectiva da Formação de Conceitos: implicações teórico-metodológicas. In: PINHO, Sheila Zambello de; SAGLITTI, José Roberto Corrêa. (org). Núcleos de Ensino - PROGRAD UNESP. I ed. São Paulo - SP: Editora UNESP, 2005. 394. $p$.

[62]. MORALES, Pedro Vallejo. A Relação Professor-Aluno O Que É, Como Se Faz. São Paulo. Editorial e Distribuidora, 2001. 167 p.

[63]. MORAN, José. Ensino e Aprendizagem Inovadores com Tecnologias Audiovisuais e Telemáticas. In: MORAN, J., MASETTO, M. e BEHRENS, M. Novas Tecnologias e Mediação Pedagógica. Campinas, SP: Papirus, 2000. 176 p.

[64]. Ensino e Aprendizagem Inovadores com Tecnologias. Revista Informática na Educação: Teoria \& Prática, Porto Alegre, v. 3, n.1, 2000. p. 137-144

[65]. MOURA, M. O. de. A Atividade de Ensino Como Ação Formadora. In: CASTRO, A. D.; CARVALHO, A. M. P. de. (Org.). Ensinar a Ensinar: didática para a escola fundamental e média. São Paulo: Pioneira Thompson, 2002. 196 p.

[66]. MOURA, Manoel Oriosvaldo de; ARAÚJO, Elaine Sampaio; MORETTI, Vanessa Dias; PANOSSIAN, Maria Lúcia; RIBEIRO, Flávia Dias. Atividade Orientadora de Ensino: unidade entre ensino e aprendizagem. Revista Diálogo Educacional. Curitiba, v. 10, n. 29, p. 205-229, jan./abr. 2010. Disponível em: <http://www2.pucpr.br/reol/pb/index.php/ dialogo?dd1=3432\&dd99=view\&dd98=pb>. Acesso em: 31 mar. 2015

[67]. NACARATO, Adair Mendes. Eu Trabalho Primeiro no Concreto. Revista de Educação Matemática, São Paulo, v.9, n. 9, 2005. P. 1-6.

[68]. NEUBAUER, Rose; DAVIS ,Cláudia; TARTUCE, Gisela Lobo B. P.; NUNES. Marina M. R. Ensino Médio no Brasil: uma análise de melhores práticas e de políticas públicas. Brasília, Revista Brasileira de Estudos Pedagógicos (RBEP), v. 92, n. 230, 2011. p. 9-10.

[69]. NÉRICI, Imídeo Giuseppe. Didática: uma introdução. São Paulo: Atlas, 1993. 120p.

[70]. NEVES, J. L. Pesquisa Qualitativa: características, usos e possibilidades. Caderno de Pesquisas em Administração, São Paulo, v. 1, n. 3, 1996. p. 1-5.

[71]. OLIVEIRA, Hélia. Percursos de Identidade do Professor de Matemática em Início de Carreira: o contributo da formação inicial. Lisboa: Quadrante, 2004. 145p. Disponível em: <https://repositorio.ul.pt/bitstream/10451/6963/1/Qu adrantePercursosldentidade.pdf $>$. Acesso em 1 mai. 2015

[72]. OLIVEIRA, Isolina; SERRAZINA, Lurdes. A Reflexão E O Professor como Investigador. Lisboa: 2002. $42 \mathrm{p}$.
[73]. OLIVEIRA, Alessandro Fábio Fonseca de. Dificuldades de Aprendizagem da Matemática: Leitura e Escrita Matemática. Anais... II Encontro Regional de Educação Matemática. SBEM. 2009. Disponível

em: <http://www.sbemrn.com.br/site/ll\%20erem/comuni ca/doc/ comunica1.pdf>. Acesso em: 21 mar. 2015

[74]. PAIS, Luiz Carlos. Ensinar e Aprender Matemática. Belo Horizonte: Autêntica, 2006. 152p.

[75]. PACHECO, Eliezer. Os Institutos Federais: uma revolução na educação profissional e tecnológica. Brasília: MEC/SETEC, 2010. 120p. Disponível em: <http://www.moderna.com.br/lumis/portal/file/fileDo wnload. jsp?fileld=8A7A83CB34572A4A01345BC3 D5404120>. Acesso em: 21 mar. 2015.

[76]. PEREIRA, Júlio César Rodrigues. Análise de dados qualitativos: estratégias metodológicas para as ciências da saúde humanas e sociais. São Paulo: Edusp, 1999. 223p.

[77]. PINTO, Jefferson de Souza; Variáveis dos Atributos Complexidade e Incerteza em Projetos: proposta de criação de Escala de Mensuração. 2012. 216f. Tese (Doutorado em Engenharia Mecânica). Faculdade de Engenharia Mecânica, Universidade Estadual de Campinas, Campinas SP.

[78]. PINTO, Antonio Henrique; Santos, Marina Gomes dos. A Matemática nas Escolas Técnicas Federais: um acessório seguro e importante no trabalho. Anais... IX Seminário Nacional de História da Matemática. 2011. Disponível em: <http://www.each.usp.br/ixsnhm/Anaisixsnhm/Com unicacoes/1_Pinto_A_H_Matem\%C3\%A1tica_nas_ Escolas_T\%C3\%A9cnicas_Federais.pdf>. Acesso em: 12 fev. 2015

[79]. PIROLA, Sandra Mara Fulco. As Marcas da Indisciplina na Escola: caminhos e descaminhos das práticas pedagógicas. Tese (Doutorado em Educação Escolar), Faculdade de Ciências Humanas, Programa de Pós- Graduação em Educação, Universidade Metodista de Piracicaba. Piracicaba, 2009. 155f. Disponível em: $<$ https://www.unimep.br/phpg/bibdig/pdfs/2006/OT PCSWFGHKVR.pdf>. Acesso em: 28 mar. 2015.

[80]. PIROLA, Sandra Mara Fulco; FERREIRA, Maria Cecília Carareto. O Problema da Indisciplina dos Alunos: um olhar para as práticas pedagógicas cotidianas na perspectiva de formação continuada de professores. Olhar de Professor, Universidade Estadual de Ponta Grossa, Ponta Grossa, v. 10, n. 002, p.81-99. Disponível em:<http://www.eventos.uepg.br/ojs2/index.php/olh ardeprofessor/article/view/ 1489/1134>. Acesso em: 19 mai. 2015.

[81]. PREARO, Leandro Campi. O uso de técnicas estatísticas multivariadas em dissertações e teses sobre o comportamento do consumidor: um estudo exploratório. 2008. 198f. Tese de Doutorado. Universidade de São Paulo. 
[82]. REBOLO, Flavinês. Professores Retirantes: um estudo sobre a evasão de professores do magistério público do estado de São Paulo. 1999. Dissertação (Mestrado em Educação) - Faculdade de Educação, Universidade de São Paulo, 1999. $167 f$. Disponível em: $<$ http://www.worldcat.org/title/professoresretirantes-um-estudo-sobre-a-evasao-deprofessores-do-magisterio-publico-do-estado-desao-paulo/oclc/55929236>. Acesso em: 28 mar. 2015

[83]. REBOLO, Flavinês; NOGUEIRA, Eliete Jussara; SOARES, Maria Lúcia de Amorim .As Entrelinhas Da Relação Professor-Aluno: notas para se pensar o bem-estar e o mal-estar docente para se pensar o bem-estar e o mal-estar docente na contemporaneidade na contemporaneidade. SérieEstudos - Periódico do Programa de PósGraduação em Educação da UCDB. Campo Grande-MS, n. 29, 120p., 2010. Disponível em: <http://www.serie-estudos.ucdb.br/index.php/serieestudos/article/view/143/70>. Acesso em: 28 mar. 2015.

[84]. RESENDE, Giovane; MESQUITA, Maria da Gloria Bastos de Freitas. Principais Dificuldades Percebidas no Processo Ensino-Aprendizagem de Matemática em Escolas do Município de Divinópolis (MG). Revista Educação Matemática Pesquisa. São Paulo, v.15, n.1, 2013. p. 199-222. Disponível

$<$ http://revistas.pucsp.br/index.php/emp/ar ticle/view/9841>. Acesso em: 12 fev. 2015

[85]. ROCHA, Lenice Mirandola da; GUELLER, Marlise. Aprendizagem em Matemática: Comprometimento dos Alunos. Anais... VI Congresso Internacional de Ensino da Matemática, 2013a. Disponível em: <http://www.conferencias.ulbra.br/index.php/ciem/ vi/paper/viewFile/1375/242>. Acesso em: 29 mar. 2014.

[86]. ROCHA, Lenice Mirandola da; GUELLER, Marlise. Fatores que Permeiam o Comprometimento dos Alunos na Aprendizagem da Matemática. Anais... I Congresso de Educación Matemática de América Central y El Caribe. República Dominicana, 2013b. Disponível em: <http://www.centroedumatematica.com/memoriasicemacyc/442-545-6-DR-C.pdf>. Acesso em: 29 set. 2014.

[87]. RODRIGUES, N. Por Uma Nova Escola: o transitório e o permanente na educação. 11. ed. São Paulo: Cortez, 1997. 120p.

[88]. RONCO, A.; PAULA, J.; SILVA, A.; GONÇALVES, F. Os aspectos da indisciplina educacional. Revista Augustus, Rio de Janeiro, v. 16, n. 32, 2011, p. 11-22. Disponível em: $<$ http://apl.unisuam.edu.br/revistas /index.php/revistaaugustus/article/view/37>. Acesso em: 1 mai. 2015.

[89]. RUBTSOV, V. A Atividade de Aprendizado e os Problemas Referentes à Formação do
Pensamento Teórico dos Escolares. In: GARNIER, C. Após Vygotsky e Piaget: perspectivas social e construtivista escolas russa e ocidental. Porto Alegre: Artes Médicas, 1996. 233 p.

[90]. SAKAGUTI, E.S. Utilização de Técnica de Análise Multivariada na Avaliação de Cruzamento Dialélicos em Coelhos. 180p. Dissertação (Mestrado em Zootecnia) - Universidade Federal de Viçosa, Viçosa 1994.

[91]. SERVILHA, Emilse A.M.; ARBACH, Máryam de P. Queixas de Saúde em Professores Universitários e sua Relação com Fatores de Risco Presentes na Organização do Trabalho. In: Anais... XVI Encontro de Iniciação Científica e I Encontro de Iniciação em Desenvolvimento Tecnológico e Inovação da PUC - Campinas, 2011. Disponível em:

<http://revistas.pucsp.br/index.php/dic/article/view/ 8274/6149>. Acesso em: 19 mai. 2015

[92]. SILVA, Nelson Pedro. Ética, Indisciplina e Violência nas Escolas. Rio de Janeiro: Vozes, 2004. $213 p$.

[93]. SILVA, M. C. O primeiro ano de docência: o choque com a realidade. Porto: Porto Editora. 1997. 80p.

[94]. SILVA, Ormenzina Garcia da; NAVARRO, Elaine Cristina. A Relação Professor-Aluno no Processo Ensino-Aprendizagem. Interdisciplinar: Revista Eletrônica da Univar. n. 8, v. 3, 2012. p. 95$100 . \quad$ Disponível em: <http://revista.univar.edu.br/downloads/relacao_pro fessor_aluno_processo.pdf>.Acesso em: 1 Mai. 2015.

[95]. SCHÖN, D. Educando o Profissional Reflexivo: um novo design para o ensino e a aprendizagem. Porto Alegre: Artmed, 2000. 256 p.

[96]. SKOVSMOSE, Ole. Educação Matemática Crítica: a questão da democracia. Campinas/SP: Papirus, 2001. 160p.

[97]. SOUSA, M. C. Quando Professores têm a Oportunidade de Elaborar Atividades de Ensino De Matemática na Perspectiva Lógico-Histórica. Bolema, Rio Claro, ano 22, n. 32, 2009. p. 83-99.

[98]. SOUZA, Ricardo Fasti de; BUSSAB, Wilton de Oliveira. Participação de mercado: uma abordagem multidimensional escalar. São Paulo, EnANPAD de Marketing, 2003. P. 184-201.

[99]. TACCA, M. C. V. R. Ensinar e Aprender: análise de processos de significação na relação professor $x$ aluno em contextos estruturados. Tese de Doutorado não-publicada. Universidade de Brasília, Brasília.

[100]. Estratégias Pedagógicas: conceituação e desdobramentos com o foco nas relações professor-aluno. In: TACCA, M. C. V. R. Aprendizagem e Trabalho Pedagógico. Campinas: Alínea, 2006. 179p. 
[101]. TARDIF, Maurice. Saberes Docentes e Formação Profissional. Petrópolis, RJ: Vozes, 2002. $328 p$

[102]. VEIGA, IIma Passos Alencastro. Repensando a Didática do Ensino. Campinas, SP: Papirus, 1993. 158p.

[103]. VEIGA, IIma Passos Alencastro; VIANA, Cleide Maria Quevedo Quixadá. Formação de Professores: um campo de possibilidades inovadoras. In: VEIGA, IIma Passos Alencastro; SILVA, Edileuza Fernandes da. A Escola Mudou. Que Mude A Formação De Professores! Campinas, SP: Papirus, 2010. 224p. Disponível em: $<$ http://periodicos.unb.br/index.php /linhascriticas/article/viewFile/3039/2637>. Acesso em: 28 mar. 2015.

[104]. VEIGA, F. H. Indisciplina e Violência na Escola: práticas comunicacionais para professores e pais. Coimbra: Almedina, 2007. 196p. Disponível em:

$<$ http://repositorio.ul.pt/handle/10451/5388?mode $=f$ ull >. Acesso em: 28 mar. 2015.

[105]. VELEZ, F.; VEIGA, F. H. Indisciplina e Violência na Escola: distribuição dos alunos pela vitimização e pela agressão, por anos de escolaridade. Anais... Atas do XI Congresso da AEPEC, Évora, Portugal, 2010. Disponível em: <http://repositorio.ul.pt/handle/10451/7034>. Acesso em: 28 mar. 2015.

[106]. VERGANI, Teresa. Educação Etnomatemática: o que é? Natal: Flecha do Tempo, 2007. 67p.

[107]. VIEIRA, Sonia. Como Elaborar Questionários. São Paulo: Atlas, 2009. 176p.

[108]. VIGOTSKI, L. S. A Formação Social da Mente. 6. ed. São Paulo: Martins Fontes, 2002. $182 p$

[109]. WERNECK, H. Se Você Finge que Ensina, eu Finjo que Aprendo. 16. ed. Petrópolis: Vozes, 1999. $88 \mathrm{p}$.

[110]. WINTERSTEIN, P. J. Motivação, Educação Física e Esporte. Revista Paulista de Educação Física, São Paulo, v. 6, n. 1, 1992. p. 53-61. Disponível em <http://www.efdeportes.com/efd134/motivacao-eeducacao-fisica-escolar.htm>. Acesso em: 28 mar. 2015. 


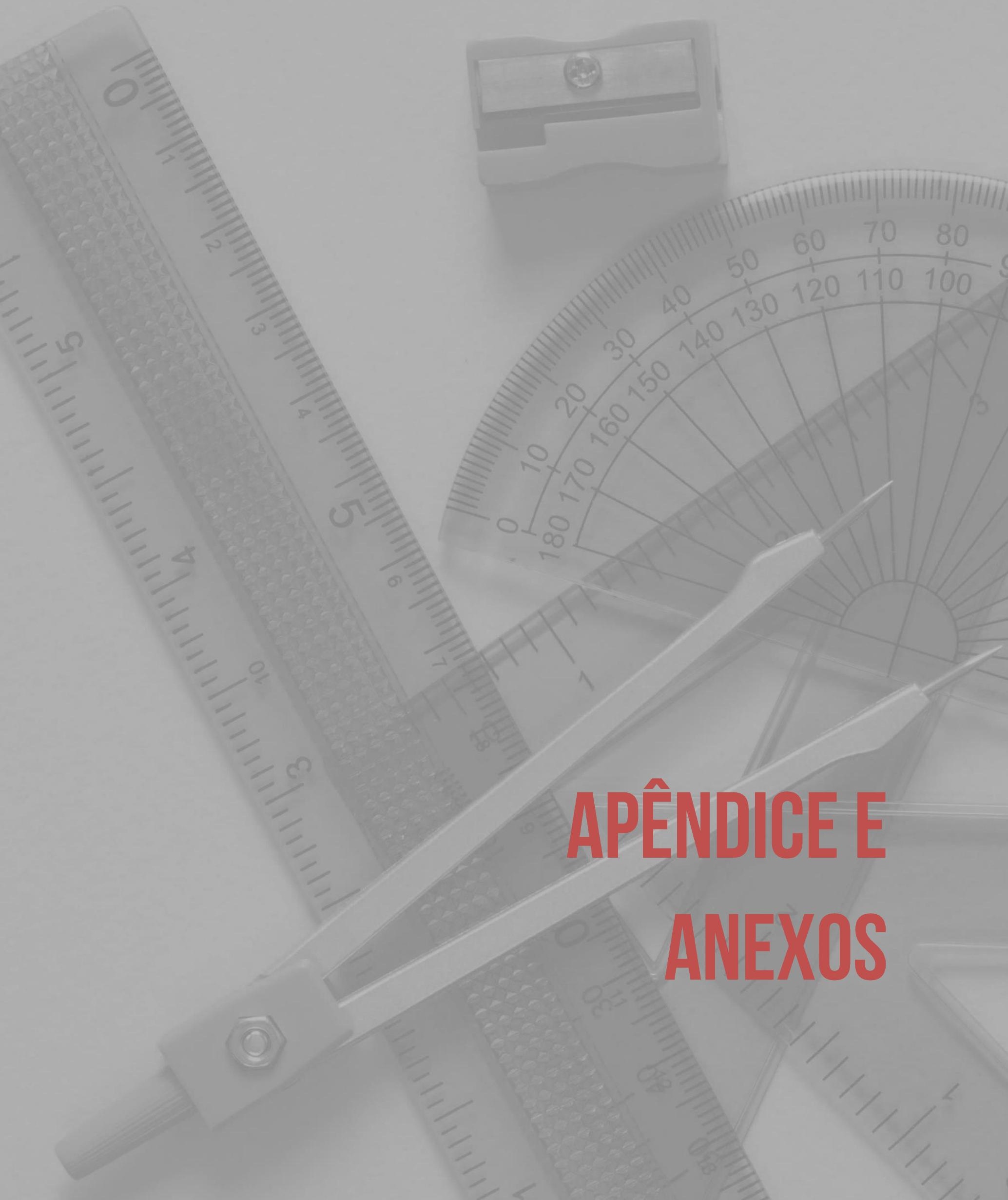




\section{INSTRUMENTO DE COLETA DE DADOS}

Esta pesquisa é componente do Trabalho de Conclusão de Curso do IFSP - câmpus Bragança Paulista e se baseia em analisar as variáveis que influenciam o ensino e a aprendizagem de matemática no ensino médio a partir dos dados coletados neste questionário.

O objetivo desta pesquisa é compreender melhor o processo de ensino e aprendizagem e o que influencia este processo. Ressalta-se que os dados fornecidos serão trabalhados de forma confidencial, servindo exclusivamente ao propósito de alcançar os objetivos desta pesquisa. $\mathrm{O}$ participante tem total direito de retirar, em qualquer tempo, sua participação nesta pesquisa sem qualquer penalidade.

\section{Instruções para preenchimento deste questionário:}

A identificação do respondente é facultativa, e os dados informados serão tratados sob sigilo.

Para responder as perguntas do Bloco II considere a seguinte escala:

1 - Nunca; 2- Raramente; 3- Eventualmente; 4- Frequentemente; 5- Sempre

\section{I - Caracterização da amostra pesquisada}

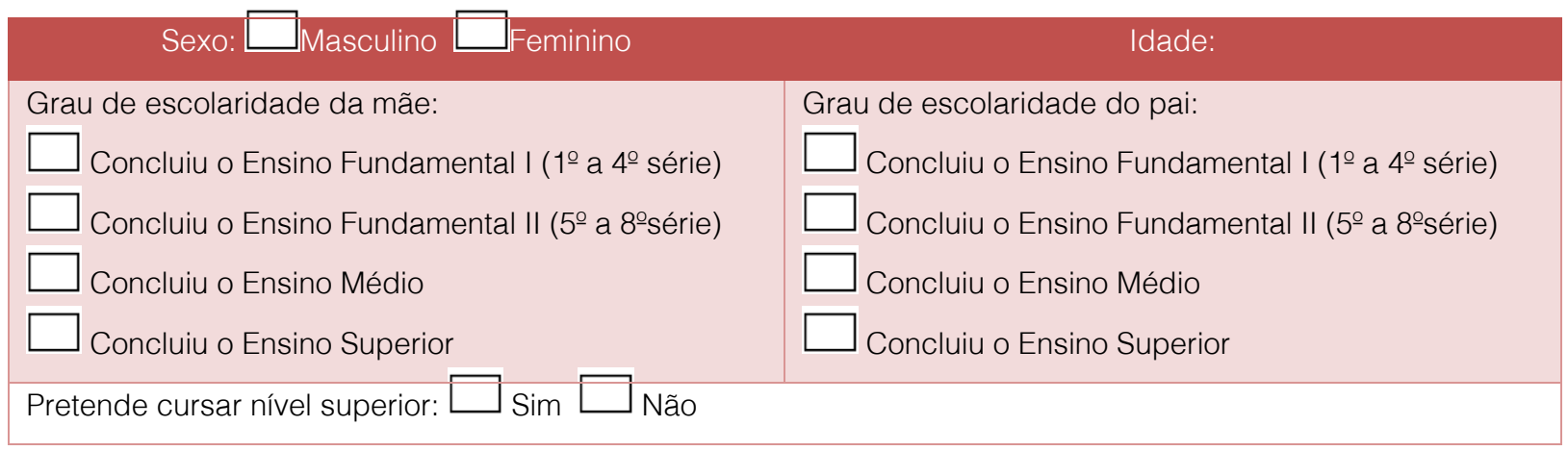

\section{II- Perfil Aprendizagem Matemática}

\begin{tabular}{|c|c|c|c|c|c|}
\hline & \multicolumn{5}{|c|}{ Escala } \\
\hline Você entende o porquê de estudar matemática? & 1 & 2 & 3 & 4 & 5 \\
\hline Você aprecia estudar matemática? & 1 & 2 & 3 & 4 & 5 \\
\hline Você acha importante seu professor ser formado em matemática? & 1 & 2 & 3 & 4 & 5 \\
\hline $\begin{array}{l}\text { Você acha que a formação do professor influencia no processo de ensino e } \\
\text { aprendizagem? }\end{array}$ & 1 & 2 & 3 & 4 & 5 \\
\hline Você se acha motivado para estudar matemática? & 1 & 2 & 3 & 4 & 5 \\
\hline Você acha seu professor motivado para ensinar matemática? & 1 & 2 & 3 & 4 & 5 \\
\hline Você acreditar que a sua indisciplina atrapalha a aprendizagem de matemática? & 1 & 2 & 3 & 4 & 5 \\
\hline $\begin{array}{l}\text { Você acha que a indisciplina de seus colegas atrapalha a sua aprendizagem de } \\
\text { matemática? }\end{array}$ & 1 & 2 & 3 & 4 & 5 \\
\hline Você acha o material utilizado pelo professor importante para a aprendizagem? & 1 & 2 & 3 & 4 & 5 \\
\hline $\begin{array}{l}\text { Você acha que se fosse utilizado outro material poderia ser mais fácil aprender } \\
\text { matemática? }\end{array}$ & 1 & 2 & 3 & 4 & 5 \\
\hline
\end{tabular}


(continuação...)

\begin{tabular}{|c|c|c|c|c|c|}
\hline Você tem um sentimento de impotência ao estudar matemática? & 1 & 2 & 3 & 4 & 5 \\
\hline Você gosta de matemática? & 1 & 2 & 3 & 4 & 5 \\
\hline Você tem prazer em estudar matemática? & 1 & 2 & 3 & 4 & 5 \\
\hline Você acha que estudar Matemática é fundamental para seu futuro? & 1 & 2 & 3 & 4 & 5 \\
\hline Você realiza as atividades propostas pelo professor em sala de aula? & 1 & 2 & 3 & 4 & 5 \\
\hline Você estuda matemática fora da sala de aula? & 1 & 2 & 3 & 4 & 5 \\
\hline $\begin{array}{l}\text { Você acredita que os conteúdos estudados em matemática influenciam seu } \\
\text { futuro? }\end{array}$ & 1 & 2 & 3 & 4 & 5 \\
\hline Você tem um método para estudar matemática? & 1 & 2 & 3 & 4 & 5 \\
\hline Você utiliza meios tecnológicos para aprender matemática? & 1 & 2 & 3 & 4 & 5 \\
\hline Você busca algum profissional fora da sala de aula para aprender matemática? & 1 & 2 & 3 & 4 & 5 \\
\hline $\begin{array}{l}\text { Você acredita que o modo como professor de Matemática trabalha para se } \\
\text { adaptar a maneira de aprender do aluno é importante? }\end{array}$ & 1 & 2 & 3 & 4 & 5 \\
\hline Você participa das atividades propostas pelo professor de matemática? & 1 & 2 & 3 & 4 & 5 \\
\hline Você faz perguntas para o professor quando não entende o que foi explicado? & 1 & 2 & 3 & 4 & 5 \\
\hline Você compara suas anotações com a de seus colegas? & 1 & 2 & 3 & 4 & 5 \\
\hline $\begin{array}{l}\text { Quando o professor esta explicando a matéria você não da atenção e pensa em } \\
\text { outras coisas? }\end{array}$ & 1 & 2 & 3 & 4 & 5 \\
\hline Você revisa suas anotações da aula em outro momento? & 1 & 2 & 3 & 4 & 5 \\
\hline
\end{tabular}


ANEXO A - TABULAÇÃO DA CARACTERIZAÇÃO DA AMOSTRA DA PESQUISA

São apresentadas as tabulações referente a caracterização da amostra que respondeu ao questionário encaminhado, conforme descrito no capítulo 03. Todas os resultados apresentados são oriundos da pesquisa.

Tabela 1 Gênero dos respondentes.

\begin{tabular}{|c|c|c|}
\hline Gênero & $N^{\circ}$ Respondentes & $\%$ \\
\hline Masculino & 85 & 56,30 \\
\hline Feminino & 66 & 43,70 \\
\hline Total & 151 & 100,00 \\
\hline
\end{tabular}

Tabela 2 Faixa Etária dos respondentes

\begin{tabular}{|c|c|c|}
\hline Faixa Etária & N & $\%$ \\
\hline 14 anos & 2 & 1,3 \\
\hline 15 anos & 40 & 26,5 \\
\hline 16 anos & 45 & 29,8 \\
\hline 17 anos & 43 & 28,5 \\
\hline 18 anos & 17 & 11,2 \\
\hline 19 anos & 2 & 1,3 \\
\hline 20 anos & 1 & 0,7 \\
\hline Outros & 1 & 0,7 \\
\hline Total & 151 & 100,00 \\
\hline
\end{tabular}

Tabela 3 Grau de escolaridade da mãe dos respondentes

\begin{tabular}{|c|c|c|}
\hline Grau de escolaridade & No Respondentes & $\%$ \\
\hline Concluiu o Ensino Fundamental I & 10 & 6,6 \\
\hline Concluiu o Ensino Fundamental II & 35 & 23,1 \\
\hline Concluiu o Ensino Médio & 49 & 32,5 \\
\hline Concluiu o Ensino Superior & 49 & 32,5 \\
\hline Outros & 8 & 5,3 \\
\hline Total & 151 & 100,00 \\
\hline
\end{tabular}


Tabela 4 Grau de escolaridade do pai dos respondentes

\begin{tabular}{|c|c|c|}
\hline Grau de escolaridade & $N^{\circ}$ Respondentes & $\%$ \\
\hline Concluiu o Ensino Fundamental I & 17 & 11,3 \\
\hline Concluiu o Ensino Fundamental II & 26 & 17,2 \\
\hline Concluiu o Ensino Médio & 58 & 38,4 \\
\hline Concluiu o Ensino Superior & 42 & 27,8 \\
\hline Outros & 8 & 5,3 \\
\hline Total & 151 & 100,00 \\
\hline
\end{tabular}

Tabela 5 O respondente pretende cursar nível superior

\begin{tabular}{|c|c|c|}
\hline Cursar nível superior & N. Respondentes & $\%$ \\
\hline Sim & 144 & 95,40 \\
\hline Não & 7 & 4,60 \\
\hline Total & 151 & 100,00 \\
\hline
\end{tabular}


ANEXO B - EXEMPLO DE SAÍDA DE RESULTADOS DO SOFTWARE IBM SPSS DAS ANÁLISES

A análise dos dados da pesquisa com o método de análise multivariada por meio da Análise de Conglomerado ou também tratado na literatura como Análise de Cluster, apresentada a seguir com um conjunto de saídas do software IBM SPSS como exemplo.

\begin{tabular}{|c|c|c|c|c|c|}
\hline \multicolumn{6}{|c|}{ Resumo de processamento do caso ${ }^{a}$} \\
\hline \multicolumn{6}{|c|}{ Casos } \\
\hline \multicolumn{2}{|c|}{ Válido } & \multicolumn{2}{|c|}{ Ausente } & \multicolumn{2}{|c|}{ Total } \\
\hline $\mathrm{N}$ & Porcentagem & $\mathrm{N}$ & Porcentagem & $\mathrm{N}$ & Porcentagem \\
\hline 120 & $100,0 \%$ & 0 & $0,0 \%$ & 120 & $100,0 \%$ \\
\hline
\end{tabular}

\section{CLUSTER}

\section{Ligação média (entre grupos)}

\begin{tabular}{|c|c|c|c|c|c|c|}
\hline \multicolumn{7}{|c|}{ Planejamento de aglomeração } \\
\hline \multirow[t]{2}{*}{ Estágio } & \multicolumn{2}{|c|}{ Cluster combinado } & \multirow[t]{2}{*}{ Coeficientes } & \multicolumn{2}{|c|}{ O cluster de estágio é exibido primeiro } & \multirow[t]{2}{*}{ Próximo estágio } \\
\hline & Cluster 1 & Cluster 2 & & Cluster 1 & Cluster 2 & \\
\hline 1 & 14 & 17 & 8,660 & 0 & 0 & 4 \\
\hline 2 & 15 & 22 & 10,488 & 0 & 0 & 9 \\
\hline 3 & 3 & 6 & 11,045 & 0 & 0 & 5 \\
\hline 4 & 1 & 14 & 12,141 & 0 & 1 & 10 \\
\hline 5 & 3 & 4 & 12,275 & 3 & 0 & 6 \\
\hline 6 & 3 & 21 & 12,806 & 5 & 0 & 8 \\
\hline 7 & 5 & 13 & 13,077 & 0 & 0 & 11 \\
\hline 8 & 3 & 9 & 13,409 & 6 & 0 & 10 \\
\hline 9 & 15 & 16 & 13,709 & 2 & 0 & 12 \\
\hline 10 & 1 & 3 & 13,737 & 4 & 8 & 18 \\
\hline 11 & 2 & 5 & 14,704 & 0 & 7 & 15 \\
\hline 12 & 15 & 23 & 15,692 & 9 & 0 & 14 \\
\hline 13 & 20 & 26 & 16,823 & 0 & 0 & 20 \\
\hline 14 & 15 & 18 & 16,887 & 12 & 0 & 15 \\
\hline 15 & 2 & 15 & 17,376 & 11 & 14 & 18 \\
\hline 16 & 10 & 19 & 17,692 & 0 & 0 & 20 \\
\hline 17 & 12 & 25 & 18,682 & 0 & 0 & 19 \\
\hline 18 & 1 & 2 & 19,080 & 10 & 15 & 21 \\
\hline 19 & 11 & 12 & 19,317 & 0 & 17 & 24 \\
\hline 20 & 10 & 20 & 19,360 & 16 & 13 & 22 \\
\hline 21 & 1 & 8 & 20,138 & 18 & 0 & 23 \\
\hline 22 & 10 & 24 & 21,244 & 20 & 0 & 23 \\
\hline 23 & 1 & 10 & 21,850 & 21 & 22 & 25 \\
\hline 24 & 7 & 11 & 22,770 & 0 & 19 & 25 \\
\hline 25 & 1 & 7 & 24,672 & 23 & 24 & 0 \\
\hline
\end{tabular}



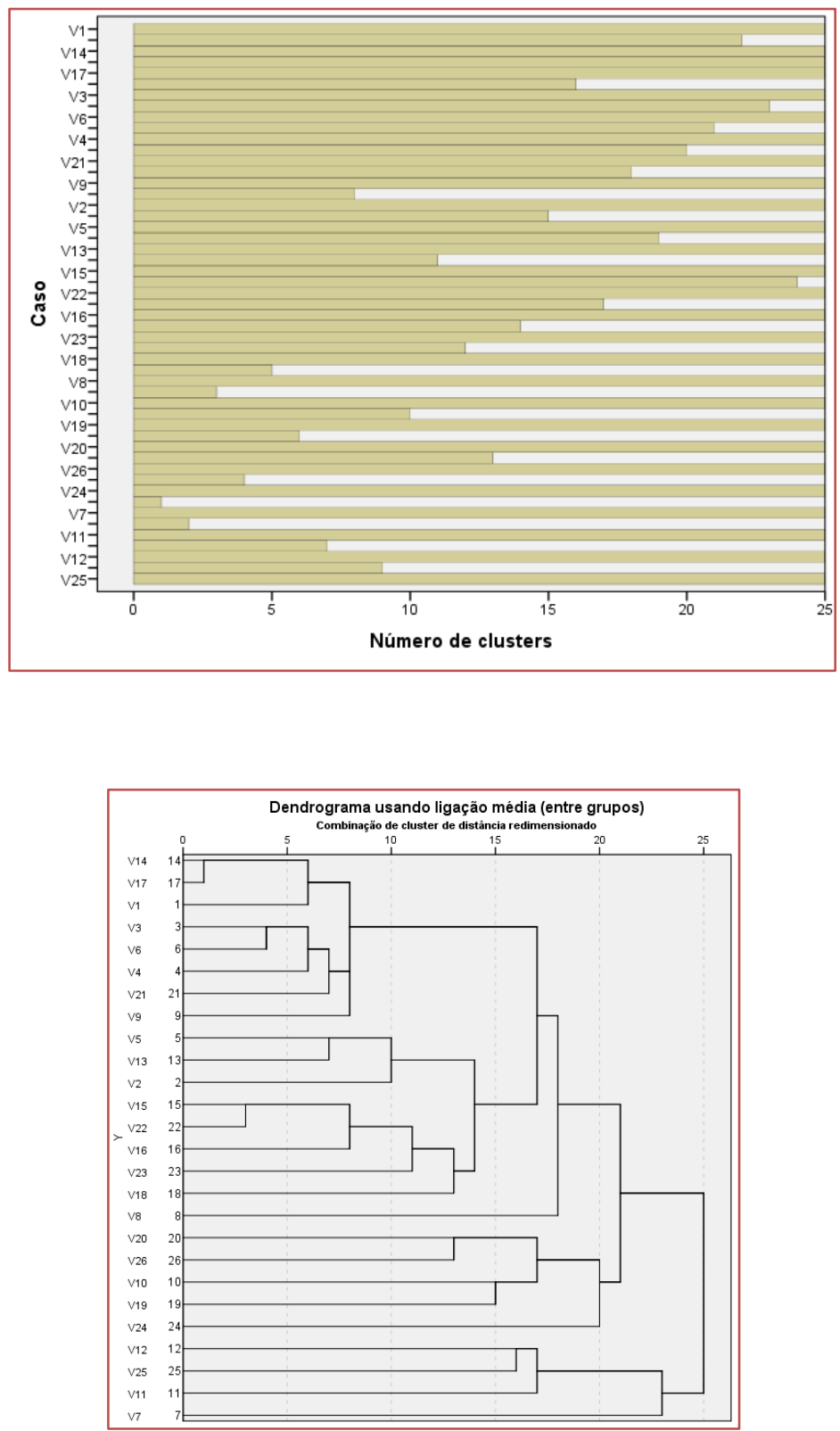

Dataset Close D0.811227882129727.

A análise dos dados da pesquisa com o método de análise multivariada, no caso o Escalonamento Multidimensional (EMD) ou também tratado na literatura como MDS - Multidimensional Scaling, é apresentada a seguir com um conjunto de saídas do software IBM SPSS como exemplo.

\section{PROXIMIDADES}

\begin{tabular}{|c|c|c|c|c|c|}
\hline \multicolumn{6}{|c|}{ Resumo de processamento do caso ${ }^{a}$} \\
\hline \multicolumn{6}{|c|}{ Casos } \\
\hline \multicolumn{2}{|c|}{ Válido } & \multicolumn{2}{|c|}{ Ausente } & \multicolumn{2}{|c|}{ Total } \\
\hline$N$ & Porcentagem & N & Porcentagem & N & Porcentagem \\
\hline 120 & $100,0 \%$ & 0 & $0,0 \%$ & 120 & $100,0 \%$ \\
\hline
\end{tabular}




\section{ALSCAL}

Alscal Procedure Options

Data Options-

Number of Rows (Observations/Matrix). 26

Number of Columns (Variables). . . 26

Number of Matrices . . . . . . 1

Measurement Level . . . . . . . Ordinal

Data Matrix Shape . . . . . . . Symmetric

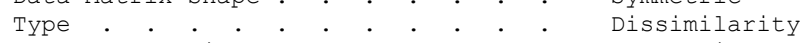

Approach to Ties . . . . . . . . . Leave Tied

Conditionality . . . . . . . . Matrix

Data Cutoff at. . . . . . . . ,000000

Model Options-

Model . . . . . . . . . . . Euclid

Maximum Dimensionality . . . . . 2

Minimum Dimensionality . . . . .

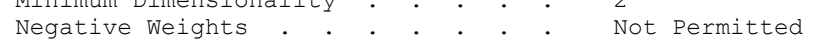

Output Options-

Job Option Header . . . . . . . Printed

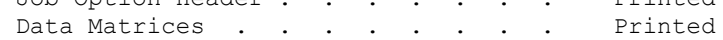

Configurations and Transformations. Plotted

Output Dataset . . . . . . . . Not Created

Initial Stimulus Coordinates . . . Computed

Algorithmic Options-

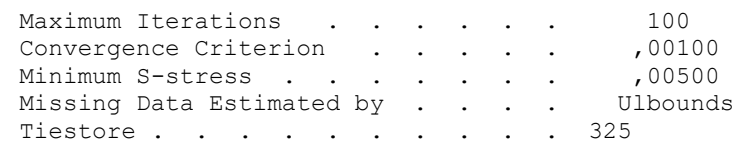

Tiestore

Raw (unscaled) Data for Subject 1

10

, 000

17,607

23,601

27,622

22,450

14,765

14,697

17,521

14,457

22,293

20,322

23,979

13,038

14,900

19,672

22,000

24,125
1
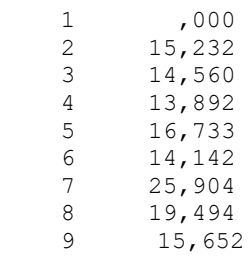

2
3
4
5
6
7
8
9

10

, 000

11

12

22,338

13

21,726

14
23,108

15

18,815

16

17,692

17

0,712

18
21,794

19

17,692

20

19,621

21

20,928

22

8,868

23
21,564

24

21,633

25

19,079

21,237

25,219

29,563

19,261

12,450

15,067

16,912

11,832

13,601

14,387
, 000
19,900

19,261

13,565

19,647

24,718

24,718

18,248

20,025

22,760

27,641

15,843

17,916

17,117

16,492

16,062

, 000
11,705
21,541

21,541

11,045

22,181

13,964

20,224
12,845

27, 019

12,884

20,199

22,561

22,517

21,119

28,178

27,622

32,741

30,216

25,080

23,622

11,874

12,329

16,093

15,811

20,347

19,313

13,856

12,689

24,860

23,770

23,875

23,388

29,052

27, 911

12,649

19,000

12,845

16,763

15,937

21,726

21,000

25,710

24,083

28,337

18,330

20,905

22,113

26,268
, 000
26,814

26,814

18,412

13,748

, 000

20,322

19,519

21,703

22,000

, 000

19,416

21,909

28,775

23,431

19,925

26,038

33,317

24,434

23,917

13,077

24,678

22,539

25,768

19,053

13,964

27,386

19,723

16,401

14,933

24,454

21,142

13,565

19,183

21,564

19,261

16,852

14,560

24,799

17,550

16,492

24,536

22,694

18,815

19,748

22,583

21,142

21,260

18,974

28,036

22,650

22,583

20,174

12,923

26,944

23,281

16,340

15,395

23,791

20,761

17,029

20,050

23,302

20,174

26,249

25,219

20,396

21,190

28,478

20,445

21,237 


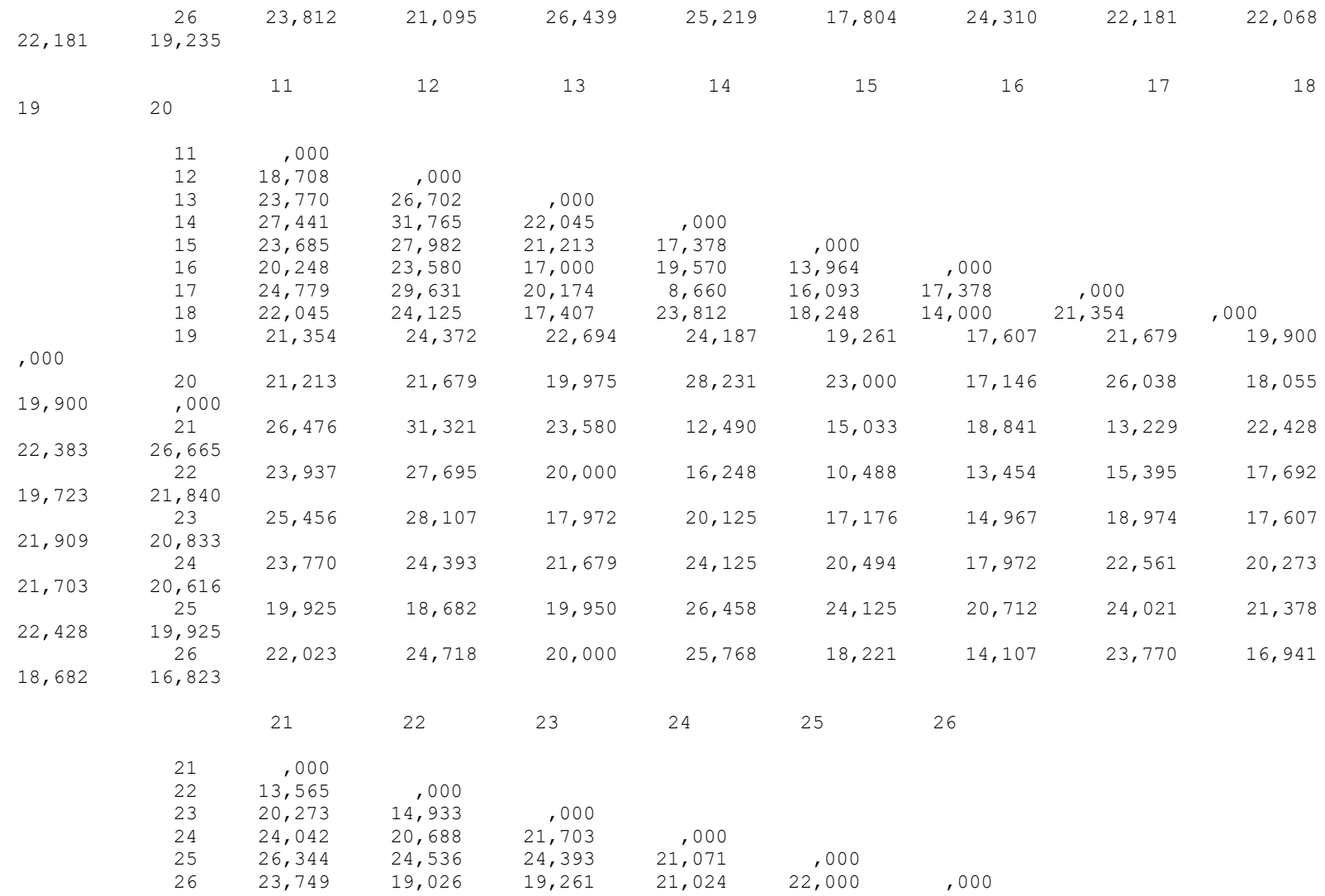

Iteration history for the 2 dimensional solution (in squared distances)

$\begin{array}{crr}\text { Young's } & \text { S-stress formula } 1 \text { is used. } \\ \text { Iteration } & \text { S-stress } & \text { Improvement } \\ 1 & , 24126 & \\ 2 & , 16792 & , 07334 \\ 3 & , 15994 & , 00798 \\ 4 & , 15782 & , 00212 \\ 5 & , 15718 & , 00064\end{array}$

Iterations stopped because
S-stress improvement is less than ,001000

RSO values are the proportion of variance of the scaled data (disparities) in the partition (row, matrix, or entire data) which is accounted for by their corresponding distances. Stress values are Kruskal's stress formula 1.

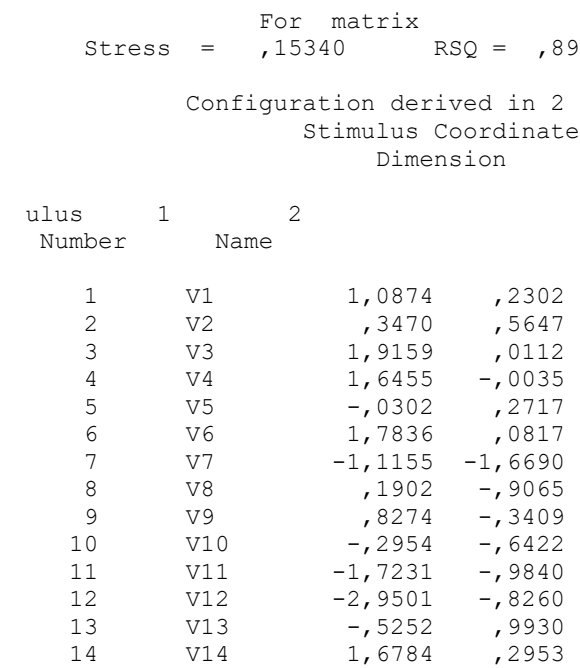


Optimally scaled data (disparities) for subject 1

$\begin{array}{lrr}\text { V15 } & , 5807 & , 2879 \\ \text { V16 } & -, 1567 & -, 0373 \\ \text { V17 } & 1,0568 & , 0235 \\ \text { V18 } & -, 7099 & , 6725 \\ \text { V19 } & -, 4295 & -, 9042 \\ \text { V20 } & -1,7981 & , 3582 \\ \text { V21 } & 1,5079 & , 1038 \\ \text { V22 } & , 5406 & , 2681 \\ \text { V23 } & , 2858 & , 7919 \\ \text { V24 } & -, 9008 & 1,0928 \\ \text { V25 } & -1,7259 & -, 3981 \\ \text { V26 } & -1,0870 & , 6648\end{array}$

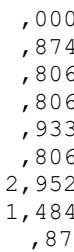$$
, 000
$$$$
1,484
$$$$
\begin{array}{r}
1,484 \\
, 681
\end{array}
$$

1,484

2,430

3,590

2,108

2,108

1,753

$$
1,686
$$$$
\begin{array}{r}
, 681 \\
1,484
\end{array}
$$$$
2,591
$$$$
1,605
$$

1,172

$$
\begin{array}{r}
, 000 \\
, 344 \\
1,686 \\
, 344 \\
3,590 \\
2,108 \\
, 806
\end{array}
$$$$
1,484
$$$$
\begin{array}{r}
, 000 \\
1,523 \\
, 428
\end{array}
$$$$
\begin{array}{r}
, 428 \\
3,290
\end{array}
$$

2,153

1,484

2,835

2,273

3,625

$$
1,620
$$

4,135

3,590

4,879

3,590

1,484

, 933

2,765

4,612

, 387

1, 172

, 933

, 344

2,430

, 874

, 933

, 933

, 933

1,172

1,686

1,686

2,108

1,396

, 681

, 933

1,311

1,172

1,605

2,108

1,605

12

$$
\begin{aligned}
& , 000 \\
& 2,108 \\
& 1,620 \\
& , 933 \\
& 1,523 \\
& 1,013 \\
& 2,181
\end{aligned}
$$

$$
\begin{array}{r}
, 000 \\
1,013 \\
1,484 \\
, 344 \\
2,430
\end{array}
$$$$
, 430
$$

$$
\begin{array}{r}
, 000 \\
1,523 \\
2,153
\end{array}
$$$$
1,484
$$$$
1,172
$$

$$
\begin{array}{r}
, 000 \\
3,290
\end{array}
$$$$
3,290
$$

$$
1,484
$$$$
1,880
$$$$
2,956
$$$$
, 681
$$$$
, 681
$$$$
1,484
$$$$
, 933
$$$$
, 933
$$$$
, 933
$$$$
, 681
$$$$
, 933
$$$$
933
$$$$
1,484
$$$$
1,396
$$$$
1,523
$$$$
, 933
$$$$
, 933
$$$$
1,523
$$$$
1,620
$$$$
1,128
$$

1,686

$$
1,484
$$

3,625

4,612

2,430

, 387

3,590

3,625

1,484

, 933

1,172

1,484

2, 591

2,430

1,484

$$
1,686
$$$$
\text { 2, } 591
$$

$$
\begin{array}{r}
, 000 \\
, 806 \\
, 933
\end{array}
$$$$
\begin{array}{r}
, 906 \\
, 933 \\
\hline
\end{array}
$$$$
1,484
$$$$
\begin{array}{r}
, 000 \\
1,013
\end{array}
$$$$
2,273
$$

1,311

1,484

3,290

, 874

, 874

$$
, 344
$$

1,013

1,605

2,591$$
806 \quad, 000
$$$$
1,013
$$$$
\begin{array}{r}
, 000 \\
1,523
\end{array}
$$$$
, 806
$$$$
2,473
$$
, 000

$$
1,753
$$$$
1,880
$$

1,484

$$
3,665
$$$$
2,273
$$$$
4,879
$$$$
2,591
$$$$
2,430
$$$$
\text { 2, } 591
$$$$
2,153
$$$$
2,952
$$$$
, 806
$$$$
3,415
$$$$
1,484
$$$$
, 874
$$$$
\text { 2, } 591
$$$$
1,620
$$$$
1,484
$$$$
1,686
$$$$
, 806
$$$$
2,765
$$$$
\text { 1, } 013
$$$$
2,591
$$$$
\text { 2, } 181
$$$$
1,311
$$$$
\text { 2, } 153
$$$$
1,620
$$$$
1,686
$$$$
3,625
$$$$
2,181
$$$$
\text { 2, } 153
$$$$
2,273
$$$$
, 656
$$$$
3,290
$$$$
1,605
$$$$
, 876
$$$$
2,430
$$$$
2,273
$$$$
1,396
$$$$
1,484
$$$$
2,956
$$$$
2,835
$$$$
1,605
$$$$
3,625
$$$$
1,605
$$$$
2,181
$$$$
1,686
$$$$
2,591
$$$$
2,108
$$$$
2,108
$$

18

1,013

1,686 , 000 1,484

1,396

2,956

1,172$$
, 681
$$

, 681

2,108

, 874

, 876

1,013

1,172

1,396

1,013

1,605

2, 153

1,523

1,484 


\begin{tabular}{|c|c|c|c|c|c|c|c|c|c|}
\hline 1,311 & $\begin{array}{r}26 \\
, 933\end{array}$ & 1,880 & 2,591 & 1,484 & 2,952 & 1,172 &, 806 & 2,430 &, 933 \\
\hline & & 21 & 22 & 23 & 24 & 25 & 26 & & \\
\hline & 21 &, 000 & & & & & & & \\
\hline & 22 &, 681 &, 000 & & & & & & \\
\hline & 23 & 1,523 &, 874 &, 000 & & & & & \\
\hline & 24 & 2,591 & 1,605 & 1,753 &, 000 & & & & \\
\hline & 25 & 3,249 & 2,591 & 2,591 & 1,605 &, 000 & & & \\
\hline & 26 & 2,430 & 1,484 & 1,484 & 1,605 & 1,880 &, 000 & & \\
\hline
\end{tabular}
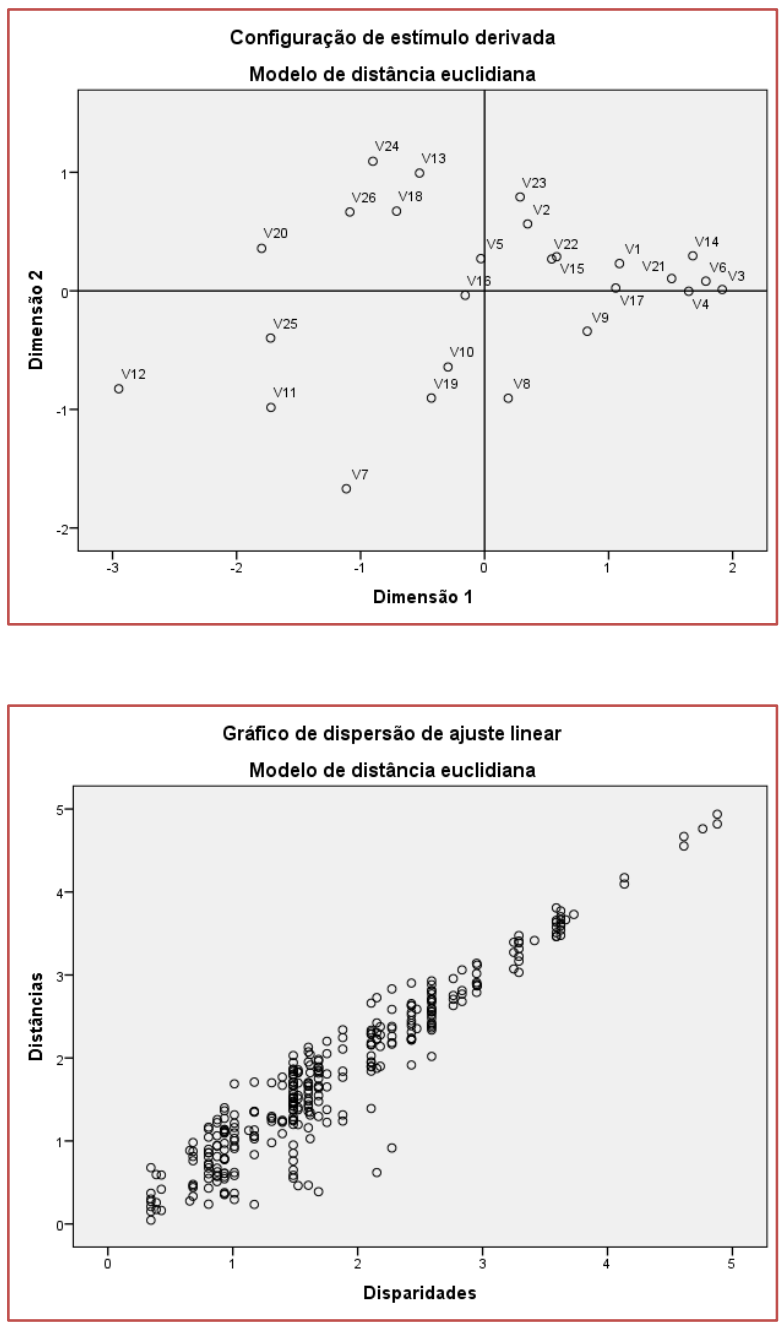

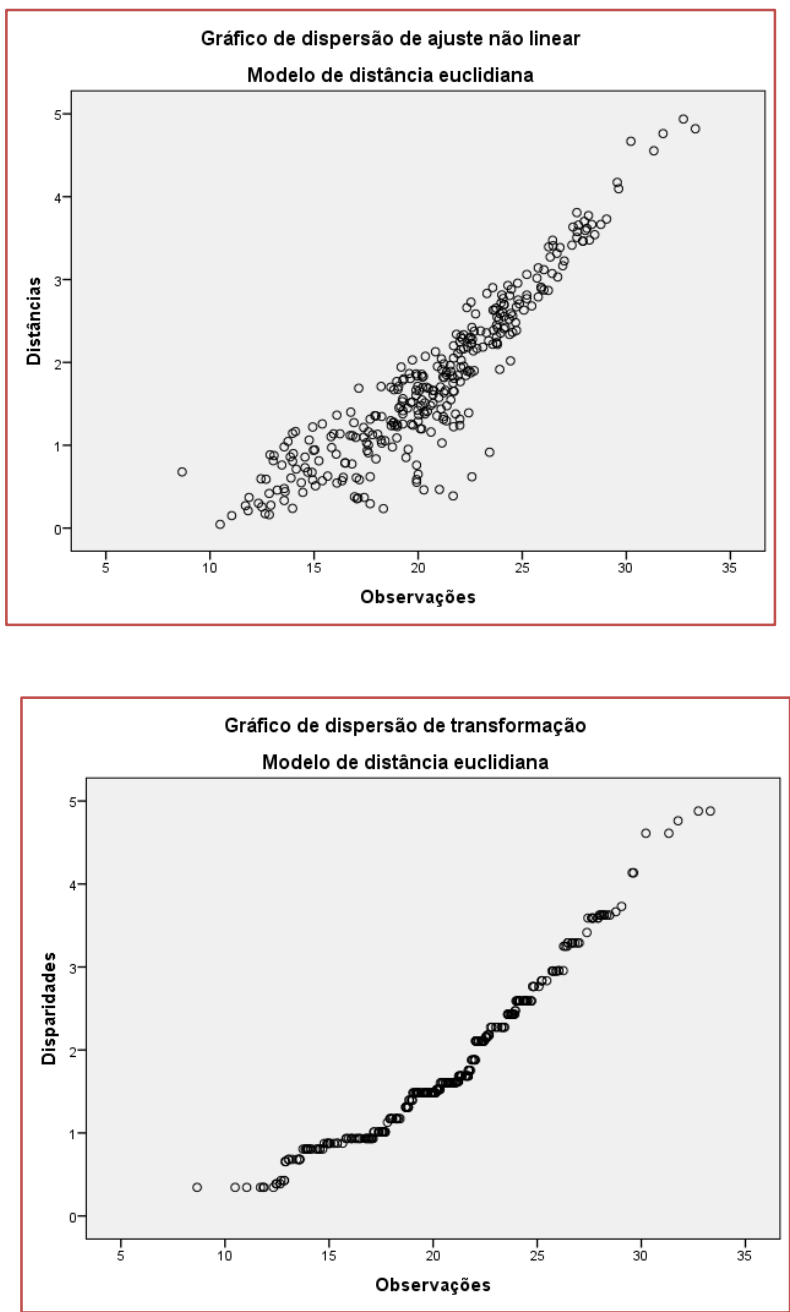

A análise dos dados da pesquisa com o método de análise fatorial exploratória, é apresentada a seguir com um conjunto de saídas do software IBM SPSS como exemplo. 
ANÁLISE FATORIAL

\begin{tabular}{|c|c|c|}
\hline \multicolumn{3}{|c|}{ Teste de KMO e Bartlett } \\
\hline Medida Kaiser-Meyer-Olkin de adequação de amostragem. &, 732 \\
\hline \multirow{2}{*}{$\begin{array}{c}\text { Teste de esfericidade de } \\
\text { Bartlett }\end{array}$} & Aprox. Qui-quadrado & 1277,121 \\
\cline { 2 - 3 } & df & 325 \\
\cline { 2 - 3 } & Sig. &, 000 \\
\hline
\end{tabular}

\begin{tabular}{|c|c|c|}
\hline \multicolumn{3}{|c|}{ Comunalidades } \\
\hline & Inicial & Extração \\
\hline V1 & 1,000 &, 559 \\
\hline V2 & 1,000 & ,623 \\
\hline V3 & 1,000 & ,646 \\
\hline V4 & 1,000 & ,638 \\
\hline V5 & 1,000 & 670 \\
\hline V6 & 1,000 & ,702 \\
\hline V7 & 1,000 & ,802 \\
\hline V8 & 1,000 & ,710 \\
\hline V9 & 1,000 & ,604 \\
\hline V10 & 1,000 & ,684 \\
\hline V11 & 1,000 & ,738 \\
\hline V12 & 1,000 & ,700 \\
\hline V13 & 1,000 & ,747 \\
\hline V14 & 1,000 & ,732 \\
\hline V15 & 1,000 & ,615 \\
\hline V16 & 1,000 & ,634 \\
\hline V17 & 1,000 & ,714 \\
\hline V18 & 1,000 & ,606 \\
\hline V19 & 1,000 & ,589 \\
\hline V20 & 1,000 & ,618 \\
\hline V21 & 1,000 & ,480 \\
\hline V22 & 1,000 & ,737 \\
\hline V23 & 1,000 &, 505 \\
\hline V24 & 1,000 &, 564 \\
\hline V25 & 1,000 & ,510 \\
\hline V26 & 1,000 &, 564 \\
\hline
\end{tabular}




\begin{tabular}{|c|c|c|c|c|c|c|c|c|c|}
\hline \multicolumn{10}{|c|}{ Variância total explicada } \\
\hline \multirow[t]{2}{*}{ Componente } & \multicolumn{3}{|c|}{ Valores próprios iniciais } & \multicolumn{3}{|c|}{$\begin{array}{l}\text { Somas de extração de } \\
\text { carregamentos ao quadrado }\end{array}$} & \multicolumn{3}{|c|}{$\begin{array}{l}\text { Somas rotativas de carregamentos } \\
\text { ao quadrado }\end{array}$} \\
\hline & Total & $\begin{array}{c}\text { \% de } \\
\text { variância }\end{array}$ & $\begin{array}{c}\% \\
\text { cumulativa }\end{array}$ & Total & $\begin{array}{c}\text { \% de } \\
\text { variância }\end{array}$ & $\begin{array}{c}\% \\
\text { cumulativa }\end{array}$ & Total & $\begin{array}{c}\text { \% de } \\
\text { variância }\end{array}$ & $\begin{array}{c}\% \\
\text { cumulativa }\end{array}$ \\
\hline 1 & 5,196 & 19,985 & 19,985 & 5,196 & 19,985 & 19,985 & 3,493 & 13,435 & 13,435 \\
\hline 2 & 2,691 & 10,349 & 30,334 & 2,691 & 10,349 & 30,334 & 3,246 & 12,485 & 25,920 \\
\hline 3 & 2,105 & 8,097 & 38,431 & 2,105 & 8,097 & 38,431 & 1,807 & 6,951 & 32,871 \\
\hline 4 & 2,015 & 7,750 & 46,181 & 2,015 & 7,750 & 46,181 & 1,740 & 6,692 & 39,563 \\
\hline 5 & 1,448 & 5,571 & 51,752 & 1,448 & 5,571 & 51,752 & 1,722 & 6,623 & 46,186 \\
\hline 6 & 1,141 & 4,388 & 56,140 & 1,141 & 4,388 & 56,140 & 1,617 & 6,219 & 52,405 \\
\hline 7 & 1,072 & 4,125 & 60,265 & 1,072 & 4,125 & 60,265 & 1,551 & 5,964 & 58,369 \\
\hline 8 & 1,022 & 3,932 & 64,197 & 1,022 & 3,932 & 64,197 & 1,515 & 5,828 & 64,197 \\
\hline 9 & ,977 & 3,758 & 67,954 & & & & & & \\
\hline 10 & ,860 & 3,308 & 71,263 & & & & & & \\
\hline 11 & ,773 & 2,973 & 74,235 & & & & & & \\
\hline 12 &, 747 & 2,873 & 77,108 & & & & & & \\
\hline 13 &, 743 & 2,857 & 79,965 & & & & & & \\
\hline 14 & ,673 & 2,588 & 82,553 & & & & & & \\
\hline 15 &, 588 & 2,261 & 84,814 & & & & & & \\
\hline 16 &, 580 & 2,231 & 87,045 & & & & & & \\
\hline 17 & ,477 & 1,836 & 88,881 & & & & & & \\
\hline 18 & ,430 & 1,654 & 90,535 & & & & & & \\
\hline 19 & ,425 & 1,636 & 92,172 & & & & & & \\
\hline 20 & 399 & 1,534 & 93,705 & & & & & & \\
\hline 21 & 363 & 1,397 & 95,102 & & & & & & \\
\hline 22 & ,334 & 1,283 & 96,385 & & & & & & \\
\hline 23 & ,294 & 1,131 & 97,516 & & & & & & \\
\hline 24 & ,266 & 1,024 & 98,540 & & & & & & \\
\hline 25 & ,193 & ,744 & 99,284 & & & & & & \\
\hline 26 & , 186 & ,716 & 100,000 & & & & & & \\
\hline
\end{tabular}


96

Matriz de componente

\begin{tabular}{|c|c|c|c|c|c|c|c|c|}
\hline \multicolumn{9}{|c|}{ Matriz de componente ${ }^{\mathrm{a}}$} \\
\hline & \multicolumn{8}{|c|}{ Componente } \\
\hline & 1 & 2 & 3 & 4 & 5 & 6 & 7 & 8 \\
\hline V1 & ,448 &,- 464 & ,047 &,- 025 &,- 168 & , 100 &,- 185 &,- 259 \\
\hline V2 & ,488 &,- 420 & ,031 & ,085 &,- 337 & ,243 &, 161 & ,034 \\
\hline V3 & ,287 &, 164 & ,094 &,- 535 &,- 076 &,- 159 &,- 206 & ,410 \\
\hline V4 & ,250 & ,056 & ,362 &,- 323 & ,142 &,- 529 & , 192 & ,019 \\
\hline V5 & ,688 &,- 335 &,- 024 &,- 030 &,- 204 & , 132 &, 141 & ,062 \\
\hline V6 &, 447 & ,312 &,- 226 &,- 563 & ,023 & , 141 &,- 014 & 129 \\
\hline V7 &, 146 & , 105 & ,351 &,- 191 & ,630 & ,389 &,- 207 & ,134 \\
\hline V8 & ,075 &,- 113 & ,235 & ,203 &, 721 &, 141 & ,058 &,- 229 \\
\hline V9 & ,304 & ,412 & ,436 &,- 251 &,- 049 &,- 003 & ,289 &,- 044 \\
\hline V10 &,- 110 &, 501 & ,246 &,- 155 &,- 195 & ,244 & ,396 &,- 286 \\
\hline V11 &,- 065 &, 186 & ,470 & ,282 &,- 397 & ,256 &,- 401 &,- 119 \\
\hline V12 &,- 274 & , 192 & ,554 & ,398 &,- 078 &,- 240 &,- 226 & ,092 \\
\hline V13 & ,473 &,- 653 &,- 081 & ,062 & ,076 & ,161 & ,234 & ,028 \\
\hline V14 &, 500 &,- 397 & ,427 &,- 323 & -,080 &,- 135 &,- 105 & ,040 \\
\hline V15 & ,581 & ,373 &,- 194 & ,077 &,- 021 &,- 174 &,- 147 &,- 207 \\
\hline V16 & ,684 & , 162 &,- 083 & ,320 & ,063 &,- 068 &,- 127 & ,082 \\
\hline V17 & ,498 &,- 382 & , 475 &,- 259 &,- 034 & ,029 &,- 146 &,- 066 \\
\hline V18 & ,579 &,- 037 &,- 118 & ,419 & ,045 &,- 101 &,- 214 & ,149 \\
\hline V19 & ,246 &, 467 & , 143 & ,029 &,- 079 & ,442 &,- 109 & ,276 \\
\hline V20 & ,425 & ,265 & ,069 & ,378 &,- 049 & ,128 & ,355 & ,275 \\
\hline V21 &, 441 & ,234 & , 181 &,- 084 &,- 057 &,- 031 & ,028 &,- 431 \\
\hline V22 & ,704 & ,273 &,- 085 & , 126 & 067 &,- 127 &,- 107 &,- 334 \\
\hline V23 & ,617 &,- 051 &,- 214 & , 100 & ,249 &,- 050 & ,013 & ,036 \\
\hline V24 & ,335 & ,049 & 305 & , 427 &,- 047 &,- 231 & ,249 & ,237 \\
\hline V25 &,- 311 &,- 255 & ,494 & ,244 & , 113 & ,006 & ,170 & ,054 \\
\hline V26 & ,588 & ,400 &,- 177 & ,139 & ,061 & ,009 & ,050 & ,012 \\
\hline & & $M e ́$ & Extrac & álise & pone & cipal. & & \\
\hline & & & a. & onente & aídos. & & & \\
\hline
\end{tabular}


Matriz de componente rotativa ${ }^{a}$

\begin{tabular}{|c|c|c|c|c|c|c|c|c|}
\hline \multicolumn{9}{|c|}{$\begin{array}{r}\text { Matriz de componente rotativa }{ }^{a} \\
\text { Componente }\end{array}$} \\
\hline & 1 & 2 & 3 & 4 & 5 & 6 & 7 & 8 \\
\hline V1 & ,207 & ,679 &,- 084 & ,062 &,- 187 &,- 091 &,- 007 &,- 011 \\
\hline V2 & ,057 &, 721 &,- 003 &,- 050 & ,234 & ,025 &,- 139 &,- 148 \\
\hline V3 & ,057 &, 060 & ,719 &,- 007 &,- 022 &,- 056 & ,341 &,- 040 \\
\hline V4 & ,080 & ,032 & ,098 &,- 082 & ,071 &, 127 & ,769 & ,045 \\
\hline V5 & ,249 & ,708 & ,125 &,- 173 & ,234 &,- 003 & ,003 &,- 078 \\
\hline V6 & ,318 & ,074 & ,654 &,- 331 &,- 096 & ,217 & ,020 & ,039 \\
\hline V7 &,- 008 & ,012 & ,295 & ,059 &,- 014 & ,040 & ,016 & ,842 \\
\hline V8 & ,086 & ,005 &,- 372 &,- 085 & ,032 &,- 015 & ,072 & ,742 \\
\hline V9 &, 141 & ,032 & ,240 & ,079 & ,217 &, 586 & ,342 & 108 \\
\hline V10 &,- 040 &,- 178 & ,012 &, 067 & ,048 & ,800 &,- 048 &,- 038 \\
\hline V11 & ,012 & ,086 & ,010 & ,811 &,- 004 &, 173 &,- 203 &,- 020 \\
\hline V12 &,- 126 &,- 273 &,- 174 & ,692 & ,208 &,- 068 & ,226 & ,036 \\
\hline V13 &, 016 &, 714 &,- 162 &,- 358 & , 180 &,- 190 &,- 036 & ,116 \\
\hline V14 & ,027 & ,654 & ,214 & ,106 &,- 040 &,- 040 & ,483 & 100 \\
\hline V15 & ,766 & ,008 & , 109 &,- 002 & ,032 & ,069 & ,063 &,- 079 \\
\hline V16 &, 659 &, 183 & ,088 & ,051 & ,354 &,- 159 &,- 003 & ,074 \\
\hline V17 & ,051 & ,687 & , 152 & , 178 &,- 076 & ,033 & ,356 & ,225 \\
\hline V18 &, 540 & ,227 &, 003 & ,092 & ,335 &,- 373 &,- 045 & ,034 \\
\hline V19 &, 172 &,- 040 &, 473 & ,247 & ,299 & ,243 &,- 299 & 188 \\
\hline V20 & ,260 & ,065 &, 047 &,- 021 & ,712 & ,164 &,- 102 & ,021 \\
\hline V21 &, 473 &, 190 &,- 033 & ,095 &,- 086 & ,408 & ,183 & ,050 \\
\hline V22 & ,824 &, 165 &,- 015 & ,003 &, 041 & ,120 &, 104 & ,059 \\
\hline V23 &, 511 & ,246 & ,050 &,- 279 & , 198 &,- 183 & ,042 & , 169 \\
\hline V24 &, 157 & , 108 &,- 138 &, 163 & ,644 &,- 029 & ,257 &,- 026 \\
\hline V25 &,- 461 & ,038 &,- 348 & ,244 & ,206 & ,005 & , 156 & ,220 \\
\hline V26 & ,643 &,- 001 & , 177 &,- 109 & ,299 &, 116 &,- 053 & ,039 \\
\hline
\end{tabular}


Método de Extração: Análise de Componente Principal.

Método de Rotação: Varimax com Normalização de Kaiser.

a. Rotação convergida em 13 iterações.

Matriz de transformação de componente

\begin{tabular}{|c|c|c|c|c|c|c|c|c|}
\hline Componente & 1 & 2 & 3 & 4 & 5 & 6 & 7 & 8 \\
\hline 1 &, 701 &, 570 &, 239 &,- 118 &, 282 &, 028 &, 150 &, 097 \\
\hline 2 &, 404 &,- 679 &, 320 &, 180 &, 156 &, 463 &,- 054 &,- 005 \\
\hline 3 &,- 287 &, 202 &,- 029 &, 623 &, 187 &, 321 &, 472 &, 358 \\
\hline 4 &, 217 &,- 105 &,- 600 &, 343 &, 529 &,- 278 &,- 327 &,- 009 \\
\hline 5 &, 089 &,- 282 &,- 140 &,- 351 &,- 027 &,- 220 &, 158 &, 834 \\
\hline 6 &,- 183 &, 269 &, 187 &, 034 &, 014 &, 321 &,- 777 &, 388 \\
\hline 7 &,- 243 &, 022 &,- 287 &,- 567 &, 492 &, 511 &, 128 &,- 127 \\
\hline 8 &,- 339 &,- 102 &, 585 &,- 041 &, 582 &,- 438 &, 005 &,- 014 \\
\hline \multicolumn{8}{|c|}{ Método de Extração: Análise de Componente Principal. } \\
\hline
\end{tabular}




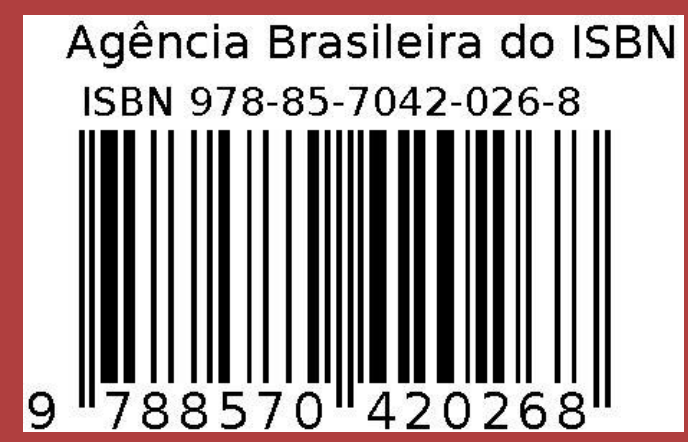

